UNIVERSIDADE DE SÃO PAULO

USP

Programa Interunidades de Pós-Graduação em Energia

PIPGE

(EP/FEA/IEE/IF)

\title{
AVALIAÇÃO DE CUSTOS DECORRENTES DE DESCARGAS ATMOSFÉRICAS EM SISTEMAS DE DISTRIBUIÇÃO DE ENERGIA
}

ALBERTO AKIO SHIGA

São Paulo 


\title{
ALBERTO AKIO SHIGA
}

\section{AVALIAÇÃO DE CUSTOS DECORRENTES DE DESCARGAS ATMOSFÉRICAS EM SISTEMAS DE DISTRIBUIÇÃO DE ENERGIA}

\begin{abstract}
Dissertação apresentada ao Programa Interunidades de Pós-Graduação em Energia da Universidade de São Paulo (Escola Politécnica / Faculdade de Economia e Administração / Instituto de Eletrotécnica e Energia / Instituto de Física) para a obtenção do título de Mestre em Energia.
\end{abstract}

Orientador: Prof. Dr. Alexandre Piantini

São Paulo 
AUTORIZO A REPRODUÇÃO E DIVULGAÇÃO TOTAL OU PARCIAL DESTE TRABALHO, POR QUALQUER MEIO CONVENCIONAL OU ELETRÔNICO, PARA FINS DE ESTUDO E PESQUISA, DESDE QUE CITADA A FONTE.

FICHA CATALOGRÁFICA

Shiga, Alberto Akio.

Avaliação de custos decorrentes de descargas atmosféricas em sistemas de distribuição de energia/ Alberto Akio Shiga; orientador Alexandre Piantini - São Paulo, 2007.

130 p. : il.; $30 \mathrm{~cm}$.

Dissertação (Mestrado - Programa Interunidades de Pós-Graduação em Energia) - EP / FEA / IEE / IF da Universidade de São Paulo.

1. Descargas Atmosféricas - custos 2. Redes de Distribuicão I.Título. 
UNIVERSIDADE DE SÃO PAULO

PROGRAMA INTERUNIDADES DE PÓS-GRADUAÇÃO EM ENERGIA

EP - FEA - IEE - IF

\section{ALBERTO AKIO SHIGA}

"Avaliação de custos decorrentes de descargas atmosféricas em sistemas de distribuição de energia"

Dissertação de Mestrado defendida e aprovada em 16/03/2007 pela Comissão Julgadora:

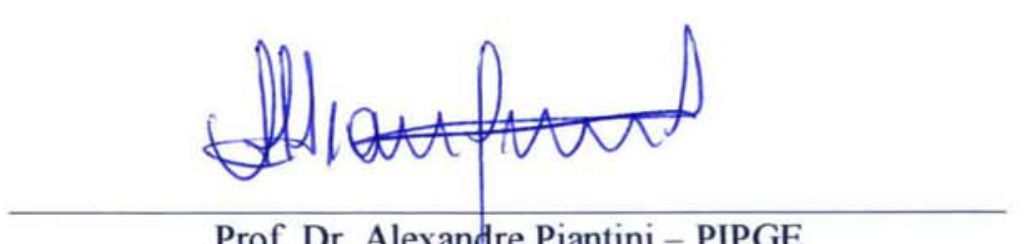

Prof. Dr. Alexandre Piantini - PIPGE

Orientador e Presidente da Comissão Julgadora
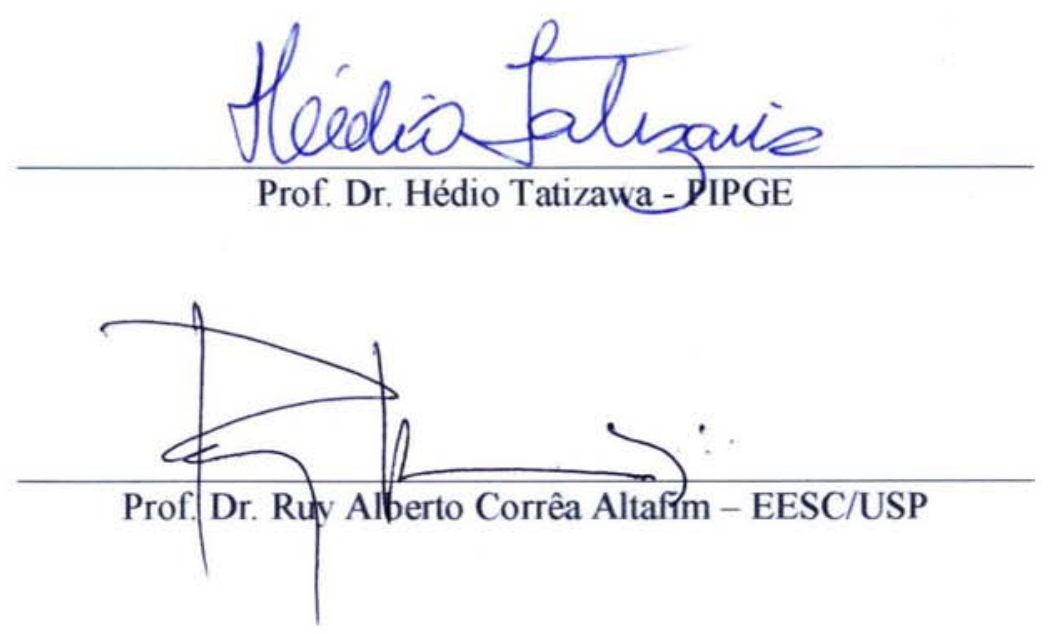
Ao ser superior,

à minha família, à minha querida esposa. 


\section{AGRADECIMENTOS}

Ao meu orientador e amigo Prof. Dr. Alexandre Piantini pelo incentivo, apoio, dedicação e esmero no desenvolvimento desta dissertação, com constantes sugestões e idéias.

Ao amigo Prof. Dr. Murilo Tadeu Werneck Fagá que sempre me incentivou a cursar e concluir o mestrado.

À AES Eletropaulo - Eletropaulo Metropolitana Eletricidade de São Paulo S/A - através dos seus executivos Cyro Vicente Boccuzzi, João José Oliveira e Fernando Mirancos da Cunha, bem como toda a equipe, que forneceram as informações necessárias para o desenvolvimento da pesquisa, além dos cases para que fosse efetuada a validação da metodologia.

À CSPE - Comissão de Serviços Públicos de Energia - através do Comissário Geral Prof. Dr. Aderbal de Arruda Penteado Junior, do Sr. Paulo Fernando Cunha Albuquerque e do Sr. Anderson da Silva Jucá, que forneceram dados de grande auxílio no desenvolvimento do trabalho. Ao Prof. Dr. Edmilson Moutinho dos Santo e Prof ${ }^{a}$ Dra. Virgínia Parente, que auxiliaram com informações da parte econômica do trabalho.

Aos amigos Meire Vibiano e Álvaro Guillermo Guardia Souto, da Arte In Arquitetura e Design, cujas informações sobre a valoração da marca foram de extrema valia.

Aos amigos e colegas professores da Universidade São Judas Tadeu que ao longo do desenvolvimento da pesquisa sempre auxiliaram com informações ou bibliografias.

Às bibliotecárias do IEE, Fátima, Penha e Lourdes pelo auxílio e agilidade nas informações solicitadas. Às secretárias Rosa, Adriana, Lourdes e Nádia que nunca pouparam esforços para o pronto atendimento e auxílio.

À equipe do CENDAT - Centro de Estudos em Descargas Atmosféricas \& Alta Tensão - pelo auxílio com informações, bem como opiniões para o desenvolvimento do trabalho.

Aos amigos e colegas do PIPGE/USP que me auxiliaram com opiniões e bibliografias. Sobretudo ao amigo Fábio Romero, companheiro de jornada no mestrado, que sempre auxiliou com informações relevantes ao desenvolvimento do trabalho, bem como o incentivo moral para prosseguirmos. Além de Mário César do Espírito Santo Ramos que sempre teve a boa vontade de auxiliar com quaisquer informações que fosse necessária.

À amiga Adalgisa pelo incentivo durante o mestrado e lembranças da atividade PID.

Ao amigo Prof. Carlos Alberto Göebel Pegollo bem como a Patrícia e a Tássia, que auxiliaram na revisão e aprimoramento do texto.

À minha família e, sobretudo, à minha esposa Agnes pela paciência e incentivo em prol deste trabalho.

E a todos que direta ou indiretamente colaboraram na realização deste trabalho. 
“É praticamente uma lei na vida, que quando uma porta se fecha para nós, outra se abre. A dificuldade está em que, freqüentemente, ficamos olhando com tanto pesar a porta fechada, que não vemos aquela que se abriu.” 


\section{RESUMO}

SHIGA, A. A. Avaliação de custos decorrentes de descargas atmosféricas em sistemas de distribuição de energia. 2007. 130 p. Dissertação de mestrado - Programa Interunidades de Pós-Graduação em Energia. Universidade de São Paulo.

As descargas atmosféricas sempre foram tratadas como acontecimentos fortuitos e de força maior, inerentes à vontade do homem. Contudo, mudanças significativas a esse respeito ocorreram recentemente na legislação brasileira, no Código Civil e na norma ABNT NBR 5410: 2004 (Instalações Elétricas de Baixa Tensão). Além disso, em 29 de abril de 2004 foi publicada a Resolução Normativa ${ }^{\circ} 61$ da ANEEL, que estabelece as disposições relativas ao ressarcimento de danos, em equipamentos elétricos instalados em unidades consumidoras, causados por perturbações no sistema elétrico. De acordo com essa nova visão, as descargas atmosféricas devem ser tratadas como fenômenos que podem ter as suas conseqüências previstas, evitadas ou ao menos minimizadas, fazendo com que os custos associados não sejam considerados simplesmente como prejuízos, mas sim passíveis de ressarcimento junto à concessionária.

Tais fatores, aliados à inexistência de uma metodologia comum para análise dos prejuízos causados por esse fenômeno, motivaram a realização deste trabalho, que teve por objetivo avaliar os custos decorrentes de descargas atmosféricas em sistemas de distribuição de energia.

Além de aspectos técnicos e jurídicos, são discutidos os custos referentes à energia não fornecida, danos em equipamentos, mão-de-obra e ressarcimento de pedidos de indenização por danos (PIDs). Discute-se ainda, embora de forma superficial, a importância de contabilização do custo da imagem da empresa junto aos consumidores. Finalmente, apresenta-se uma metodologia para determinação de tais custos, a qual é aplicada a casos reais, com comparação e análise dos resultados obtidos em diferentes situações.

Palavras-chave: descargas atmosféricas - custos, descargas atmosféricas, interrupções de fornecimento de energia, redes de distribuição. 


\begin{abstract}
SHIGA, A. A. Evaluation of the costs arising from atmospheric discharges in power distribution systems. 2007. 130 p. Master's Degree Thesis - Interunit Program for PostGraduation in Energy. Universidade de São Paulo.

Lightning discharges have always been treated as Acts of God and force majure events, inherent to man's will. However, significant changes to this regard have recently occurred in the Brazilian Law, in the Civil Code and on the Brazilian Standard ABNT NBR 5410: 2004 (Low Voltage Electric Installations). In addition, on April 29 ${ }^{\text {th }}$, 2004, ANEEL Normative Resolution No. 61 was published, which establishes the provisions regarding reimbursement of damages in electrical equipment installed in consumer units, caused by disturbances in the electrical system. According to this new version, the lightning discharges must be treated as phenomena which may have their consequences foreseen, avoided or at least minimized, causing the associated costs to be considered not only as losses, but also entitled to reimbursement with the operator.
\end{abstract}

Such factors, allied to the non-existence of a common methodology for the review of the losses caused by such phenomenon, motivated the development of this work, which aimed at assessing the lightning-related costs in power distribution systems.

In addition to the technical and legal aspects, the costs regarding non-supplied power, equipment damage, labor and indemnity claims (PIDs), are also discussed. Although superficially, the importance of taking into account the cost of the company's image with the consumers is also discussed. Finally, a methodology for the determination of such costs is presented and applied to actual cases, with comparison and analysis of the results obtained in different situations.

Key-words: distribution networks, lightning, lightning-related costs, power supply interruptions. 


\section{LISTA DE FIGURAS}

Figura 1 - Mapa Isoceráunico do Brasil.

Figura 2 - Esquemas de conexão dos DPSs no ponto de entrada da linha de energia ou no quadro de distribuição principal da edificação.

Figura 3 - Evolução de pedidos de indenizações nas concessionárias de energia elétrica paulistas no período de 1999 a 2005.

Figura 4 - Gravura ilustrativa do experimento de Benjamin Franklin. 42

Figura 5 - Tipos de nuvens.

Figura 6 - Nuvem cúmulo-nimbo (cumulonimbus). 43

Figura 7 - Classificação ilustrativa dos diversos tipos de descargas atmosféricas existentes na natureza. 45

Figura 8 - Forma de onda típica de corrente da primeira descarga de retorno negativa. 47

Figura 9 - Situação do sistema de detecção de descargas no Brasil em 1995.

Figura 10 - Evolução do sistema de detecção de descargas atmosféricas no Brasil de 1988 até 2004

Figura 11 - Mapa da localização dos sensores da RINDAT em 2006.

Figura 12 - Diagrama da central de processamento. 58

Figura 13 - Esquema ilustrativo do método Time of Arrival para a detecção de descargas atmosféricas por sensores do tipo LPATS.

Figura 14 - Esquema ilustrativo de uma ambigüidade no cálculo da posição de uma descarga atmosférica, quando utilizados apenas três sensores LPATS na detecção.

Figura 15 - Esquema ilustrativo do método MDF para a detecção de descargas atmosféricas.

Figura 16 - Esquema ilustrativo de detecção de uma descarga atmosférica por meio de 2 sensores do tipo IMPACT.

Figura 17 - Esquema ilustrativo da detecção de uma descarga atmosférica por sensores do tipo LPATS e do tipo IMPACT em uma rede híbrida.

Figura 18 - Esquema ilustrativo da eficiência na detecção computacional para descargas atmosféricas na faixa de $5 \mathrm{kA}$ a $10 \mathrm{kA}$ (maio de 2001).

Figura 19 - Índices DEC e FEC do estado de São Paulo no período de 1996 a 2005.72

Figura 20 - Índices DEC e FEC da região sudeste do Brasil no período de 1996 a 2005. 73

Figura 21 - Índices DEC e FEC do Brasil no período de 1996 a 2005. 
Figura 22 - Índice DEC de descargas atmosféricas Vs. outras causas, período mensal de 2003 a 2005.

Figura 23 - Índice FEC de descargas atmosféricas Vs. outras causas, período mensal de 2003 a 2005.

Figura 24 - Evolução do número de pedidos de indenização nas concessionárias paulistas no período de 1999 a 2005.

Figura 25 - Evolução do valor ressarcido por PIDs devido a descargas atmosféricas, no ano de 2005 e no primeiro trimestre de 2006.

Figura 26 - Fluxograma correspondente à metodologia proposta para determinação dos custos decorrentes de descargas atmosféricas em sistemas de distribuição de energia.

Figura 27 - Mapa ilustrativo com as projeções UTM no mundo.

Figura 28 - Distribuição das descargas atmosféricas na região do alimentador analisado no Caso A.

Figura 29 - Distribuição das descargas atmosféricas na região do alimentador analisado no Caso B.

Figura 30 - Distribuição das descargas atmosféricas na região do alimentador analisado no Caso C. 


\section{LISTA DE TABELAS}

Tabela 1 - Descargas atmosféricas.

Tabela 2 - Valores médios de custo de interrupção segmento INDUSTRIAL

(US\$ / kWh).

Tabela 3 - Valores médios de custo de interrupção segmento COMERCIAL / SERVIÇOS (US\$ / kWh).

Tabela 4 - Valores médios de custo de interrupção segmento RESIDENCIAL (US\$ / kWh).

Tabela 5 - Valores médios para uma interrupção de 01 (uma) hora de duração (US\$ / kWh).

Tabela 6 - Custo da interrupção em algumas concessionárias do Brasil.

Tabela 7 - Custo da interrupção categoria residencial

Tabela 8 - Custo da interrupção, valores médios do estado de São Paulo.

Tabela 9 - Reclamações na Bahia em 2002.

Tabela 10 - Parâmetros: descarga atmosférica.

Tabela 11 - Parâmetros: descarga de retorno.

Tabela 12 - Número de sensores por país (situação em 2004).

Tabela 13 - Lista de sensores de detecção de descargas atmosféricas da RINDAT no Brasil.

Tabela 14 - Relação entre custo lado da concessionária e custo lado do consumidor. 


\section{LISTA DE ABREVIATURAS E SIGLAS}

ABNT

ABRADEE

AGERBA

ANEEL

ARSI

CEMIG

CODI

COELBA

COFINS

CSPE

CTEEP

DEC

DNAEE

DPG

DPS

DVD

ELEKTRO

ELETROPAULO

ERM

FEC

FURNAS

GPS

$\mathrm{GT} / \mathrm{PH}$

ICMS

IEEE

IMPACT

INPE

LLP

LPATS

MDF

P\&D
Associação Brasileira de Normas Técnicas

Associação Brasileira de Distribuidores de Energia Elétrica

Agência Estadual de Regulação de Serviços Públicos de Energia,

Transportes e Comunicações da Bahia

Agência Nacional de Energia Elétrica

Atmospheric Research Inc.

Companhia Energética de Minas Gerais

Comitê de Distribuição de Energia Elétrica

Companhia de Eletricidade do Estado da Bahia

Contribuição para o Financiamento da Seguridade Social

Comissão de Serviços Públicos de Energia

Companhia de Transmissão de Energia Elétrica Paulista

Duração Equivalente de Interrupção por Unidade Consumidora

Departamento Nacional de Água e Energia Elétrica (atual ANEEL)

Disposição a Pagar

Dispositivo de Proteção contra Surto

Digital Video Disc

ELEKTRO Eletricidade e Serviços S/A

Eletropaulo Metropolitana Eletricidade de São Paulo S/A

Extended Rusck Model

Freqüência Equivalente de Interrupção por Unidade Consumidora FURNAS Centrais Elétricas S/A

Global Positioning System - Sistema de Posicionamento Global

Departamento de Planejamento Hidroenergético da CEMIG

Imposto sobre Circulação de Mercadorias e Prestação de Serviços

Institute of Electrical and Electronics Engineers

IMProved Accuracy from Combined Technology

Instituto Nacional de Pesquisas Espaciais

Lightning Location and Protection

Lightning Positioning and Tracking System

Magnetic Direction Finding

Pesquisa e Desenvolvimento 
Pedido de Indenização por Danos

PIS

Programa de Integração Social

RIDAT

Rede Integrada de Detecção de Descargas Atmosféricas

RINDAT

Rede Integrada Nacional de Detecção de Descargas Atmosféricas

SBSE

Simpósio Brasileiro de Energia Elétrica

SENDI

Seminário Nacional de Distribuição de Energia Elétrica

SIMEPAR

Instituto Tecnológico SIMEPAR (Sistema Meteorológico do Paraná)

SISDAT

Sistema de Detecção de Descargas Atmosféricas

SLT

Sistema de Localização de Tempestades

TN

Centro de Tecnologia e Normalização

TOA

Time Of Arrival - tempo de chegada

UPS

Unidade Padrão de Serviço

UTM

Universal Transverse Mercator 


\section{LISTA DE SÍMBOLOS}

$\begin{array}{ll}\mathrm{A} & \text { ampère } \\ \mathrm{I} & \text { corrente } \\ \mathrm{N}_{\mathrm{g}} & \text { densidade de descargas ao solo } \\ { }^{\circ} \mathrm{C} & \text { grau Celsius } \\ { }^{\circ} \mathrm{F} & \text { grau Fahrenheit } \\ \mathrm{Hz} & \text { hertz } \\ \mathrm{h} & \text { hora } \\ \mathrm{M} & \text { mega } \\ \mathrm{m} & \text { metro } \\ \mu & \text { micro } \\ \mathrm{min} & \text { minuto } \\ \S & \text { parágrafo } \\ \mathrm{k} & \text { quilo } \\ \mathrm{S} & \text { segundo } \\ C_{o} & \text { velocidade da luz } \\ \mathrm{W} & \text { watt } \\ \mathrm{Wh} & \text { watt hora }\end{array}$




\section{RESUMO}

\section{ABSTRACT}

LISTA DE FIGURAS

LISTA DE TABELAS

LISTA DE ABREVIATURAS E SIGLAS

LISTA DE SÍMBOLOS

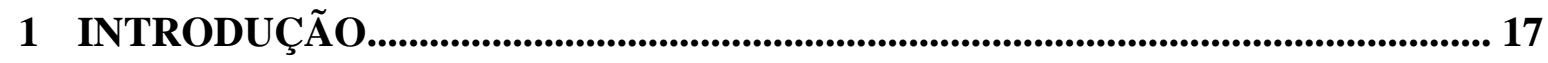

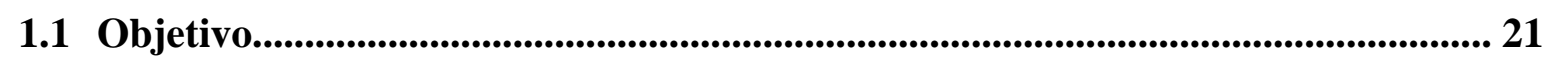

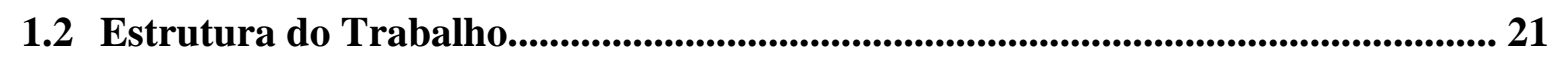

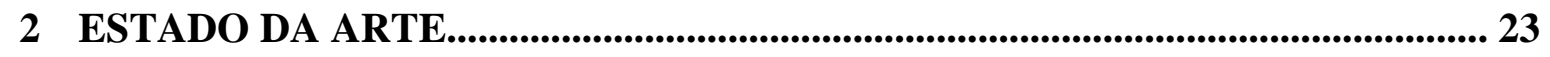

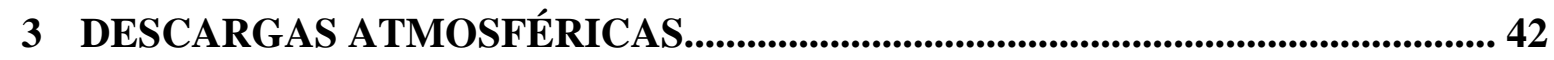

3.1 Considerações Gerais...................................................................................... 42

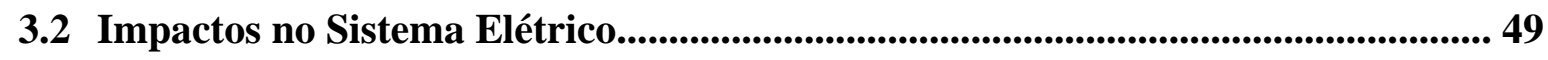

3.3 Sistema de Deteç̧ão e Localização de Descargas Atmosféricas............................ 53

4 CUSTOS DA INTERRUPÇÃO DE ENERGIA ELÉTRICA.................................. 65

4.1 Considerações Gerais..................................................................................... 65

4.2 Custo pelo Lado da Oferta - Concessionária....................................................66

4.3 Custo pelo Lado da Demanda - Consumidor.................................................... 67

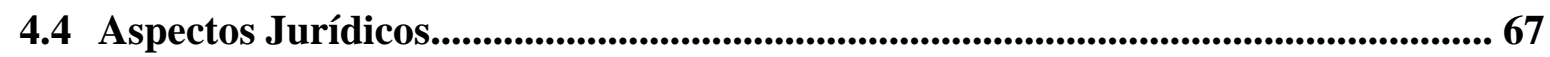

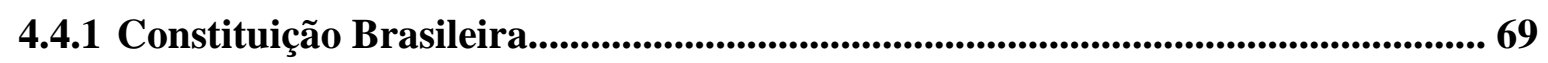

4.4.2 Código de Defesa do Consumidor................................................................. 69

4.4.3 ANEEL (Agência Nacional de Energia Elétrica) /

CSPE (Comissão de Serviços Públicos de Energia)................................................. 70

4.5 O Pedido de Indenização - PID................................................................................... 75

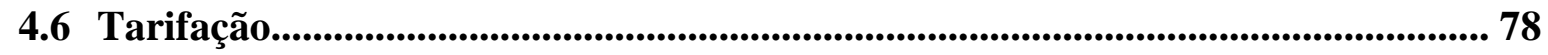

4.7 Unidade Padrão de Serviço (UPS)...................................................................... 82

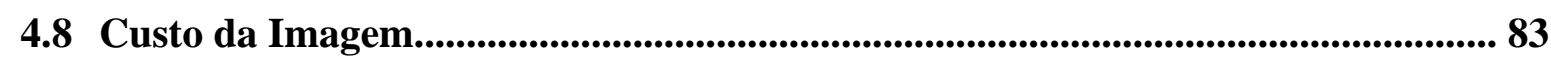

5 PROPOSTA DE METODOLOGIA DE APURAÇÃO DE CUSTOS E APLICAÇÃO EM CASOS REAIS.................................................................... 86

5.1 Proposta de Metodologia para Apuração de Custos.................................................. 86

5.2 Considerações Gerais Aplicadas aos Casos Reais.................................................. 89 


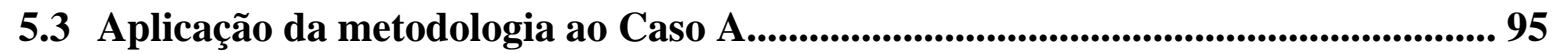

5.4 Aplicação da metodologia ao Caso B.................................................................... 102

5.5 Aplicação da metodologia ao Caso C.................................................................. 109

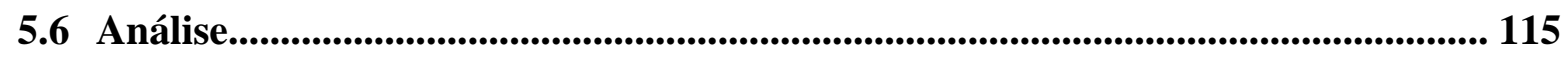

5.6.1 Custo pelo lado concessionária Vs. custo lado consumidor................................. 115

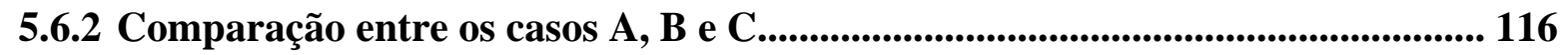

5.6.3 Custo da energia não vendida Vs. Custo de mão-de-obra e serviços.................... 116

5.7 Estimativa anual para toda a área de concessão.................................................... 117

6 CONCLUSÕES E PROPOSTAS DE TRABALHOS FUTUROS.............................. 120

REFERÊNCIAS BIBLIOGRÁFICAS.......................................................................... 122 


\section{INTRODUÇÃO}

Em função da sua localização geográfica e da sua extensão territorial, o Brasil sofre uma grande incidência de descargas atmosféricas, que causam grandes prejuízos à nossa sociedade. Assim é muito comum que as descargas atmosféricas sejam responsabilizadas por vários problemas, tais como: avarias em equipamentos, incêndios, explosões, óbitos de seres humanos e animais, pelos mais diversos setores, tais como o elétrico, o industrial, o de telecomunicação, o agrícola, o de construção civil, o aeronáutico e vários outros. Com certeza, o setor elétrico é o mais afetado; estima-se que cerca de $70 \%$ dos desligamentos das linhas de transmissão e que de $30 \%$ a $60 \%$ dos desligamentos das redes de distribuição são causados por descargas atmosféricas.

Embora a maioria dos desligamentos não produza danos irreversíveis, têm sido observadas com freqüência falhas em equipamentos e componentes de redes, em especial transformadores de distribuição e isoladores de pino, particularmente em casos de redes atravessando áreas rurais, expostas a uma maior incidência de descargas diretas (SILVA et al., 2003). Desta forma, as descargas atmosféricas são freqüentemente consideradas as responsáveis por uma parcela expressiva das falhas e interrupções não programadas de fornecimento de energia em sistemas elétricos, podendo assim provocar danos permanentes a equipamentos sensíveis e normalmente caros. Tais danos freqüentemente resultam em parada de máquinas, perdas de produtividade e de dados, contribuindo de forma significativa (e negativa) para a composição dos índices de qualidade de energia, mesmo no caso de regiões com níveis ceráunicos moderados.

Com o uso maciço de dispositivos semicondutores nos aparelhos e equipamentos eletroeletrônicos nos diversos segmentos (industriais, comerciais e domésticos), sobretudo na informática, automação e telecomunicações, a sociedade começou a perceber e se incomodar com qualquer tipo de distúrbio (JUCÁ, 2003). Agregado a isso, o acesso à informação e a maior divulgação dos direitos do consumidor têm ocasionado um aumento no número de PIDs - Pedidos de Indenização por Danos às concessionárias. Em resumo, hoje em dia não se aceita mais problemas na qualidade e na continuidade do fornecimento de energia elétrica, pois a sociedade tornou-se dependente das comodidades ofertadas pela energia elétrica, ou ainda, pela eficiência no uso desta.

A descarga atmosférica é um dos fenômenos da natureza que muito intrigam o ser humano desde a antiguidade, e devido ao seu poder, sempre foi vista como algo muito superior e considerada como um “act of God” (ação de Deus). Ou seja, sempre foram vistas como algo 
acima de qualquer possibilidade de contestação, por se tratar de um fenômeno da natureza e de proporções elevadas. Desta forma, a legislação sempre a tratou como algo fortuito e de força maior, ou seja, independente da vontade do homem. Assim, os custos devido às descargas atmosféricas sempre foram considerados como prejuízos. Isso pode ser verificado nas três legislações básicas brasileiras (Constituição da República Federativa do Brasil, Código de Defesa do Consumidor e Novo Código Civil Brasileiro), conforme se observa a seguir:

Constituição da República Federativa do Brasil de 1988 no seu artigo 37:

[...] $\S 6^{\circ}$ - As pessoas jurídicas de direito público e as de direito privado prestadoras de serviços públicos responderão pelos danos que seus agentes, nessa qualidade, causarem a terceiros, assegurado o direito de regresso contra o responsável nos casos de dolo ou culpa. [...] (BRASIL, 1988)

Lei 8.078/1990 (Código de Defesa do Consumidor) no seu artigo 14:

[...] Art. 14. O fornecedor de serviços responde, independentemente da existência de culpa, pela reparação dos danos causados aos consumidores por defeitos relativos à prestação dos serviços, bem como por informações insuficientes ou inadequadas sobre sua fruição e riscos.

$\S 1^{\circ} \mathrm{O}$ serviço é defeituoso quando não fornece a segurança que o consumidor dele pode esperar, levando-se em consideração as circunstâncias relevantes, entre as quais:

I - o modo de seu fornecimento;

II - o resultado e os riscos que razoavelmente dele se esperam;

III - a época em que foi fornecido.

$\S 2^{\circ} \mathrm{O}$ serviço não é considerado defeituoso pela adoção de novas técnicas.

$\S 3^{\circ} \mathrm{O}$ fornecedor de serviços só não será responsabilizado quando provar:

I - que, tendo prestado o serviço, o defeito inexiste;

II - a culpa exclusiva do consumidor ou de terceiro.

$\S 4^{\circ}$ A responsabilidade pessoal dos profissionais liberais será apurada mediante a verificação de culpa [...] (BRASIL, 1990). 
Lei 10.406/2002 (Novo Código Civil Brasileiro), no seu artigo 393:

[...] Art. 393. O devedor não responde pelos prejuízos resultantes de caso fortuito ou força maior, se expressamente não se houver por eles responsabilizado. [...]

[...] Parágrafo único. O caso fortuito ou de força maior verifica-se no fato necessário, cujos efeitos não era possível evitar ou impedir [...] (BRASIL, 2002).

Um dos mais polêmicos desligamentos creditados a uma descarga atmosférica foi o blecaute ocorrido no dia 11/03/1999, que deixou a região sudeste do país às escuras a partir das 22h16min (horário fora do consumo de ponta). Independentemente de se comprovar que o raio tenha caído dentro da subestação em Bauru, ou em uma linha de transmissão, sabe-se que os prejuízos diretos e indiretos foram grandes. Somente a multa aplicada à CTEEP Companhia de Transmissão de Energia Elétrica Paulista - foi de R\$ 3.374.421,09 (SALATA et al., 2000).

Pode-se perceber que com o desenvolvimento e o progresso da sociedade, exige-se cada vez mais das empresas fornecedoras de produtos e serviços, uma melhor qualidade com baixos custos, forçando maior interação entre fornecedor e consumidor.

No caso das empresas de energia elétrica, a relação com o cliente vinha se caracterizando historicamente pela unilateralidade, não havendo por vezes, por parte das empresas, preocupação com as necessidades dos clientes, impondo regras e exigências, não avaliando a problemática pela sua ótica deles (consumidor). O Código de Defesa do Consumidor proporcionou uma maior conscientização dos consumidores, que se tornam cada vez mais exigentes no que se refere aos seus direitos.

A qualidade da prestação do serviço de energia elétrica é um ponto importante nos dias de hoje, principalmente em relação à continuidade, nível de tensão e ao pronto restabelecimento do fornecimento, que agora são versados por força de lei. Pode-se citar a Resolução ${ }^{\circ}{ }^{0} 24$ de 27/01/2000, que trata da continuidade da distribuição de energia às unidades consumidoras, e da Resolução $n^{\circ} 456$ de 29/11/2000, que trata das condições gerais de fornecimento de energia elétrica, que passaram a ser uma preocupação constante das empresas de energia elétrica. Isto porque os atuais sistemas distribuidores, de modo geral, não atendem em sua plenitude, a essa exigência, seja pelos diversos fatores externos à rede não controláveis (por exemplo, a descarga atmosférica), pela infra-estrutura de atendimento de emergência, nem sempre 
quantitativamente bem dimensionada ou ainda, pela necessidade de desligamentos para a execução de serviços programados (ABRADEE-CODI, 1996).

Quanto aos desligamentos não programados, é evidente que apesar de todos os esforços que venham a ser realizados, o sistema sempre estará sujeito a problemas que podem levar a interrupção no fornecimento de energia aos consumidores, sendo portanto, importante que se entendam os problemas ocasionados por essas interrupções, bem como os custos a elas associados. No setor de eletricidade, os custos diretos são bem conhecidos por parte das empresas concessionárias de energia. Contudo, analisando-se sobre o ponto de vista do consumidor, a questão se torna muito mais complicada. Como a energia elétrica é um insumo para o consumidor, a sua falta pode provocar diversos tipos de transtornos como, por exemplo, perda de produção, perda de matéria-prima, ociosidade das instalações e de mão-deobra, perda de lazer, etc. Assim, faz-se necessário conhecer o custo da interrupção no fornecimento para cada tipo de consumidor, de modo a se determinar o ponto ideal entre a melhora na confiabilidade de suprimento em função dos custos de investimentos e de interrupção (GOMES; SCHILLING, 1997).

Diante desse cenário, as concessionárias de energia do Brasil têm utilizado os Programas de Pesquisa e Desenvolvimento no intuito de criarem ferramentas de apoio à análise nas ocorrências da rede de distribuição, sobretudo nas respostas aos PIDs (KAGAN, 2003).

Contudo, o fator gerador de mudanças de uma forma considerável ocorreu quando a Agência Nacional de Energia Elétrica - ANEEL, publicou a Resolução Normativa $\mathrm{n}^{\circ} 61$ em 29/04/2004, em que os danos causados pelas descargas atmosféricas passaram a ter relevância nas análises dos PIDs, uma vez que o poder público, representado então pela ANEEL, acredita que hoje já existe a tecnologia necessária para se prever, analisar e mesmo se evitar ou minimizar os efeitos das descargas atmosféricas, como se observa no seu artigo $5^{\circ}$ :

[...] Art. $5^{\circ}$ No processamento do pedido de ressarcimento, a concessionária deve comprovar a existência ou não do nexo de causalidade.

Parágrafo único. Na comprovação do nexo de causalidade devem ser considerados os eventos prováveis causadores do dano, entre outros, descargas atmosféricas e sobretensões oriundas da energização de circuitos, os quais não eximem a concessionária da responsabilidade do ressarcimento [...] (ANEEL, 2004). 
Diante desta variação de interpretações jurídicas, ficam várias questões:

- Como comprovar o nexo causal se até então as descargas atmosféricas eram consideradas caso fortuito e de força maior?

- Como analisar e quantificar os problemas causados pelas descargas atmosféricas, haja vista ser um fenômeno aleatório e de alta complexidade?

- Qual o real custo, para a concessionária e para o consumidor, dos danos causados pelas descargas atmosféricas?

Assim, a caracterização e avaliação de custos decorrentes das descargas atmosféricas em sistemas de distribuição de energia não é um trabalho fácil, apesar de ser de extrema importância face às mudanças ocorridas na tecnologia e na legislação vigente.

\subsection{Objetivo}

O presente trabalho visa a caracterização, o desenvolvimento de metodologia para análise e a avaliação dos custos decorrentes de descargas atmosféricas em sistemas de distribuição de energia. A caracterização consiste na determinação dos custos relacionados ao não fornecimento de energia, da manutenção corretiva, de materiais e equipamentos, da imagem da empresa e de ressarcimentos apontados nos pedidos de indenização por danos (PIDs), bem como aqueles associados a tais análises.

\subsection{Estrutura do Trabalho}

Este trabalho está estruturado em seis capítulos. Após esta introdução, o trabalho apresenta, no Capítulo 2, o "Estado da Arte”, ou seja, uma visão do cenário de hoje, o que rege a legislação, quais são os problemas e o que já existe de ações nesta área.

O Capítulo 3 trata do fenômeno descarga atmosférica, apresenta conceitos relevantes e alguns resultados de estudos e trabalhos desenvolvidos sobre o tema, principalmente aqueles que abordam as interferências em redes de distribuição. Na seqüência são abordados os métodos de detecção e localização de descargas atmosféricas, em especial a rede existente no Brasil, e que podem ser utilizados pelas concessionárias. 
No Capítulo 4 são apresentadas algumas conceituações de custos e a forma de apropriá-los, sob o enfoque contábil / econômico, aí sendo explanados os custos tangíveis e intangíveis, com enfoque pelo lado da oferta (concessionária) e da demanda (consumidor). São também discutidos os aspectos jurídicos envolvidos, com base na Constituição Brasileira, no Código Civil, no Código de Defesa do Consumidor, e nas resoluções ANEEL, bem como os aspectos envolvendo os PIDs, seja na sua forma ou valores envolvidos, principalmente após a vigência da Resolução Normativa nº 61 de 29/04/2004 (ANEEL 2004).

No Capítulo 5 é apresentada a metodologia para apropriar custos relacionados ao não fornecimento de energia, localização da falha (existente ou não), de manutenção aos danos causados pelas descargas atmosféricas e da imagem da concessionária que se desgasta perante o consumidor. São apresentados também estudos de casos reais relativos a redes de distribuição e a aplicação da metodologia proposta, bem como uma análise da evolução dos PIDs com a vigência da Resolução Normativa $n^{\circ} 61$ da ANEEL.

Finalmente, no Capítulo 6, são apresentadas as principais conclusões do trabalho e apontadas propostas para desenvolvimentos futuros. 


\section{ESTADO DA ARTE}

Os custos decorrentes das descargas atmosféricas sempre foram vistos como algo acima de qualquer possibilidade de contestação, por se tratar de um fenômeno da natureza de proporções elevadas. A seguir são apresentados os principais estudos correlacionados aos custos decorrentes das descargas atmosféricas em sistemas de distribuição de energia, mostrando a visão jurídica e econômica do problema e a posição das concessionárias de energia elétrica antes e após a publicação da Resolução Normativa ${ }^{\circ} 61$ da ANEEL que versa sobre o ressarcimento dos danos.

Antes de iniciar o enfoque jurídico deve ser lembrada a hierarquia das leis, onde são classificadas pela ordem de importância da seguinte forma (FÜHRER, 2002):
a. Constituição,
b. Emendas à Constituição,
c. Leis Complementares,
d. Leis Ordinárias,
e. Decretos Regulamentadores,
f. Outras normas de hierarquia inferior.

Cabe lembrar que nenhuma delas deve contrariar a lei e ferir a Constituição, sob pena de ser considerada ilegal.

Para um melhor funcionamento dos três poderes (executivo, legislativo e judiciário) é comum a designação de órgãos para a função de regular uma matéria específica que lhe afeta. A ANEEL é um exemplo disso, criada através da lei $n^{0} 9.427$ de 26/12/1996, tem a função de órgão regulador para a exploração da atividade de energia elétrica (DI PIETRO, 2004). Assim, ela pode deliberar atos administrativos normativos, aqueles que contêm um comando do executivo para uma correta aplicação da lei. Dentre estes atos existem os decretos, os regulamentos, os regimentos, as resoluções administrativas e as deliberações. Destaca-se novamente que em nenhum momento estes podem contrariar a lei, sob pena de serem ilegais (FÜHRER, 2002). 
Com as privatizações das empresas distribuidoras e com o aumento de questionamentos acerca dos aspectos referentes aos danos e ressarcimentos (em especial quanto às descargas atmosféricas), e objetivando definir responsabilidades, a agência reguladora editou a Resolução Normativa n ${ }^{\circ} 61$ de 29/04/2004 da ANEEL, onde explicita:

[...] Art. $5^{\circ}$ No processamento do pedido de ressarcimento, a concessionária deve comprovar a existência ou não do nexo de causalidade.

Parágrafo único. Na comprovação do nexo de causalidade devem ser considerados os eventos prováveis causadores do dano, entre outros, descargas atmosféricas e sobretensões oriundas da energização de circuitos, os quais não eximem a concessionária da responsabilidade do ressarcimento [...] (ANEEL, 2004).

Essa resolução foi citada em artigo no caderno "Dinheiro" do jornal Folha de São Paulo no dia 01/05/2004: [...] de acordo com a Agência Reguladora, as distribuidoras são responsáveis por danos em equipamentos elétricos causados pelo fornecimento de energia elétrica, mesmo que não tenham culpa. Ou seja, mesmo em caso de acidentes, como descargas elétricas (raios) que sobrecarregam a rede [...]. Neste mesmo artigo, Luiz Carlos Silveira Guimarães (diretor executivo da ABRADEE - Associação Brasileira dos Distribuidores de Energia Elétrica) comenta: [...] a associação pretende encaminhar um recurso à agência para que as empresas não sejam responsabilizadas em caso de descargas atmosféricas. Raio é um caso fortuito, não implica indenização [...] (FOLHA, 2004).

Para uma interpretação dos termos Caso Fortuito e Força Maior, convêm analisar inicialmente a Lei 10.406/2002, correspondente ao Novo Código Civil Brasileiro:

[...] Art. 393. O devedor não responde pelos prejuízos resultantes de caso fortuito ou força maior, se expressamente não se houver por eles responsabilizado".

"Parágrafo único. O caso fortuito ou de força maior verifica-se no fato necessário, cujos efeitos não era possível evitar ou impedir [...] (BRASIL, 2002).

Haja vista que o artigo em questão mantém o mesmo teor do artigo 1.058 do Código Civil de 1916, nada impede em se adicionar o artigo 159 do Código Civil de 1916, [...] aquele que, por ação ou omissão voluntária, negligência, ou imprudência, violar direito, ou causar prejuízo a outrem, fica obrigado a reparar o dano [...]. Contudo, essa expressão causa uma certa 
polêmica entre os advogados, não estando clara ainda nos dias de hoje a sua real extensão. Segundo Jucá (2003, p.52),

[...] ÁLVARES (1962) apud CAVALCANTI (1948) explicita que o conceito de caso fortuito ou força maior decorre de três elementos: inevitabilidade, imprevisibilidade e irresistibilidade. Não há acontecimentos que possam, a princípio, ser sempre considerados casos fortuitos ou força maior. Tudo depende das condições de fato em que se verifique o evento e do grau de evolução da sociedade.

Assim, o que no início deste século era considerado caso fortuito ou de força maior, hoje talvez já não o seja, e o que hoje se caracteriza como tal, amanhã poderá deixar de sê-lo, em virtude do progresso da ciência, do desenvolvimento da tecnologia ou da maior providência humana. Percebe-se, pois, que a simples alegação da ocorrência de caso fortuito ou força maior para as hipóteses de descargas atmosféricas, temporais, árvores sobre a rede, abalroamentos em postes, objetos estranhos atirados sobre a rede, etc., não mais poderão ser aceitos como excludentes de responsabilidades. A concessionária deve provar que tais fatos extrapolaram os limites tolerável e aceitável, sendo provocados por agentes externos, imprevisíveis e irresistíveis ao sistema supridor (ANDRADE et al., 2001) [...]

Já Di Pietro, no seu livro Direito Administrativo, comenta:

[...] Força maior é acontecimento imprevisível, inevitável e estranho à vontade das partes, como uma tempestade, um terremoto, um raio. Não sendo imputável à Administração, não pode incidir a responsabilidade [...]

[...] Já na hipótese de caso fortuito, em que o dano seja decorrente de ato humano, de falha da administração, não ocorre a mesma exclusão; quando se rompe, por exemplo, uma adutora ou cabo elétrico, causando dano a terceiros, não se pode falar em força maior [...] (DI PIETRO, 2004).

A Constituição da República Federativa do Brasil de 1988 no seu Artigo 37, deixa vaga a questão da responsabilidade, uma vez que o direito de regresso não é possível de se aplicar:

[...] $\S 6^{\circ}$ - As pessoas jurídicas de direito público e as de direito privado prestadoras de serviços públicos responderão pelos danos que seus agentes, nessa qualidade, causarem a terceiros, assegurado o direito de regresso contra o responsável nos casos de dolo ou culpa [...] (BRASIL, 1988). 
A Lei 8.078 / 1990 (Código de Defesa do Consumidor) se coloca do lado do consumidor, garantindo assim o direito de ressarcimento pela concessionária, que é o fornecedor do serviço, neste caso o suprimento da energia.

[...] Art. 14. O fornecedor de serviços responde independentemente da existência de culpa, pela reparação dos danos causados aos consumidores por defeitos relativos à prestação dos serviços, bem como por informações insuficientes ou inadequadas sobre sua fruição e riscos.

$\S 1^{\circ} \mathrm{O}$ serviço é defeituoso quando não fornece a segurança que o consumidor dele pode esperar, levando-se em consideração as circunstâncias relevantes, entre as quais:

I - o modo de seu fornecimento;

II - o resultado e os riscos que razoavelmente dele se esperam;

III - a época em que foi fornecido.

$\S 2^{\circ} \mathrm{O}$ serviço não é considerado defeituoso pela adoção de novas técnicas.

$\S 3^{\circ} \mathrm{O}$ fornecedor de serviços só não será responsabilizado quando provar:

I - que, tendo prestado o serviço, o defeito inexiste;

II - a culpa exclusiva do consumidor ou de terceiro.

$\S 4^{\circ}$ A responsabilidade pessoal dos profissionais liberais será apurada mediante a verificação de culpa [...] (BRASIL, 1990).

Retornando à análise da Resolução Normativa $n^{\circ} 061$ / 2004 da ANEEL, que em sua totalidade estabelece as disposições quanto ao ressarcimento de danos elétricos em equipamentos elétricos instalados em unidades consumidoras, causados por perturbações ocorridas no sistema elétrico, não há dúvidas quanto à responsabilidade da concessionária em provar a inexistência de nexo causal ou então mau uso dos equipamentos que se danificaram.

[...] Art. $3^{\circ}$ As disposições desta Resolução se aplicam, exclusivamente, para os casos de dano elétrico causado a equipamentos elétricos alimentados na mesma tensão de atendimento contratada no ponto de entrega ou de conexão de energia elétrica, aplicando-se ao ressarcimento o disposto no inciso VIII do artigo anterior. $\S 1^{\circ}$ Esta Resolução não se aplica ao ressarcimento de dano elétrico em equipamentos pertencentes a consumidores atendidos em tensão superior a 2,3 kV. 
$\S 2^{\circ}$ A ANEEL e as agências conveniadas devem analisar as reclamações considerando, exclusivamente, o dano elétrico do equipamento, não lhes competindo acatar pedido de ressarcimento por danos morais, lucros cessantes ou outros danos emergentes.

Art. $5^{\circ}$ No processamento do pedido de ressarcimento, a concessionária deve comprovar a existência ou não do nexo de causalidade.

Parágrafo único. Na comprovação do nexo de causalidade devem ser considerados os eventos prováveis causadores do dano, entre outros, descargas atmosféricas e sobretensões oriundas da energização de circuitos, os quais não eximem a concessionária da responsabilidade do ressarcimento.

Art. 10. A concessionária responde independentemente da existência de culpa, pelos danos elétricos causados a equipamentos elétricos de consumidores, nos termos do caput do art. $3^{\circ}$ desta Resolução.

Parágrafo único. A concessionária só poderá eximir-se do ressarcimento nos seguintes casos:

I - quando comprovar a inexistência de nexo causal, nos termos do art. $5^{\circ}$;

II - quando o consumidor providenciar, por sua conta e risco, a reparação do(s) equipamento(s) sem aguardar o término do prazo para a inspeção, salvo nos casos em que houver prévia autorização da concessionária; ou

III - quando comprovar que o dano foi ocasionado pelo uso incorreto do equipamento ou por defeitos gerados a partir das instalações internas da unidade consumidora [...] (ANEEL, 2004)

\section{A Comissão de Serviços Públicos de Energia do Estado de São Paulo (CSPE) em 15/08/2000, antes mesmo da publicação da resolução normativa $n^{0} 61$, realizou reunião para uniformizar as respostas aos pedidos de indenização de danos (PIDs), tendo acordado que:}

[...]

O indeferimento se caracterizará, quando:

a) o concessionário não dispuser de registro de ocorrência para o alimentador e transformador de suprimento à unidade consumidora do reclamante, sendo a mesma a única solicitação existente para esta data, horário e local. A ocorrência será caracterizada por qualquer forma de registro, tanto aqueles decorrentes do contato dos consumidores (telefone, e-mail, carta, balcão de agência, etc.) quanto àqueles decorrentes de falhas de desempenho ou de ocorrências no sistema próprio ou interligado com influência naquela unidade consumidora; 
b) estiver configurada que a potencialidade do evento registrado não seja suficiente para causar o dano a que se solicita ressarcimento, em função das características do equipamento danificado. Ficou acordado que a configuração da potencialidade de eventos, de uma forma geral, deve ser evidenciada através de estudos específicos e contar com as particularidades decorrentes de rede, inerente ao fornecimento da unidade consumidora solicitante, a ser caracterizado após conclusão do projeto de P\&D cooperativo, ora em desenvolvimento. Portanto, os estudos de caracterização da potencialidade de eventos decorrentes de falhas do sistema elétrico, não se encontra disponível atualmente e deverão ser gradativamente integrados aos mecanismos de análise de PID's, sempre que for obtido o consenso entre concessionárias e órgãos reguladores sobre a sua aplicabilidade;

c) as análises de PID’s desenvolvidas pelas concessionárias deverão incluir identificações do sistema elétrico que supre a unidade consumidora, por exemplo, o alimentador e a unidade (ou Estação) transformadora para consumidores em baixa tensão (110) 127/220 volts.

[...](ANDRADE et al., 2001).

A norma ABNT NBR 5410:2004 - Instalações Elétricas de Baixa Tensão, que é a norma que dita as regras e diretrizes nas instalações elétricas, também trata a questão do surto na sua nova versão (de setembro de 2004, com data de vigência a partir de 01/04/2005). A primeira alteração ocorreu com um melhor detalhamento na tabela de descargas atmosféricas, que acrescentou o limite do nível ceráunico ${ }^{1}$ de 25 dias de trovoadas por ano (que é condição da maior parte da região brasileira, vide Figura 1), conforme indicado na Tabela 1.

Tabela 1 - Descargas atmosféricas.

\begin{tabular}{ccccc}
\hline Código da norma & Classificação do Risco & $\begin{array}{c}\text { Nível ceráunico - Td } \\
\text { (trovoada dias por ano) }\end{array}$ & Risco na instalação & Aplicações / exemplos \\
\hline AQ1 & Desprezíveis & $\mathrm{Td}<25$ & - & $\begin{array}{c}\text { Instalações } \\
\text { AQ2 }\end{array}$ \\
Indiretas & $\mathrm{Td}>25$ & $\begin{array}{c}\text { Provenientes da rede } \\
\text { de alimentação }\end{array}$ & $\begin{array}{c}\text { alimentadas por redes } \\
\text { aéreas }\end{array}$ \\
AQ3 & Diretas & $\begin{array}{c}\text { Provenientes da } \\
\text { exposição dos } \\
\text { componentes da } \\
\text { instalação }\end{array}$ & $\begin{array}{c}\text { Partes da instalação } \\
\text { situadas no exterior } \\
\text { das edificações }\end{array}$ \\
\hline
\end{tabular}

Fonte: adaptada da ABNT NBR 5410:2004.

\footnotetext{
${ }^{1}$ Nível ceráunico (Td): número médio de dias de trovoada por ano.
} 


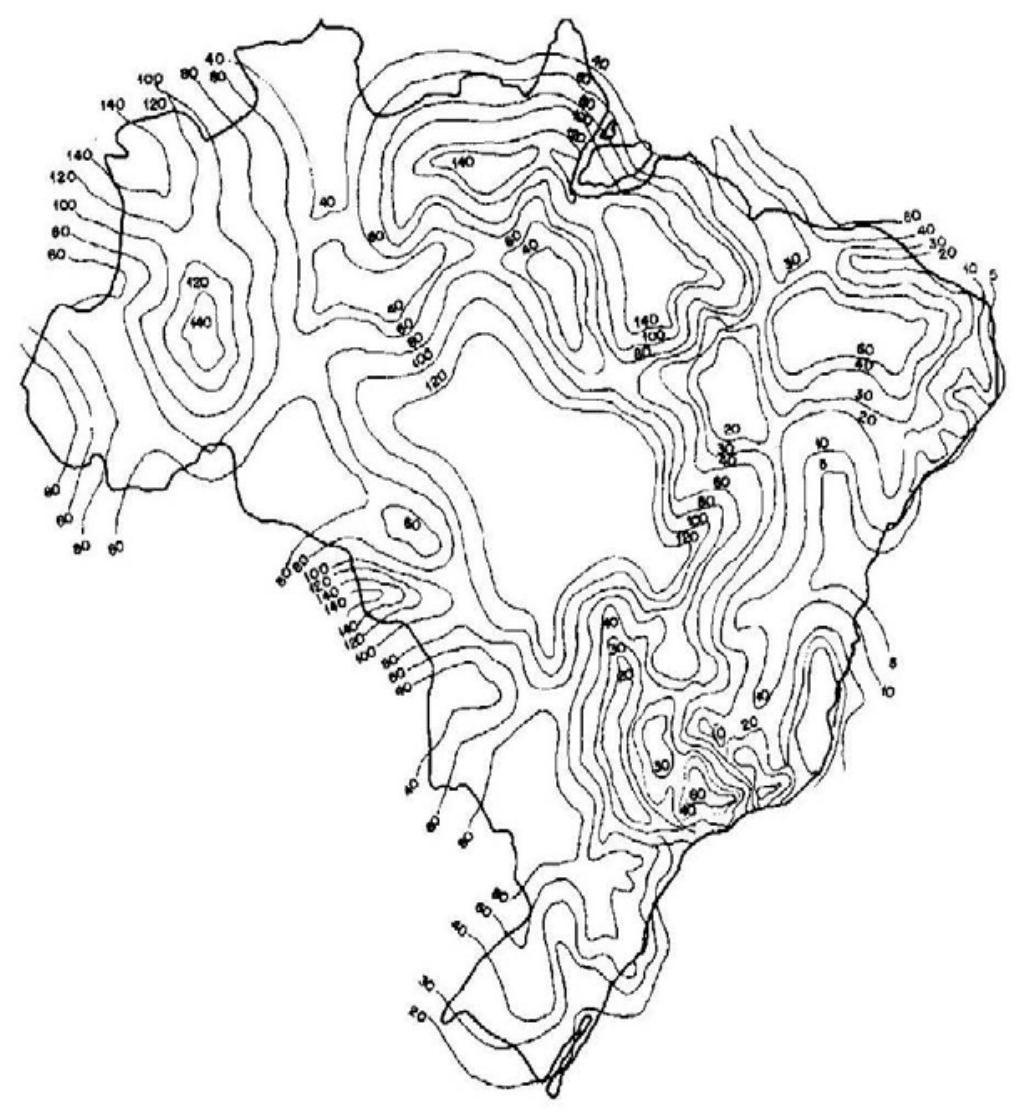

Figura 1 - Mapa Isoceráunico do Brasil.

Fonte: (ABNT NBR 5419:2001).

A segunda alteração foi a inclusão dos dispositivos de proteção contra sobretensões (DPSs) para a proteção contra sobretensões transitórias em linhas de energia:

[...] 5.4.2.1.1 Deve ser provida proteção contra sobretensões transitórias, com uso dos meios indicados em 5.4.2.1.2, nos seguintes casos:

a) quando a instalação for alimentada por linha total ou parcialmente aérea, ou incluir ela própria linha aérea, e se situar em região sob condições de influências externas AQ2 (mais de 25 dias de trovoadas por ano);

b) quando a instalação se situar em região sob condições de influências externas AQ3 (ver tabela 15).

NOTA: admite-se que a proteção contra sobretensões exigida em 5.4.2.1.1 possa não ser provida se as conseqüências dessa omissão, do ponto de vista estritamente material, constituírem um risco calculado e assumido. Em nenhuma hipótese a proteção pode ser dispensada se essas conseqüências puderem resultar em risco direto ou indireto à segurança e à saúde das pessoas. 
5.4.2.1.2 A proteção contra sobretensões requerida em 5.4.2.1.1 deve ser provida:

a) por dispositivo de proteção contra surtos (DPSs), conforme 6.3.5.2; ou

b) por outros meios que garantam uma atenuação das sobretensões no mínimo equivalente àquela obtida conforme a alínea a) [...].

\section{[...] 6.3.5.2 Proteção em linhas de energia}

\subsection{Uso e localização dos DPSs}

Nos casos em que for necessário o uso de DPS, como previsto em 5.4.2.1.1, e nos casos em que esse uso for especificado, independentemente das condições de 5.4.2.1.1, a disposição dos DPS deve respeitar os seguintes critérios:

a) quando o objetivo for a proteção contra sobretensões de origem atmosférica transmitida pela linha externa de alimentação, bem como a proteção contra sobretensões de manobra, os DPS devem ser instalados junto ao ponto de entrada da linha na edificação ou no quadro de distribuição principal, localizado o mais próximo possível do ponto de entrada; ou

b) quando o objetivo for a proteção contra sobretensões provocadas por descargas atmosféricas diretas sobre a edificação ou em suas proximidades, os DPS devem ser instalados no ponto de entrada da linha na edificação.

\section{NOTAS}

1) Ver definição de "ponto de entrada (na edificação)" (3.4.4)

2) Excepcionalmente, no caso de instalações existentes, de unidades consumidoras em edificações de uso individual atendidas pela rede pública de distribuição de baixa tensão, admite-se que os DPS sejam dispostos juntos à caixa de medição, desde que a barra PE aí usada para conexão dos DPS seja interligada ao barramento de eqüipotencialização principal da edificação (BEP), conforme exigido em 6.4.2.1, e desde que a caixa de medição não diste mais de $10 \mathrm{~m}$ do ponto de entrada na edificação.

3) Podem ser necessários DPS adicionais, para proteção de equipamentos sensíveis. Estes DPS devem ser coordenados com os DPS de montante e de jusante (ver 6.3.5.2.4-f).

4) Quando os DPS fizerem parte da instalação fixa, mas não estiverem alojados em quadros de distribuição (por exemplo, incorporados a tomadas de corrente), sua presença deve ser indicada por meio de etiqueta, ou algum tipo de identificador similar, na origem ou o mais próximo possível da origem do circuito no qual se encontra inserido [...] (ABNT, 2004) 
A Figura 2 ilustra os esquemas de conexão de DPSs, conforme a ABNT NBR 5410 : 2004.

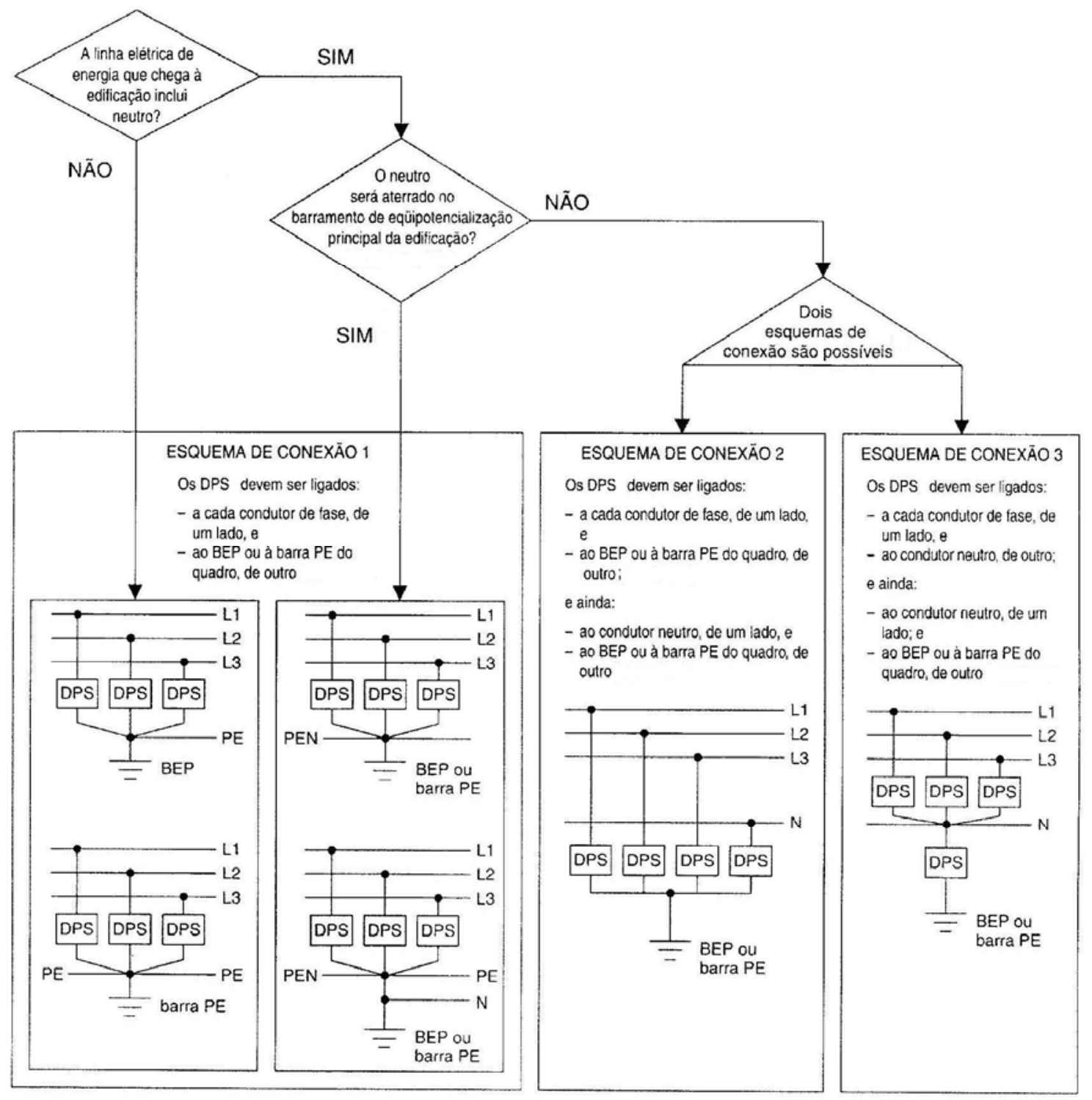

Figura 2 - Esquemas de conexão dos DPSs no ponto de entrada da linha de energia ou no quadro de distribuição principal da edificação.

Fonte: (adaptada da ABNT NBR 5410:2004).

$\mathrm{Na}$ análise dos custos decorrentes de descargas atmosféricas, os estudiosos se deparam com uma situação difícil de mensurar, pois até então o problema era tratado como um simples prejuízo decorrente de uma força da natureza, e não havia a quem reputar a responsabilidade. Assim, não existem trabalhos coligando custos às descargas atmosféricas, há estudos sob a ótica estatística ou econômica dos custos da interrupção dentro de um processo de produção e de faturamento (MASSAUD et al., 1994), avaliações que são feitas a partir de métodos como 
pesquisa direta (ELETROBRÁS, 1991), regressões econométricas ${ }^{2}$ e matriz insumo - produto (GOMES; SCHILLING, 1997).

Um dos primeiros trabalhos que teve como objetivo mensurar o custo de interrupção e que se baseava numa metodologia apresentada num relatório técnico de 1987 foi apresentado pela Eletrobrás (ELETROBRÁS, 1991), em parceria com a Fundação Instituto de Administração da FEA / USP. A apuração do custo de interrupção era feita por classe de consumidores (residencial, comercial e industrial), a partir de um questionário padrão e em seguida a elaboração de uma análise estatística das informações coletadas.

Contudo, a preocupação com o custo do fornecimento de energia elétrica vem de épocas mais antigas. Em 1986, Cyro Vicente Boccuzzi, da Eletropaulo, apresentava a necessidade de determinar o impacto econômico das interrupções de fornecimento (BOCCUZZI, 1986), utilizando-se da estimativa de custo de interrupção. Neste trabalho já se mencionava a importância da redução do índice FEC (Freqüência Equivalente de Interrupção por Unidade Consumidora) a partir de manutenções preventivas, reduzindo, assim, os defeitos ou as interferências por origem externa (mau tempo, galhos de árvore, etc.), obtendo através do estudo uma forma, uma estimativa dos custos de interrupção de fornecimento de energia elétrica em US\$/MWh e em US\$/hora, além da especificação de índices de continuidade globais para as diferentes áreas atendidas, à luz de sua caracterização qualitativa e dos custos de interrupção de fornecimento.

Em 1986, Luiz Carlos Silveira Guimarães (GUIMARÃES, 1986) publicou um artigo no informativo do CODI - Comitê de Distribuição de Energia Elétrica, questionando a validade dos índices DEC (Duração Equivalente de Interrupção por Unidade Consumidora) e FEC (Freqüência Equivalente de Interrupção por Unidade Consumidora) para demonstrar o quanto o consumidor está satisfeito ou não com a qualidade da energia elétrica, pois eram os únicos índices analisados na época como indicadores desta satisfação do cliente. Explana também que o custo econômico-social da interrupção, ao nível dos consumidores, não é uma novidade para o Setor Elétrico, pois vários autores estrangeiros já o haviam determinado e, naquela época, a COPEL (Companhia Paranaense de Energia) estava apresentando uma metodologia baseada em pesquisa econômica - social. Comenta, contudo, a dificuldade em se determinar este custo, uma vez que existem muitas variáveis subjetivas na pesquisa, tanto no questionário quanto na resposta do consumidor, citando como exemplo a dificuldade em converter em

\footnotetext{
${ }^{2}$ Econométrico: descrição de relações econômicas por meio de modelos matemáticos, para se estimar parâmetros com o uso de dados estatísticos.
} 
moeda componentes como lazer, conforto, e trabalho do lar, no caso residencial. Questiona também quanto o consumidor estaria disposto a pagar para ter o aumento desta qualidade. Em 1989, Paulo de Tarso Camargo, no capítulo III de sua Tese de Mestrado intitulada “Custo Social da Energia Elétrica” (CAMARGO, 1989), faz uma explanação quanto ao custo por falhas no fornecimento de energia elétrica para as indústrias, nas unidades residenciais e comerciais. No caso das indústrias, comenta que os custos não são uniformes e dependem muito de indústria para indústria e o quanto são dependentes da energia elétrica, além da necessidade de análise de outros fatores como a duração e freqüência das interrupções e existência ou não de equipamentos de geração de energia elétrica. Já no caso residencial, seria necessário apurar o quanto as unidades residenciais estariam dispostas a pagar para que as falhas ou interrupções não ocorressem. Salienta também que a valoração para minimizar estas falhas, para estas mesmas unidades residenciais, varia muito de horário ao longo do dia e da data da ocorrência. No caso das unidades comerciais, por estarem intimamente correlacionadas com a residencial, pois são nelas que encontramos as diversões, serviços bancários, serviços de restaurante, etc., não haveria necessidade de uma análise mais aprofundada, mas sim utilizar as mesmas premissas das unidades residenciais cabendo, assim, a subjetividade na análise dos valores.

Em 1994, Massaud, Schilling e Hernandez apresentam (MASSAUD et al., 1994) os dados brasileiros quanto aos custos da interrupção de energia e as metodologias de apuração. A seguir serão mostrados os valores típicos médios de US\$ / kWh por classe de consumidor (independentemente do horário da interrupção e do tempo da duração), obtidos a partir de custos de vários países pela Tennessee Valley Authority dos EUA (GOMES et al., 1996).

\section{5,35 US\$ / kWh para classe industrial. \\ 2,61 US\$ / kWh para classe comercial, \\ 1,87 US\$ / kWh para classe residencial,}

Nesta pesquisa, Massaud et al. percebem que o período do ano tem uma influência significativa nos custos de uma interrupção para cada classe de consumidores. O custo pode variar inclusive mês a mês, apesar de que uma análise entre verão e inverno já seria extremamente válida. Um outro ponto importante para a avaliação do custo é o horário em que ocorre a interrupção, por exemplo, manhã, tarde, noite ou madrugada. Ou seja, o custo sofre variações ao longo do horário e também pelo tempo da interrupção, sendo também diferente em função do tipo de consumidor, seja ele residencial comercial ou industrial (Tabelas 2, 3 e 4). 
Tabela 2 - Valores médios de custo de interrupção segmento INDUSTRIAL (US\$ / kWh).

\begin{tabular}{ccccccc}
\hline $\begin{array}{c}\text { Início } \\
\text { Evento }\end{array}$ & 00 a 03 min. & 03 a 15 min & 15 a 30 min & 30 a 60 min & 60 a 120 min & Hora adicional \\
\hline $\begin{array}{c}00-08 \\
\text { horas }\end{array}$ & 2,87 & 1,23 & 1,07 & 0,90 & 0,81 & 0,78 \\
$08-18$ & 2,73 & 1,26 & 1,20 & 0,95 & 0,86 & 0,78 \\
horas & & & & & \\
$18-24$ & 2,80 & 1,14 & 1,06 & 0,83 & 0,75 & 0,78 \\
horas & & & & & & \\
\hline
\end{tabular}

Fonte: Gomes; Schilling, 1997.

Tabela 3 - Valores médios de custo de interrupção segmento COMERCIAL / SERVIÇOS (US\$ / kWh).

\begin{tabular}{|c|c|c|c|c|c|c|}
\hline \multirow{2}{*}{$\begin{array}{l}\text { Início } \\
\text { Evento }\end{array}$} & \multicolumn{6}{|c|}{ Duração da Interrupção } \\
\hline & 00 a 03 min. & 03 a $15 \mathrm{~min}$ & 15 a $30 \mathrm{~min}$ & 30 a $60 \mathrm{~min}$ & 60 a $120 \mathrm{~min}$ & Hora adicional \\
\hline $\begin{array}{c}00-08 \\
\text { horas }\end{array}$ & 0,98 & 1,83 & 2,80 & 2,55 & 2,45 & 2,69 \\
\hline $\begin{array}{c}08-18 \\
\text { horas }\end{array}$ & 1,83 & 3,16 & 4,25 & 4,36 & 4,76 & 3,76 \\
\hline $\begin{array}{c}18-24 \\
\text { horas }\end{array}$ & 1,81 & 3,03 & 3,92 & 3,77 & 4,10 & 3,14 \\
\hline
\end{tabular}

Fonte: Gomes; Schilling, 1997.

Tabela 4 - Valores médios de custo de interrupção segmento RESIDENCIAL (US\$ / kWh).

\begin{tabular}{cc}
\hline Início & Custo (independente da duração da interrupção) \\
\hline $00-08$ horas & 0,00 \\
$08-18$ horas & 0,00 \\
$18-24$ horas & 1,11 \\
\hline
\end{tabular}

Fonte: Gomes; Schilling, 1997. 
Também são apresentados valores a título de comparação com os dados do Canadá e dos Estados Unidos (Tabela 5).

Tabela 5 - Valores médios para uma interrupção de 01 (uma) hora de duração (US\$ / kWh).

\begin{tabular}{cccc}
\hline País & Residencial & Comercial & Industrial \\
\hline EUA & 0,50 & 7,00 & 6,00 \\
Canadá & 0,38 & 13,15 & 12,70 \\
\hline
\end{tabular}

Fonte: Massaud et al., 1994.

Em 1996 Gomes et al. publicou um artigo onde os custos provocados pela interrupção no fornecimento de energia são subdivididos em custo do não faturamento, ou custo do déficit, e custo da interrupção:

Custo do não faturamento: custo que diz respeito ao prejuízo sofrido pela concessionária de energia elétrica pelo fato da mesma não ter concretizado a venda de energia aos seus usuários. Sua avaliação, portanto, não apresenta maiores dificuldades, já que depende somente da tarifa praticada (energia não vendida).

Custo do déficit: este custo está associado às restrições de natureza energética ou das capacidades instaladas nos sistemas de Geração, Transmissão ou Distribuição (GTD) (venda de energia reduzida até que se sane a anomalia, seja pelo reparo do sistema ou incremento da capacidade de geração / transmissão ou distribuição).

Custo da interrupção: reflete os prejuízos do usuário causados pela restrição de energia que o surpreende de forma intempestiva e para a qual não tem como se precaver.

A título de ilustração, a Tabela 6 apresenta os valores obtidos com a pesquisa de Gomes e Schilling (1997), onde estão apresentadas duas interrupções, uma de 3 e outra de 5 minutos de duração. 
Tabela 6 - Custo da interrupção de algumas concessionárias do Brasil.

\begin{tabular}{|c|c|c|}
\hline \multirow[b]{2}{*}{ Empresa } & \multicolumn{2}{|c|}{ Custo da interrupção utilizando-se valores médios nacionais - US\$ / kWh } \\
\hline & $\begin{array}{l}\text { Interrupção com } 3 \text { minutos de } \\
\text { duração das } 08 \text { às } 18 \text { horas }\end{array}$ & $\begin{array}{l}\text { Interrupção com } 5 \text { minutos de } \\
\text { duração das } 08 \text { às } 18 \text { horas }\end{array}$ \\
\hline CEMIG & 2,22 & 2,08 \\
\hline ESCELSA & 2,12 & 2,01 \\
\hline ENERSUL & 1,34 & 1,40 \\
\hline CEMAT & 1,22 & 1,27 \\
\hline CELESC & 1,94 & 1,86 \\
\hline CELPA & 1,32 & 1,36 \\
\hline SAELPA & 1,59 & 1,58 \\
\hline CELG & 1,65 & 1,63 \\
\hline LIGHT & 1,99 & 1,75 \\
\hline ELETROPAULO & 1,98 & 1,88 \\
\hline
\end{tabular}

Fonte: Gomes; Schilling, 1997.

Uma análise dos custos pelo lado da demanda (consumidor) também pode ser conveniente, e é descrita em pesquisa apresentada pela Comissão de Serviços Públicos de Energia do Estado de São Paulo (CSPE). Nela a metodologia para a avaliação dos custos de interrupção seguiu características distintas por categoria de consumidores e foram utilizados dois modelos: o primeiro considerando os custos diretos associados à interrupção de fornecimento e o segundo modelo indireto baseado no conceito da disposição a pagar (DPG), principalmente na classe residencial. A seguir as descrições apresentadas por MAGALHÃES et al. (2001):

\section{Classe Residencial}

\section{Modelo - custo indireto}

Para a classe residencial foi utiliza o conceito de "função utilidade" da microeconomia, ou seja, é especificada como uma função do preço a ser pago para auferir o benefício de uma alternativa em função da renda do indivíduo. Ou quanto se estaria disposto a pagar para se obter o benefício. 
Modelo - custo direto

Custo de proteção: custo fixo incorrido pelos consumidores para se protegerem das falhas do sistema de energia. Caso o domicílio não disponha de equipamentos de proteção, este custo é nulo.

Custo de reparos: gastos relativos aos reparos ou aquisição de novos aparelhos eletrodomésticos danificados pela interrupção súbita da energia ou de seu retorno em faixa de tensão fora da faixa adequada.

Custo de produtos estocados deteriorados ou estragados: custo direto associado à perda de produtos estocados (carnes, leite e derivados, legumes e quaisquer outros), em meio frio (geladeira, freezer), que se deterioram ou perdem valor devido à interrupção de energia. Este custo varia em função do tempo da interrupção sofrida.

\section{Classe Comercial e Industrial de Pequeno Porte (<13,8 kV)}

\section{Modelo - custo direto}

> Custo de geração própria: custo devido à produção de energia através de geradores, baterias, etc., caso haja a interrupção.

Custo de proteção: custo para o consumidor se proteger das falhas do sistema de energia elétrica.

> Custo de reparos: gastos com reparos em equipamentos danificados pela interrupção súbita da energia e de seu retorno em faixa de tensão fora da faixa adequada.

Custo de produtos estocados deteriorados ou estragados: custo associado à perda de produtos estocados em meio frio, que se deterioram ou perdem valor devido à interrupção de energia, custo este variável com o tempo da interrupção sofrida.

Custo de vendas não realizadas: custo de oportunidade associado à perda de vendas devido à interrupção, ou seja, receita não auferida durante o período da interrupção.

Custo de horas extras para compensar períodos interrompidos: custo associado à operação do estabelecimento quando seu período normal de funcionamento é prolongado devido à interrupção.

> Custo de perdas de informação: custo associado a perdas de informações guardadas em meio computadorizado (dados, arquivos, etc.), decorrentes de interrupção ocorrida no estabelecimento, que motivam a reposição de dados e reprocessamento computacional. 
Custo de outros fatores ou custos extras: outros custos associados e não previstos.

Industrial de grande porte $(>=13,8 \mathrm{kV})$

\section{Modelo - custo direto}

Custo de geração própria: custo devido à produção de energia através de geradores, baterias, etc., caso haja a interrupção.

Custo de proteção: custo para o consumidor se proteger das falhas do sistema de energia elétrica.

> Custo de reparos: gastos com reparos em equipamentos danificados pela interrupção súbita da energia e de seu retorno em faixa de tensão fora da faixa adequada.

Custo de matéria-prima ou produtos estocados deteriorados ou estragados: custo direto associado à perda de produtos primários ou matérias-primas, estocados, por exemplo, em meio frio, que se deterioram ou perdem valor devido à interrupção de energia. Este custo é admitido como sendo variável em função do tempo da interrupção sofrida. E similar ao do comercial, com a diferença que o custo de matéria prima deve ser acrescentado.

Custos de produtos em elaboração estragados ou danificados: custo direto associado à perda de produtos durante seu processo de fabricação. Variável conforme o tempo de duração da interrupção.

Custos de produtos acabados, estragados ou danificados: custo direto associado à perda de produtos acabados, ou em estoque. Custo também variável com o tempo de duração da interrupção.

> Custo da produção perdida: corresponde à perda de produção considerada irrecuperável, referindo-se aos produtos que estão sendo processados.

Custo de retomada ou reinício da produção: custo devido aos procedimentos de retomada do ritmo normal da produção no caso de ocorrência de uma interrupção, incluindo o tempo gasto com reprogramação da produção, preparo de equipamentos, limpeza de resíduos, reposição de ferramentas, aferição de padrões e outros procedimentos.

Custo de horas extras para compensar períodos interrompidos: custo associado à operação do estabelecimento, quando seu período normal de funcionamento é prolongado devido à interrupção. 
Custo de perdas de informação: custo associado a perdas de informações guardadas em meio computadorizado (dados, arquivos, etc.), decorrentes de interrupção ocorrida no estabelecimento, que motivam a reposição de dados e reprocessamento computacional.

Custo de outros fatores ou custos extras: outros custos associados e não previstos.

As Tabelas 7 e 8 apresentadas a seguir (MAGALHÃES et al., 2001), mostram respectivamente, os custos de interrupção para a categoria residencial e os custos de interrupção médios para o Estado de São Paulo.

Tabela 7 - Custo da interrupção categoria residencial.

\begin{tabular}{ccc}
\hline $\begin{array}{c}\text { Faixa de consumo } \\
\text { kWh mês }\end{array}$ & $\begin{array}{c}\text { Renda média } \\
\text { US\$ / mês }\end{array}$ & $\begin{array}{c}\text { Custo da interrupção } \\
\text { US\$ / kWh }\end{array}$ \\
\hline $0-150$ & 98,00 & 0,79 \\
$151-300$ & 525,00 & 0,91 \\
$>301$ & $1.148,00$ & 1,75 \\
Média & 270,00 & 0,90 \\
\hline
\end{tabular}

Fonte: Magalhães et al., 2001.

Tabela 8 - Custo da interrupção, valores médios do estado de São Paulo.

\begin{tabular}{cc}
\hline Categorias utilizadas na pesquisa & $\begin{array}{c}\text { Custo de interrupção médio } \\
\text { US\$ / kWh interrompido }\end{array}$ \\
\hline Custo Unitário no Estado & 1,20 \\
Residencial (incluindo rural residencial) & 0,90 \\
Comercial, Serviços e Poderes Públicos & 1,70 \\
(incluindo iluminação Pública) & 5,30 \\
Industrial (incluindo agroindústria) & \\
\hline
\end{tabular}

Fonte: Magalhães et al., 2001.

Mudando-se agora o foco para as reclamações sobre a qualidade do fornecimento, estes são uma constante dentro das concessionárias, uma vez que o produto "energia elétrica” tem se tornado cada vez mais imprescindível. Em pesquisa feita na Bahia (NUNES FILHO, 2004) na concessionária COELBA - Companhia de Eletricidade do Estado da Bahia e na agência 
reguladora local AGERBA - Agência Estadual de Regulação de Serviços Públicos de Energia,Transportes e Comunicações da Bahia, o autor mostra um índice bastante relevante quanto aos tipos de reclamações, conforme apresentado na Tabela 9, onde “danos elétricos e materiais” possuem uma participação elevada, refletindo diretamente nos processos de pedido de indenização de danos (PIDs).

Tabela 9 - Reclamações na Bahia em 2002.

\begin{tabular}{cc}
\hline Qualidade do Fornecimento & Participação (\%) \\
\hline Manutenção / Melhoramentos & 4,0 \\
Danos Elétricos e Materiais & 77,1 \\
Oscilação de Tensão & 20,3 \\
Interrupção do Fornecimento & 2,6 \\
TOTAL & 100,0 \\
\hline
\end{tabular}

Fonte: adaptado de Nunes Filho, 2004.

A Figura 3 apresenta a evolução do número de pedidos de indenizações de 1999 a 2005, no Estado de São Paulo (dados obtidos junto a CSPE - Comissão de Serviços Públicos de Energia) onde se pode notar uma tendência crescente na quantidade de pedidos (SHIGA et al., 2006a)

No XVII SENDI - Seminário Nacional de Distribuição de Energia Elétrica foi apresentado, através de dados históricos coletados desde 2003 (referente à concessionária Eletropaulo), um aumento significativo dos custos de ressarcimento por parte das concessionárias de energia elétrica, tendo como causa as descargas atmosféricas. Em 2003 apenas 1,4\% dos PIDs procedentes foram devidos a este fenômeno, já em 2004 este valor subiu para 9,4\% e em 2005 atingiu 10,8\% (SHIGA et al., 2006b), aumento este (de 9,4 pontos percentuais em 2 anos) que com certeza ocorreu após a vigência, em 2004, da resolução normativa nº 61 . 


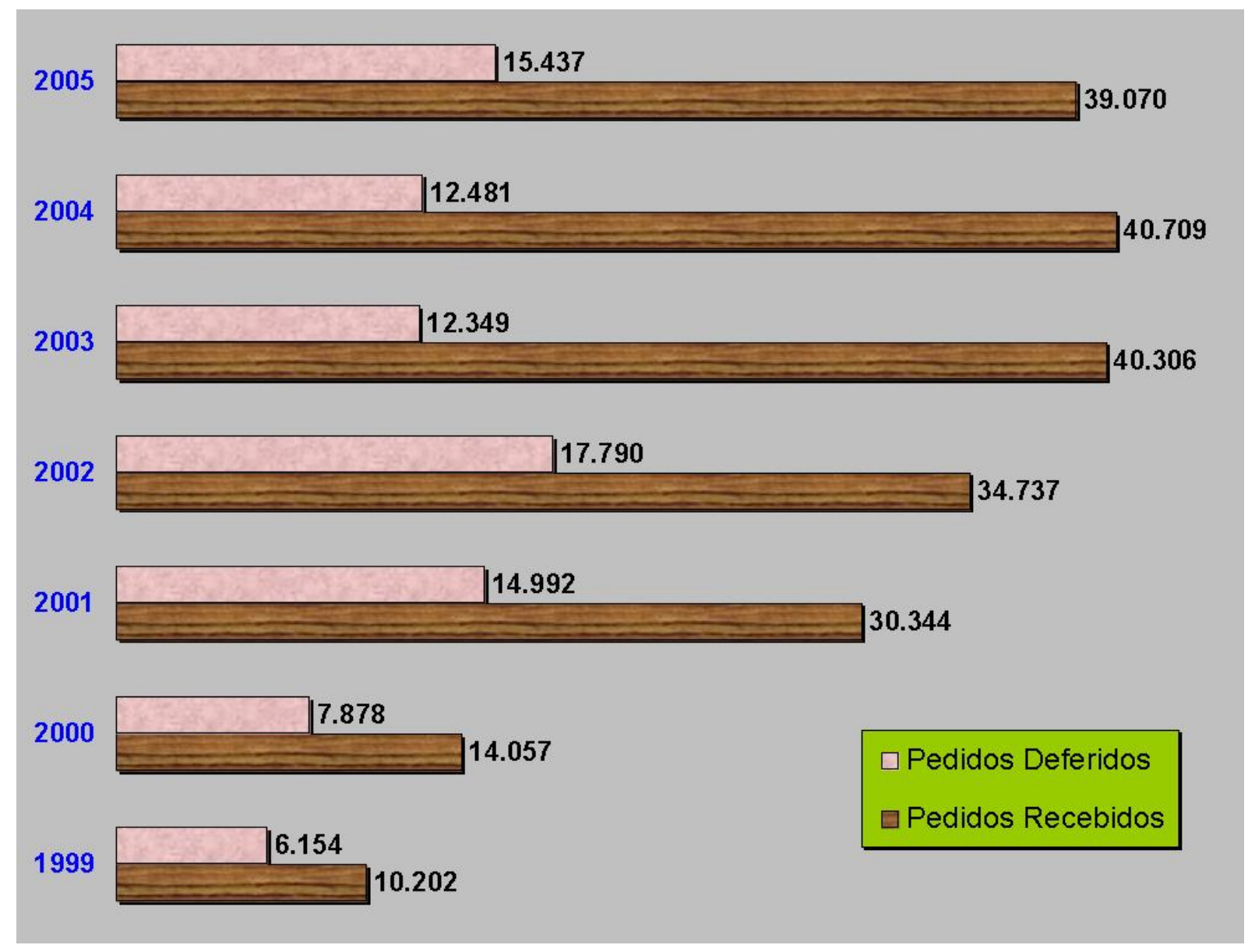

Figura 3 - Evolução de pedidos de indenizações nas concessionárias de energia elétrica paulistas no período de 1999 a 2005.

Fonte: (SBSE - Simpósio Brasileiro de Energia Elétrica, 2006).

Fica evidente, portanto, que uma análise e avaliação dos custos decorrentes de descargas atmosféricas em sistemas de distribuição de energia são necessárias. Principalmente devido à inexistência de uma metodologia de avaliação quanto aos custos e em função de ser um fenômeno natural de intenso poder de destruição, os custos de ressarcimento e reparos são bastante expressivos, agora mais ainda com o amparo legal da legislação brasileira para a cobrança. 


\section{DESCARGAS ATMOSFÉRICAS}

\subsection{Considerações Gerais}

A descarga atmosférica é um fenômeno que sempre existiu, fazendo parte, inclusive, da própria evolução e formação do planeta Terra. Quando se deu o processo de resfriamento do planeta, as tempestades eram mais abundantes e violentas, o que ao longo dos tempos começou a se estabilizar, mantendo-se assim, um equilíbrio natural. Porém, com as ações humanas sobre o meio ambiente, percebe-se que estão ocorrendo mudanças significativas neste equilíbrio natural.

Neste contexto, as descargas atmosféricas, sempre foram associadas a deuses e divindades, ou seja, algo que ocorria devido à vontade dos deuses, existindo relatos nas literaturas grega, chinesa e até mesmo na Bíblia. (KINDERMANN, 1992).

O estudo científico deste fenômeno, e assim o início da desmistificação, somente se iniciou com Benjamin Franklin (1706 - 1790), quando este efetuou a célebre experiência de içar uma “pipa” que estava presa a um fio condutor durante uma tempestade (Figura 4). Assim, a carga induzida na "pipa” deslocava-se ao longo do fio, provocando uma pequena descarga entre um condutor preso, e a sua extremidade e a sua mão. Cabe ressaltar que muitos morreram nos anos seguintes tentando reproduzir a experiência.

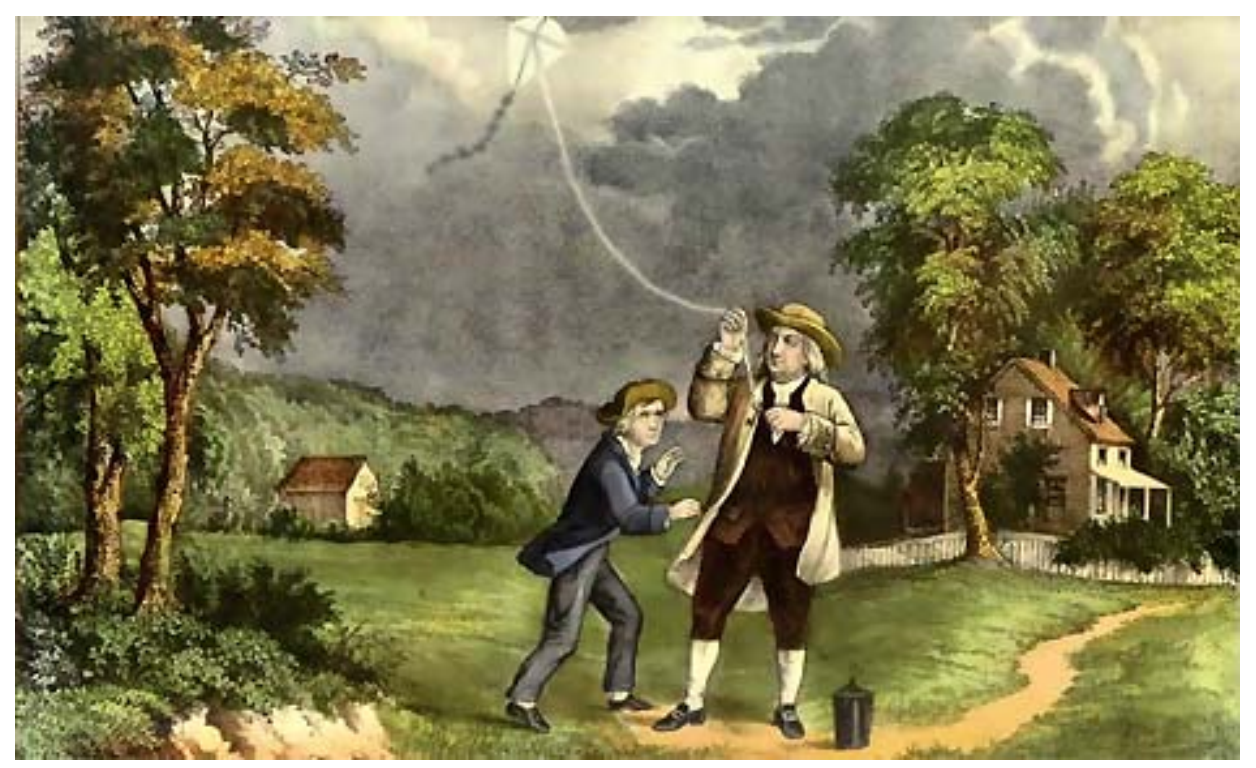

Figura 4 - Gravura ilustrativa do experimento de Benjamin Franklin. Fonte: http://www.carnetdevol.org/actualite/franklin/benjamin.htm 
Para a realização do estudo das descargas atmosféricas é importante conhecer a nuvem típica que se forma durante uma tempestade, denominada de cúmulo-nimbo (cumulonimbus) (Figura 5 e 6), que é uma nuvem de trovoada formada por gotas d’água, cristais de gelo, gotas de água super-resfriadas, flocos de neve e granizo, que possui o formato de uma bigorna, pois o topo apresenta expansão horizontal devido aos ventos superiores, formado por cristais de gelo, com diâmetro médio entre $10 \mathrm{~km}$ a $20 \mathrm{~km}$, começando de 0,7 km a 1,5 km e chegando à altura média de $8 \mathrm{~km}$ a $12 \mathrm{~km}$ (UMAN, 1984). Elas podem estar paradas em um determinado local ou deslocar-se com uma velocidade média de $40 \mathrm{~km} / \mathrm{h}$ a $50 \mathrm{~km} / \mathrm{h}$. Normalmente uma tempestade destas tem duração média de 30 minutos a 1 hora e meia (PINTO Jr.; PINTO, 2000).

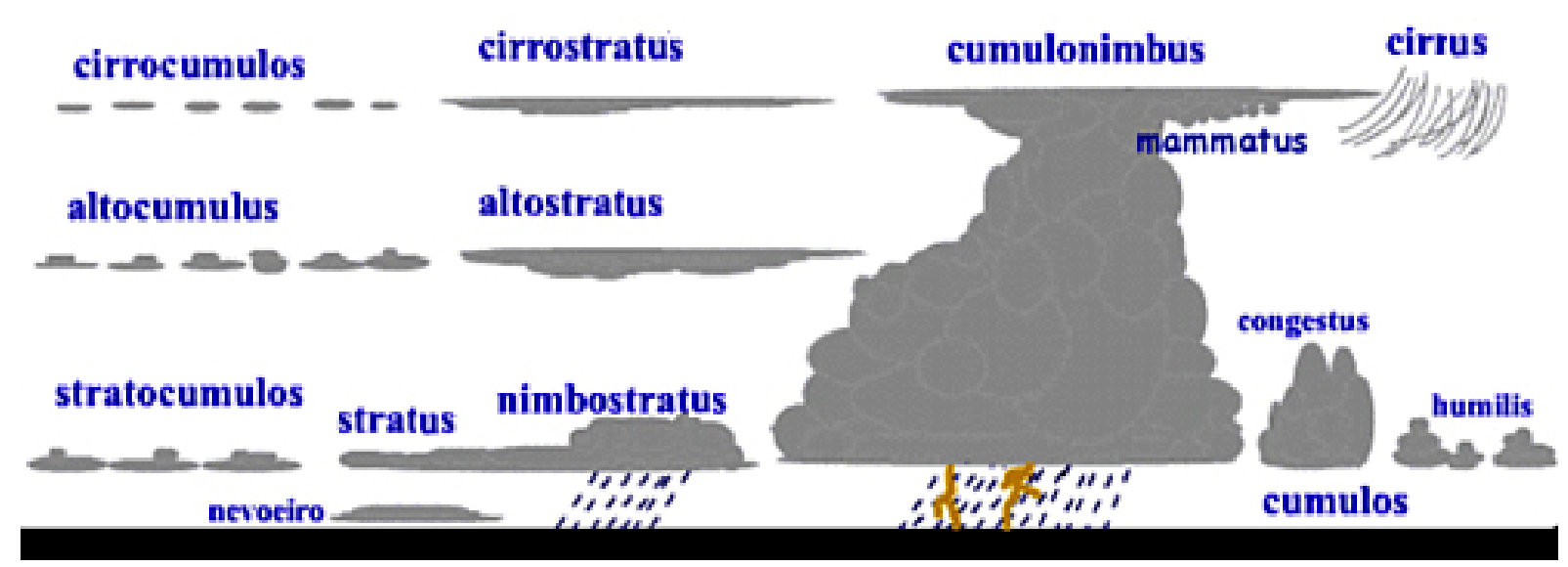

Figura 5 - Tipos de nuvens.

Fonte: http://pt.wikipedia.org/wiki/nuvem

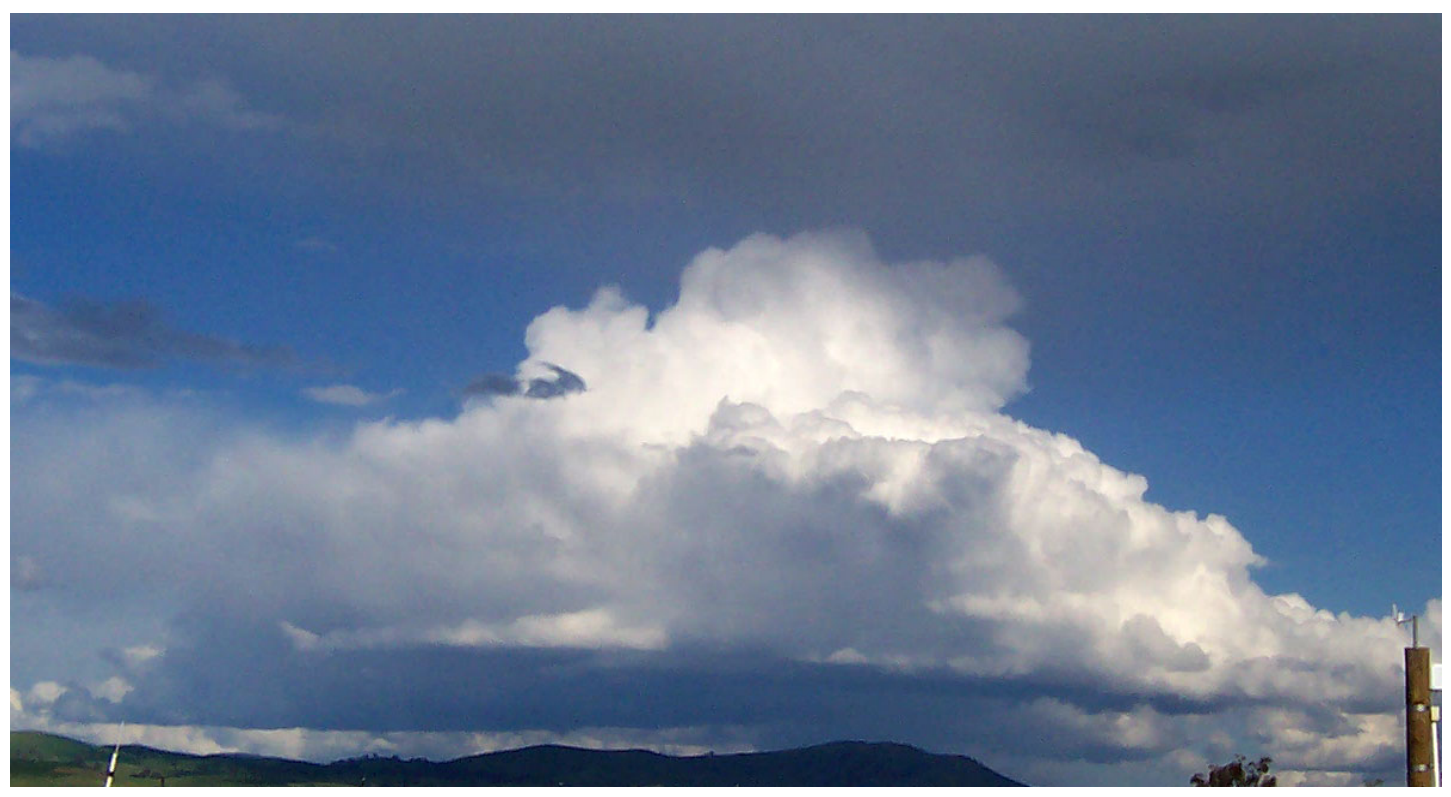

Figura 6 - Nuvem cúmulo-nimbo (cumulonimbus).

Fonte: http://pt.wikipedia.org/wiki/nuvem 
A descarga atmosférica inicia-se quando o campo elétrico produzido pelas cargas elétricas contidas nas nuvens excede a capacidade isolante do ar em um dado local na atmosfera, que pode ser dentro da nuvem ou próximo ao solo. Uma vez quebrada a rigidez dielétrica do ar, ionizam-se os átomos de ar e inicia-se um rápido movimento de elétrons de uma região de cargas negativas para uma região de cargas positivas (RINDAT, 2006).

As descargas atmosféricas (Figura 7) podem ser classificadas:

a) descargas nuvem-solo negativas (negative cloud-to-ground lightning): ocorrem da nuvem para o solo, ou seja, transferem cargas negativas (elétrons) de uma região carregada negativamente dentro da nuvem para o solo;

b) descargas nuvem-solo positivas (positive cloud-to-ground lightning): ocorrem da nuvem para o solo, transferindo elétrons do solo para a nuvem, o que, na realidade, equivale ao transporte de cargas positivas de uma região carregada positivamente de dentro da nuvem para o solo (freqüentemente ocorrem no topo de montanhas);

c) descargas solo-nuvem negativas (negative ground-to-clound lightning): se iniciam no solo e partem para a nuvem, transferindo cargas negativas da nuvem para o solo, o que equivale ao transporte de cargas positivas do solo para a nuvem;

d) descargas solo-nuvem positivas (positive ground-to-cloud lightning): se originam no solo e partem para a nuvem, transferindo elétrons do solo para a nuvem, o que equivale ao transporte de cargas positivas da nuvem para o solo;

e) descargas intranuvem (intra-cloud lightning): ocorrem dentro da nuvem;

f) descargas no ar (cloud-to-air lightning): ocorrem da nuvem para um ponto qualquer na atmosfera;

g) descargas entre nuvens (cloud-to-cloud lightning): ocorrem entre nuvens.

As descargas intranuvem são as mais freqüentes, devido à existência de cargas com polaridades opostas nas nuvens e pelo fato da capacidade isolante do ar diminuir com a altura em função da diminuição da densidade do ar. Assim, essas descargas ficam restritas à atmosfera, não entrando em contato com o solo. Já as descargas que envolvem o solo ocorrem em menor quantidade (algo em torno de $20 \%$ do total). Dentre as descargas que atingem a terra, a mais freqüente é a nuvem-solo negativa, representando algo em torno de $90 \%$ dos casos. 


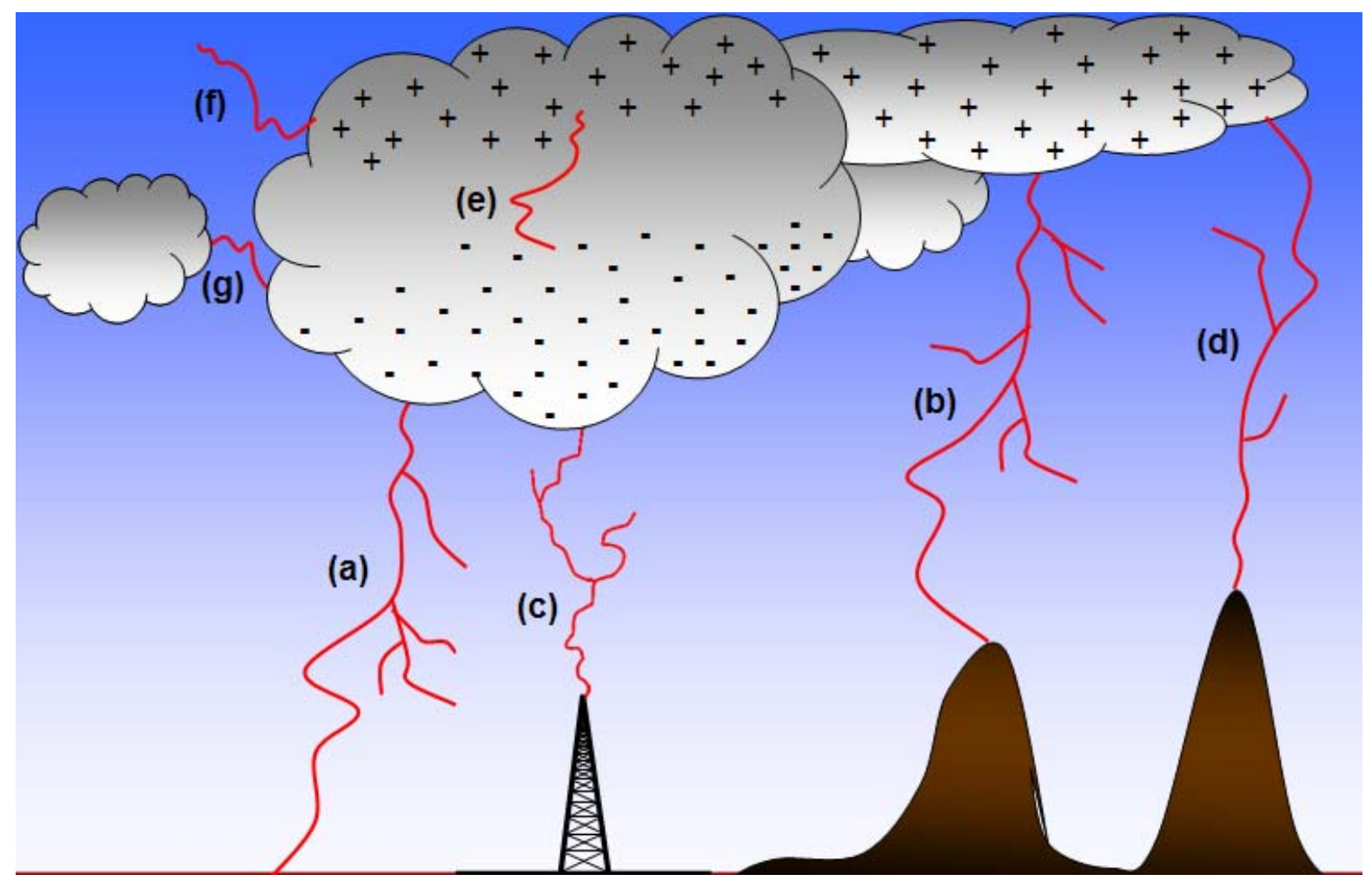

Figura 7 - Classificação ilustrativa dos diversos tipos de descargas atmosféricas existentes na natureza.

(a) nuvem-solo negativa, (b) nuvem-solo positiva, (c) solo-nuvem negativa, (d) solo-nuvem positiva, (e) intranuvem, (f) descarga para o ar, (g) entre nuvens.

Fonte: (ROMERO, 2007).

A descarga atmosférica nuvem-solo negativa é constituída de diversas etapas, iniciando-se com descargas de intensidade fracas dentro da nuvem, a alturas em torno de $3 \mathrm{~km}$ a $5 \mathrm{~km}$, durante um período de $10 \mathrm{~ms}$ a $100 \mathrm{~ms}$, e conhecida como momento de quebra da rigidez dielétrica. Após a quebra da rigidez dielétrica, uma fraca descarga (geralmente não visível), denominada de “descarga piloto” ou "líder escalonado" (stepped leader), propaga-se da região de cargas negativas em direção ao solo com uma velocidade de propagação da ordem de $400.000 \mathrm{~km} / \mathrm{h}$ ao longo de um canal luminoso com diâmetro de aproximadamente $1 \mathrm{~m}$. As cargas negativas se depositam nesse canal denominado de canal da descarga. O líder escalonado segue um caminho tortuoso e ramificado, cada um deles percorrendo de $30 \mathrm{~m}$ a $100 \mathrm{~m}$, com duração aproximada de $1 \mu \mathrm{s}$, e com um intervalo entre os deslocamentos da ordem de $50 \mu$ s (UMAN, 1984, 1994).

Com a aproximação do líder escalonado ao solo (a distâncias de algumas dezenas ou centenas de metros), há a formação de um intenso campo elétrico entre a frente do líder escalonado e o 
solo. Assim, este campo causa a quebra da rigidez do ar em um ou vários pontos no solo, fazendo com que se criem, a partir do solo, as descargas positivas ascendentes ou líder ascendente (upward leaders). A estimativa desse parâmetro é de grande importância para o projeto de sistemas de proteção e para a avaliação do desempenho de linhas de transmissão e distribuição frente a descargas atmosféricas.

Com o encontro entre o líder ascendente e o líder escalonado, há a formação da descarga principal, denominada descarga de retorno (return stroke), de intensidade luminosa, com sentido ascendente, e possuindo velocidade variando na faixa de $6 \%$ a $87 \%$ da velocidade da luz no vácuo (RAKOV, 2001). Ela tem tempo de subida variando de $2 \mu$ s a $10 \mu$ s e duração média da ordem de 100 s. A região visível do canal da descarga possui diâmetro médio da ordem de $1 \mathrm{~m}$ e a temperatura no interior do canal pode chegar a valores de $28.000{ }^{\circ} \mathrm{C}$, o que representa, aproximadamente, uma temperatura cinco vezes maior que a superfície solar (SMIDT, 2003). A abrupta expansão local do ar, devido à intensa temperatura do canal da descarga, provoca o fenômeno auditivo denominado trovão, cuja máxima intensidade está na faixa de $50 \mathrm{~Hz}$ a $100 \mathrm{~Hz}$. Contudo, apenas 1\% da energia se converte em ondas sonoras audíveis aos seres humanos, a maior parte é convertida em ondas ultrasônicas. A intensidade do clarão ocasionada pela descarga principal depende da temperatura, pressão e da densidade dos elétrons do canal.

As correntes das descargas de retorno possuem valores de pico elevados, produzindo no solo um pico de corrente média de $30 \mathrm{kA}$ a $40 \mathrm{kA}$. Valores superiores a $200 \mathrm{kA}$ correspondem a menos de 0,1\% dos casos (PINTO Jr., 2005).

Se a descarga atmosférica terminar após a descarga de retorno, ela é denominada como descarga simples. Entretanto, na maioria dos casos, após uma pausa de $40 \mathrm{~ms}$ a $60 \mathrm{~ms}$, uma nova descarga ocorre. Outras pausas sucessivas de mesma duração e outras descargas de retorno também podem ocorrer. Estas outras descargas são denominadas descargas subseqüentes (ou strokes subseqüentes). Descargas atmosféricas com strokes subseqüentes são denominadas descargas múltiplas.

Segundo Anderson e Eriksson (1980), as descargas atmosféricas podem ser caracterizadas pelos seguintes aspectos:

parâmetros de incidência, levando em consideração as descargas múltiplas;

amplitude da corrente, que corresponde ao parâmetro mais importante para aplicações em engenharia;

forma do impulso da corrente de descarga, com ênfase na taxa de subida. 
Parâmetros de incidência: um dos principais parâmetros para se estimar o desempenho dos sistemas elétricos frente às descargas atmosféricas é a densidade de descargas ao solo $\left(\mathrm{N}_{\mathrm{g}}\right)$, que pode ser medida através de contadores, como os contadores CIGRÈ (500 Hz e $10 \mathrm{kHz}$ ). Tais contadores foram desenvolvidos pelo Grupo de Trabalho 33.01 do CIGRÈ. O parâmetro $\mathrm{N}_{\mathrm{g}}$ representa o número de descargas ao solo por $\mathrm{km}^{2}$ ao ano (ANDERSON; ERIKSSON, 1980).

Distribuição da amplitude da corrente: Popolansky determinou, em 1972 (ANDERSON; ERIKSSON, 1980), o valor médio de 25 kA para o pico da corrente, considerando a medição de 624 amostras e levando em conta descargas descendentes e ascendentes. Posteriormente, Anderson e Eriksson (1980) estimaram que 90\% das descargas do tipo nuvem-solo eram negativas quando medidas em torres com alturas inferiores a $60 \mathrm{~m}$ (situação mais representativa para fins práticos, como projetos de engenharia).

Parâmetros das ondas de corrente: as primeiras caracterizações dos parâmetros foram feitas por Berger et al. em 1975, com os dados obtidos no Monte San Salvatore, sendo posteriormente completados por Anderson e Eriksson (1980), que introduziram alguns parâmetros adicionais.

A análise é feita com base na Figura 8, que corresponde a uma frente de onda típica de uma descarga negativa.

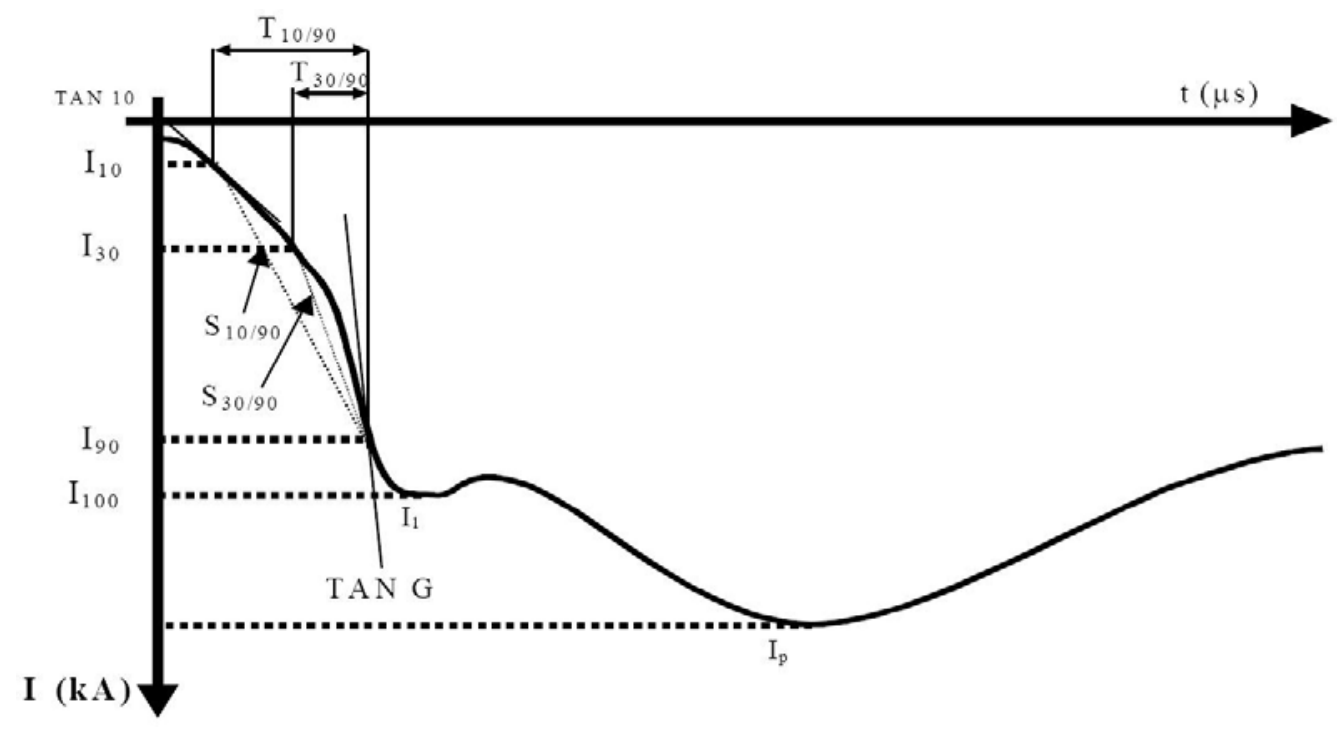

Figura 8 - Forma de onda típica de corrente da primeira descarga de retorno negativa. Fonte: (SHIGIHARA, 2005).

Da Figura 8 são definidos os seguintes parâmetros (ANDERSON; ERIKSSON, 1980): 
$\mathrm{I}_{1}$ e $\mathrm{I}_{\mathrm{p}}$ : primeiro e segundo valores de pico da corrente, respectivamente. Os parâmetros $T_{10 / 90}, T_{30 / 90}, S_{10 / 90}, S_{30 / 90}$ e TANG são definidos em função de $I_{1}$ e $T_{50}$ em função de $I_{p}$. Geralmente, as primeiras descargas de retorno são as que apresentam duas cristas, com $I_{p}$ normalmente maior que $I_{1}$. As descargas subseqüentes apresentam apenas um pico;

$\mathrm{T}_{10 / 90}$ : duração da frente de onda expressa como o intervalo de tempo entre os pontos correspondentes a $10 \%$ e $90 \%$ de $\mathrm{I}_{1}$;

$\mathrm{T}_{30 / 90}$ : duração da frente de onda expressa como o intervalo de tempo entre os pontos correspondentes a $30 \%$ e $90 \%$ de $\mathrm{I}_{1}$;

$\mathrm{T}_{50}$ : intervalo entre o valor de $2 \mathrm{kA}$ definido e o valor correspondente a $50 \%$ do valor de pico, $\mathrm{I}_{\mathrm{p}}$;

$\mathrm{S}_{10 / 90}$ : taxa de crescimento médio da corrente entre $10 \%$ e 90 \% em relação a $\mathrm{I}_{1}$;

$\mathrm{S}_{30 / 90}$ : taxa de crescimento médio da corrente entre $30 \%$ e $90 \%$ em relação a $\mathrm{I}_{1}$;

TAN 10: taxa de crescimento correspondente à tangente para $10 \%$ de $\mathrm{I}_{1}$;

TANG: máxima taxa de crescimento para frente de onda da corrente;

$t_{f}$ : tempo de frente da onda, $t_{f}=\frac{T_{10 / 90}}{0,8}$ ou $t_{f}=\frac{T_{30 / 90}}{0,6}$

Carga: corresponde à integração da corrente no tempo, di/dt .

As Tabelas 10 e 11 mostram conjunto de parâmetros para caracterizar as descargas atmosféricas e descargas de retorno selecionadas por Berger et al. (1975) e adaptadas por Shigihara (2005).

Tabela 10 - Parâmetros: descarga atmosférica.

\begin{tabular}{lll}
\hline & & Descarga Atmosférica \\
\hline I & Valor de pico & O valor máximo da corrente da descarga \\
& & Tempo total da descarga em que há fluxo de corrente, \\
II & Duração da descarga & mesmo que haja descargas múltiplas \\
& & Intervalo entre descargas em que não é possível detectar \\
III & Intervalos sem descarga & corrente \\
IV & Carga da descarga & Carga total transferida na descarga
\end{tabular}

Fonte: Shigihara, 2005. 
Tabela 11 - Parâmetros: descarga de retorno.

\begin{tabular}{lll}
\hline & & Descarga de Retorno \\
\hline I & Valor de pico & O valor máximo da corrente da descarga \\
II & Duração da frente & Intervalo de tempo entre 2 kA e o primeiro pico da corrente \\
III & Duração da descarga & Intervalo de tempo entre 2 kA e quando a corrente decai em \\
IV & Máxima taxa de crescimento & Maior taxa (di/dt) da descarga \\
V & Carga do impulso & Carga elétrica transportada pela onda impulsiva da descarga \\
VI & Carga da descarga & Carga total da descarga \\
VII & Energia da descarga & Energia dissipada durante o fluxo da corrente da descarga \\
& & pelo canal
\end{tabular}

Fonte: Shigihara, 2005.

\subsection{Impactos no Sistema Elétrico}

As descargas atmosféricas são responsáveis, em todo o mundo, por causar perturbações em sistemas de transmissão e distribuição de energia elétrica, além de serem alguns motivos alegados para pleito de indenização às seguradoras quanto ao ressarcimento pela perda de equipamentos elétricos e eletrônicos, ou até mesmo no comprometimento dos indicadores de qualidade da energia fornecida pelas concessionárias. Artigos mostram que entre 1992 e 1997, na Alemanha, 26\% do pagamento de apólices de seguro foram devidas a surtos de origem atmosférica, e que entre 1993 e 1994, na Colômbia, foi registrado um aumento de 30\% nos pagamentos de apólices por danos em equipamentos elétricos, que em 1994, chegou a um valor de US\$ 16 milhões (IBÁÑEZ et al., 2005, 2006). No Brasil, mais precisamente no estado de São Paulo, 40\% dos PIDs anuais estão concentrados nos meses de janeiro, fevereiro e março, período do ano coincidente com a época de chuvas (JUCÁ, 2003).

Os distúrbios provavelmente sempre estiveram presentes na rede de distribuição, mas não eram sentidos pelo fato dos equipamentos serem, normalmente, eletromecânicos, apresentando maior suportabilidade elétrica. Porém, atualmente, a maior parte dos aparelhos e equipamentos é produzida com dispositivos semicondutores que embora apresentem algumas vantagens em relação aos eletromecânicos, apresentam, por outro lado a desvantagem de serem mais sensíveis a distúrbios na energia fornecida, ou seja, são sensíveis à interferência e às interrupções de curta duração. Assim, tem-se buscado obter, cada vez mais, uma melhor 
compreensão dos fenômenos envolvidos na questão e a determinação de soluções técnicas e economicamente viáveis, que proporcionem uma melhoria efetiva da energia fornecida, o que faz das descargas atmosféricas uma das responsáveis pela maior parte das interrupções não programadas das linhas de distribuição, mesmo em regiões com níveis ceráunicos moderados (PIANTINI; JANISZEWSKI, 2005).

O circuito primário de uma rede de distribuição convencional é muito exposto a descargas atmosféricas, logo, sobretensões surgem nesse circuito em decorrência de descargas diretas (que atingem os condutores fase), ou indiretas (quando ocorrem próximas à linha) e são transferidas para o circuito secundário através do transformador, podendo provocar danos às instalações consumidoras e, ocasionalmente, a queima do próprio transformador.

As sobretensões causadas por descargas atmosféricas podem ser originadas por (PIANTINI; SILVA NETO, 2004):

$>$ descargas entre nuvens ou intranuvem;

> descargas atmosféricas diretas na rede secundária;

tensões induzidas por descargas indiretas;

tensões transferidas devido a descargas diretas na rede primária;

tensões transferidas do primário pelo transformador;

descargas diretas em edificações.

Embora as sobretensões decorrentes da incidência de descargas diretas atinjam amplitudes superiores, as tensões induzidas por descargas indiretas representam normalmente um problema maior, em virtude da sua alta freqüência de ocorrência. Por essa razão, são consideradas as principais responsáveis pelas interrupções sofridas por linhas de classe igual ou inferior a $15 \mathrm{kV}$. A complexidade do mecanismo de indução das tensões no caso de descargas indiretas é consideravelmente maior que no caso de descargas diretas, e essa é, sem sombra de dúvidas, umas das razões para a existência de diferentes métodos de cálculo de tensões induzidas, tais como os modelos de Chowdhuri, Liew-Mar e o de Rusck. Este último foi modificado (PIANTINI, 1991) de modo a possibilitar levar em consideração os comprimentos finitos da linha e do canal da descarga atmosférica, bem como o caso de descargas em estruturas metálicas nas proximidades da linha e o efeito do líder ascendente. O novo modelo foi denominado ERM (Extended Rusck Model) (PIANTINI; JANISZEWSKI, 1998). 
Nesse modelo, ao contrário do original, a linha não precisa ser retilínea e o efeito de condutores multiaterrados (neutro ou cabo guarda) pode ser levado em conta, assim como a presença de equipamentos como transformadores e pára-raios (PIANTINI; JANISZEWSKI, 2005). Com base nas amplitudes e freqüências de ocorrência das sobretensões, pode-se dizer que as mais importantes, nas redes de distribuição são aquelas causadas por descargas indiretas (PIANTINI; SILVA NETO, 2004). Além das tensões induzidas na rede de baixa tensão, são também importantes aquelas transferidas ao secundário quando da incidência de descargas diretas no primário; essa transferência pode ocorrer pela disrupção dos isoladores, atuação dos pára-raios e via transformador (OBASE et al., 2004).

Para as áreas urbanas, o estudo das características das tensões induzidas por descargas atmosféricas em linhas de distribuição se torna necessário devido a três aspectos:

a) grande número de falhas de transformadores atribuídas a descargas atmosféricas (PIANTINI; JANISZEWSKI, 2002);

b) quantidade considerável de desligamentos dos circuitos (alimentadores) aparentemente sem causa determinada em épocas de incidência de raios;

c) presença de estruturas altas, próximas à linha de distribuição, em áreas urbanas, diminuindo a sua exposição às descargas diretas, contudo possibilitando a ocorrência de descargas muito próximas à rede (descargas indiretas), as quais podem induzir sobretensões de amplitude muito elevadas (PIANTINI; JANISZEWSKI, 2000, 2001, 2002).

Um estudo das tensões induzidas em linhas de distribuição em área urbana se torna muito complexo, pois além da presença de edificações em suas proximidades, as linhas possuem as características de vários ramais e uma densidade maior de pára-raios e transformadores quando comparados com uma linha de distribuição em área rural. Ou seja, um número muito maior de parâmetros começa a influenciar as sobretensões.

Segundo Piantini e Janiszewski (2002), cada ponto de conexão do tronco com os ramais representa um ponto de descontinuidade, enquanto que a presença de edificações altera o campo eletromagnético nas vizinhanças da linha. Ambos os efeitos afetam diretamente as tensões induzidas. A presença do neutro também contribui nesse sentido, visto que o mesmo tem efeito análogo ao do cabo guarda no caso de descargas indiretas, reduzindo em função do acoplamento, as tensões induzidas nos condutores fase. A complexidade do problema é, portanto, ainda maior que no caso de linhas rurais. Neste caso, houve a implementação, pelos 
autores, de um modelo em escala reduzida, com fator de escala para comprimentos igual a 1:50 para se avaliar então os efeitos dessas tensões induzidas por descargas atmosféricas indiretas. Para essa investigação foi simulada uma linha urbana típica, trifásica, com neutro, transformadores e pára-raios, além dos ramais. Foram consideradas diferentes configurações, tendo as tensões induzidas sido medidas nos terminais primários de modelos de transformadores situados tanto no alimentador como em finais de ramais. Apurou-se também que estruturas altas podem atrair descargas a distâncias muito curtas em relação à linha, de modo que sobretensões elevadas podem ser induzidas mesmo no caso de descargas com intensidades relativamente moderadas.

A utilização de um bom modelo, adequado para representação do comportamento dos transformadores, é de suma importância para o estudo dos fenômenos associados à transferência dos surtos do primário para o secundário (PIANTINI; KANASHIRO, 2002; KANASHIRO; PIANTINI, 2003).

Alguns estudos (SILVA NETO; PIANTINI, 2004; OBASE; PIANTINI, 2005) mostram que as tensões transferidas ao secundário do transformador apresentam características oscilatórias, com freqüência superior à da rede. As amplitudes dessas tensões são fortemente dependentes da forma de onda da tensão no primário do transformador e podem freqüentemente atingir valores da ordem de alguns quilovolts. No estudo, foram abordados aspectos importantes a respeito do cálculo das tensões, como por exemplo, a modelagem do transformador e das instalações elétricas dos consumidores e dos ramais de ligação e os casos de linhas com e sem dispositivos de proteção.

Quanto ao transformador de distribuição, verificou-se que a sua presença afeta as amplitudes e formas de onda das tensões induzidas na rede secundária. As amplitudes das tensões fase-terra na rede secundária podem apresentar valores elevados, chegando em alguns casos a valores da ordem de dezenas de quilovolts. Esses valores podem ser altos o suficiente para acarretar a queima de equipamentos e disrupções elétricas em pontos susceptíveis da rede. Os finais da rede são os pontos mais solicitados quando os DPSs (dispositivos de proteção contra surtos) são instalados somente no secundário do transformador.

A instalação de DPSs garante níveis baixos de tensão somente nos pontos em que os mesmos são instalados. Embora haja reduções nas tensões fase-neutro ao longo da rede com a instalação de DPSs no transformador e nos finais da linha, tal fato não assegura níveis baixos de tensão em pontos intermediários.

No caso de tensões transferidas devido a surtos de tensões induzidas no primário, os estudos mostram que a maior amplitude de tensão na rede secundária ocorre quando os pára-raios 
atuam. Ou seja, a parcela decorrente da elevação de potencial do neutro pela atuação dos pára-raios dos transformadores é em geral maior que a parcela decorrente da "transferência direta” pelo transformador. Essas tensões, da ordem de alguns quilovolts, podem provocar danos aos consumidores. Porém, quando a amplitude do surto não é suficientemente elevada para provocar a atuação dos pára-raios, praticamente toda a tensão transferida à rede secundária é proveniente da transferência via transformador. Essas tensões também podem chegar a alguns quilovolts, sendo portanto suficientes para provocar a queima de equipamentos do consumidor. Assim, a representação adequada do transformador tem grande importância para estudos de transferência de surtos (PIANTINI; SILVA NETO, 2006; OBASE; PIANTINI, 2006).

\subsection{Sistema de Detecção e Localização de Descargas Atmosféricas}

O uso de sistemas de detecção de descargas atmosféricas no Brasil teve início em novembro de 1988 (PINTO Jr. ,2005), no estado de Minas Gerais, quando o então Centro de Tecnologia e Normalização (TN) da Companhia Energética de Minas Gerais (CEMIG), através de seu Departamento de Planejamento Hidroenergético (GT/PH), implantou um sistema de detecção de descargas atmosféricas, denominado Sistema de Localização de Tempestades (SLT). Este foi o primeiro sistema dessa natureza a entrar em operação na América do Sul. Iniciou-se com quatro sensores do tipo LPATS-III (Lightning Positioning and Tracking System) instalados nas cidades de Três Marias, Volta Grande, Ipatinga e Lavras, distantes cerca de 350 km um do outro e sincronizados por um sinal via satélite. O sistema havia sido adquirido da empresa americana Atmospheric Research Inc. (ARSI), sediada na Flórida, e utilizava exclusivamente a técnica do "tempo de chegada”.

Em 1995, após a compra da ARSI pela empresa Lightning Location and Protection (LLP), que comercializava sensores utilizando a técnica de direção magnética, a CEMIG comprou mais dois sensores, desta vez do tipo IMPACT-141T, expandindo sua área de cobertura principalmente no norte do estado. Os novos sensores foram instalados em Três Marias e Volta Grande, e os sensores LPATS-III, já existentes, foram realocados em Emborcação e Capitão Enéas. O sistema também passou a ter uma nova central de processamento, do tipo APA-2000, alterando a sincronização dos sensores para o sistema GPS. A Figura 9 mostra a localização dos sensores. 


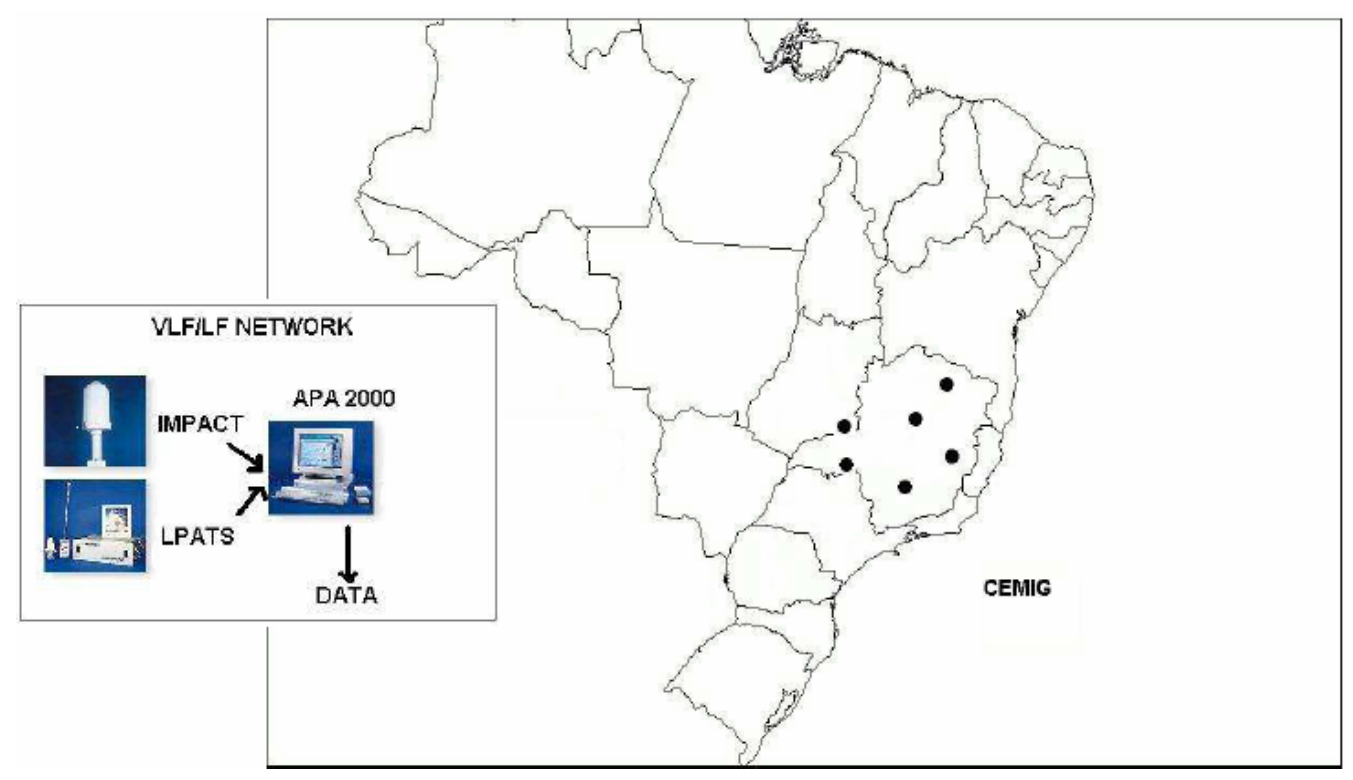

Figura 9 - Situação do sistema de detecção de descargas no Brasil em 1995.

Fonte: (adaptado de PINTO Jr et al., 2006).

Em 1996, o Instituto Tecnológico SIMEPAR instalou um sistema composto por seis sensores LPATS-III no estado do Paraná. Também neste ano, sob a coordenação da Assessoria de Planejamento da Informação (API.T), deu-se início ao projeto de aquisição e implantação do SISDAT (Sistema de Deteç̧ão de Descargas Atmosféricas) de FURNAS Centrais Elétricas S.A., que entrou em operação em agosto de 1998 tendo sido instalados seis sensores LPATSIV e dois sensores IMPACT-141T nos estados de Goiás, Espírito Santo, Rio de Janeiro, São Paulo e Paraná, onde um dos sensores IMPACT foi instalado praticamente no mesmo local de um sensor LPATS-III pertencente ao SIMEPAR. O objetivo era minimizar a contaminação dos dados por relâmpagos intranuvem, visto que nesse estado só haviam sensores LPATS-III pertencentes ao SIMEPAR. Ao mesmo tempo, em 1997, o INPE (Instituto Nacional de Pesquisas Espaciais) instalou um sensor IMPACT-141T no estado de São Paulo, interligando-o ao sistema SLT da CEMIG por meio de um convênio de cooperação. Em 2001, a CEMIG instalou outro sensor tipo LPATS-III em Belo Horizonte e o INPE instalou outro sensor do tipo IMPACT-ES no estado de São Paulo, interligando-o também ao SLT. Ainda em 2001, a CEMIG, FURNAS e o SIMEPAR estabeleceram um convênio de cooperação criando a Rede Integrada de Detecção de Descargas Atmosféricas (RIDAT).

A pedido da ELEKTRO Eletricidade e Serviços S.A., entre 2002 e 2003 foi realizado um estudo de modo a verificar que tipo e em que locais sensores de descargas precisariam ser instalados para que o sistema de detecção de descargas já existente e operando de forma conjunta pela CEMIG, FURNAS, INPE e SIMEPAR passasse a apresentar na área de 
concessão da empresa uma eficiência de detecção de pelo menos $80 \%$ e com precisão de localização do ponto de impacto da descarga no solo inferior a 1 km (NOSAKI et al., 2001). Como resultado desse estudo, realizado pelo INPE com o apoio da CEMIG, foi estabelecido que ao menos dois novos sensores deveriam ser instalados nas regiões de Pirassununga, no estado de São Paulo, e em Campo Grande, no estado do Mato Grosso do Sul. As informações obtidas por estes sensores, somadas às informações obtidas pelos sensores já existentes, em especial os sensores instalados pelo INPE em Cachoeira Paulista e em São José dos Campos, e por FURNAS em Ibiúna e em Jupiá, todos no estado de São Paulo, permitiriam a obtenção da confiabilidade desejada. Os sensores foram definidos como sendo do tipo IMPACT-ESP e a instalação ficou sob a responsabilidade do INPE.

Posteriormente, em 2004, o INPE passou a fazer parte do convênio firmado entre CEMIG, FURNAS e SIMEPAR, criando então a Rede Integrada Nacional de Detecção de Descargas Atmosféricas (RINDAT). Apesar do nome, a RINDAT tem como objetivo detectar apenas as descargas atmosféricas entre a nuvem e o solo, e não todos os tipos de descargas atmosféricas. Com a integração, os dados dos sensores são compartilhados entre as três centrais de processamento da RINDAT (Curitiba/PR, Rio de Janeiro/RJ e Belo Horizonte/MG), estendendo a área de monitoramento e, por conseqüência, melhorando a eficiência na detecção e a confiabilidade da informação de localização das descargas atmosféricas. A Figura 10 mostra a evolução do número de sensores instalados do sistema de detecção do Brasil de 1988 até 2004.

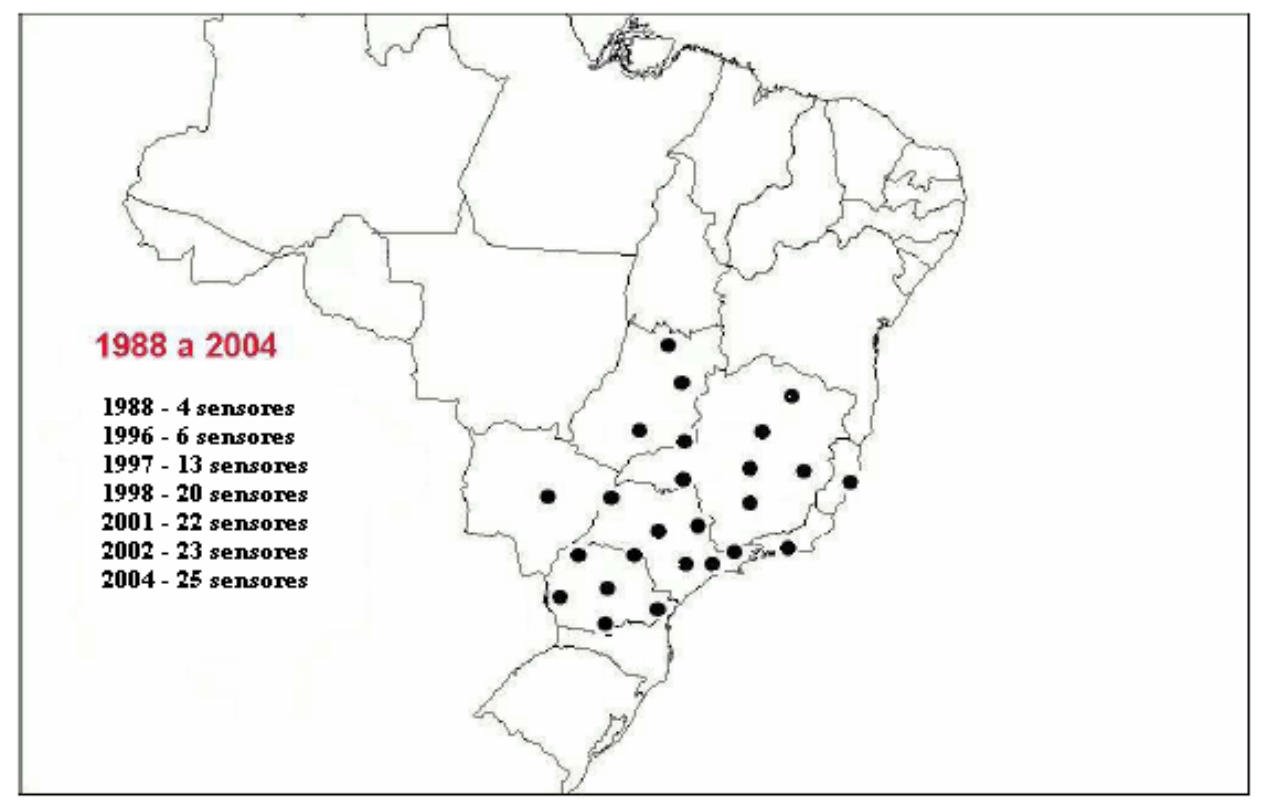

Figura 10 - Evolução do sistema de detecção de descargas atmosféricas no Brasil de 1988 até 2004. Fonte: (adaptado de PINTO Jr et al., 2006). 
Em média a distância entre os sensores mais próximos é de cerca de $300 \mathrm{~km}$. Contudo, no Vale do Paraíba, no estado de São Paulo, estão instalados os sensores com as menores distâncias (100 km). Com a sua criação, a RINDAT passou a ser a maior rede de detecção de descargas atmosféricas na região tropical e a terceira rede nacional do mundo, atrás apenas das redes americana NLDN e canadense CLDN, como mostrado na Tabela 12.

Tabela 12 - Número de sensores por país (situação em 2004).

\begin{tabular}{lccc}
\hline \multicolumn{1}{c}{ País } & \multicolumn{3}{c}{ Número de sensores } \\
& IMPACT & LPATS & TOTAL \\
\hline Estados Unidos & 105 & - & 105 \\
Canadá & 26 & 55 & 81 \\
BRASIL & 8 & 17 & 25 \\
Japão & 7 & 17 & 24 \\
França & 17 & - & 17 \\
China & $?$ & $?$ & $?$ \\
\hline
\end{tabular}

Fonte: adaptado de Pinto Jr et al., 2006.

A Figura 11 mostra o número de sensores e a Tabela 13 mostra a lista de localização dos sensores sob a responsabilidade de cada instituição pertencente ao RINDAT.

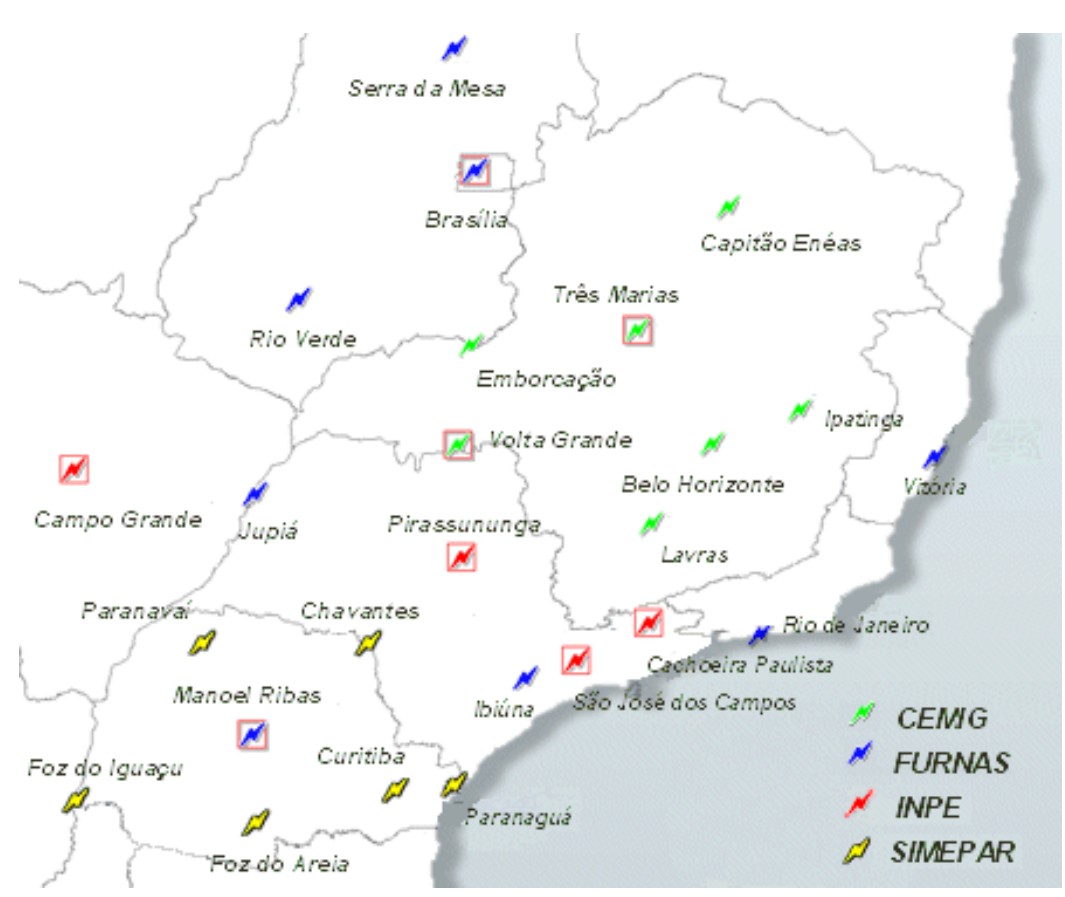

Figura 11 - Mapa da localização dos sensores da RINDAT em 2006.

Fonte: (RINDAT, 2006). 
Tabela 13 - Lista de sensores de detecção de descargas atmosféricas da RINDAT no Brasil.

\begin{tabular}{|c|c|c|c|c|c|}
\hline Cidade & UF & Empresa & Sensor & $\begin{array}{l}\text { Latitude } \\
\text { (decimal) }\end{array}$ & $\begin{array}{l}\text { Longitude } \\
\text { (decimal) }\end{array}$ \\
\hline Belo Horizonte & $\mathrm{MG}$ & CEMIG & $\overline{\text { LPATS III }}$ & -19.84953 & -43.91383 \\
\hline Capitão Enéas & MG & CEMIG & LPATS III & -16.31723 & -43.72241 \\
\hline Emborcação & MG & CEMIG & LPATS III & -18.45649 & -48.00371 \\
\hline Ipatinga & MG & CEMIG & LPATS III & -19.47610 & -42.53148 \\
\hline Lavras & MG & CEMIG & LPATS III & -21.24885 & -45.00428 \\
\hline Três Marias & MG & CEMIG & IMPACT & -18.22604 & -45.24897 \\
\hline Volta Grande & MG & CEMIG & IMPACT & -20.02583 & -48.22056 \\
\hline Brasília & DF & FURNAS & IMPACT & -15.78917 & -47.92392 \\
\hline Ibiúna & SP & FURNAS & LPATS IV & -23.66018 & -47.10349 \\
\hline Jupiá & SP & FURNAS & LPATS IV & -20.78050 & -51.60594 \\
\hline Manoel Ribas & PR & FURNAS & IMPACT & -24.53300 & -51.65090 \\
\hline Rio de Janeiro & $\mathrm{RJ}$ & FURNAS & LPATS IV & -22.95550 & -43.19150 \\
\hline Rio Verde & $\mathrm{GO}$ & FURNAS & LPATS IV & -17.78542 & -50.97649 \\
\hline Serra da Mesa & $\mathrm{GO}$ & FURNAS & LPATS IV & -13.84901 & -48.30378 \\
\hline Vitória & ES & FURNAS & LPATS IV & -20.19995 & -40.29122 \\
\hline Cachoeira Paulista & SP & INPE & IMPACT & -22.68600 & -44.99929 \\
\hline Campo Grande & MS & INPE & IMPACT & -20.45869 & -54.66596 \\
\hline Pirassununga & $\mathrm{SP}$ & INPE & IMPACT & -21.99186 & -47.32926 \\
\hline São José dos Campos & $\mathrm{SP}$ & INPE & IMPACT & -23.21188 & -45.86612 \\
\hline Xavantes & PR & SIMEPAR & LPATS III & -23.29336 & -50.07833 \\
\hline Curitiba & PR & SIMEPAR & LPATS III & & \\
\hline Foz do Areia & PR & SIMEPAR & LPATS III & -26.00432 & -51.66846 \\
\hline Foz do Iguaçu & PR & SIMEPAR & LPATS III & -25.55571 & -54.57866 \\
\hline Paranaguá & PR & SIMEPAR & LPATS III & -25.52369 & -48.51150 \\
\hline Paranavaí & PR & SIMPEAR & LPATS III & -23.09010 & -52.47529 \\
\hline
\end{tabular}

Fonte: adaptado de Pinto Jr, 2005 e Beneti et al., 2005.

Como se pode observar, o Brasil utiliza dois tipos básicos de sensores: LPATS (séries III e IV) e IMPACT. As diferenças entre os dois tipos de sensores estão, principalmente, na forma 
de processamento da localização das descargas e no número mínimo de sensores para identificação da descarga atmosférica (BENETI et al. 2005):

LPATS III e IV empregam o algoritmo TOA (Time Of Arrival - tempo de chegada) para detectar e localizar raios, sendo necessário um mínimo de 3 sensores (atualmente as centrais de processamento da RINDAT utilizam o mínimo de 4 sensores) para definir com precisão a localização do evento;

> IMPACT (IMProved Accuracy from Combined Technology) que emprega uma combinação do algoritmo TOA e de MDF (Magnetic Direction Finding - busca de direção magnética), necessitando apenas de dois sensores deste tipo para localizar as descargas atmosféricas.

Os sinais dos sensores são transmitidos através de canal de comunicação dedicado à central de processamento, onde são processados e distribuídos para unidades de visualização e armazenamento de dados. A Figura 12 apresenta um diagrama da central de processamento atualmente em uso no Brasil.

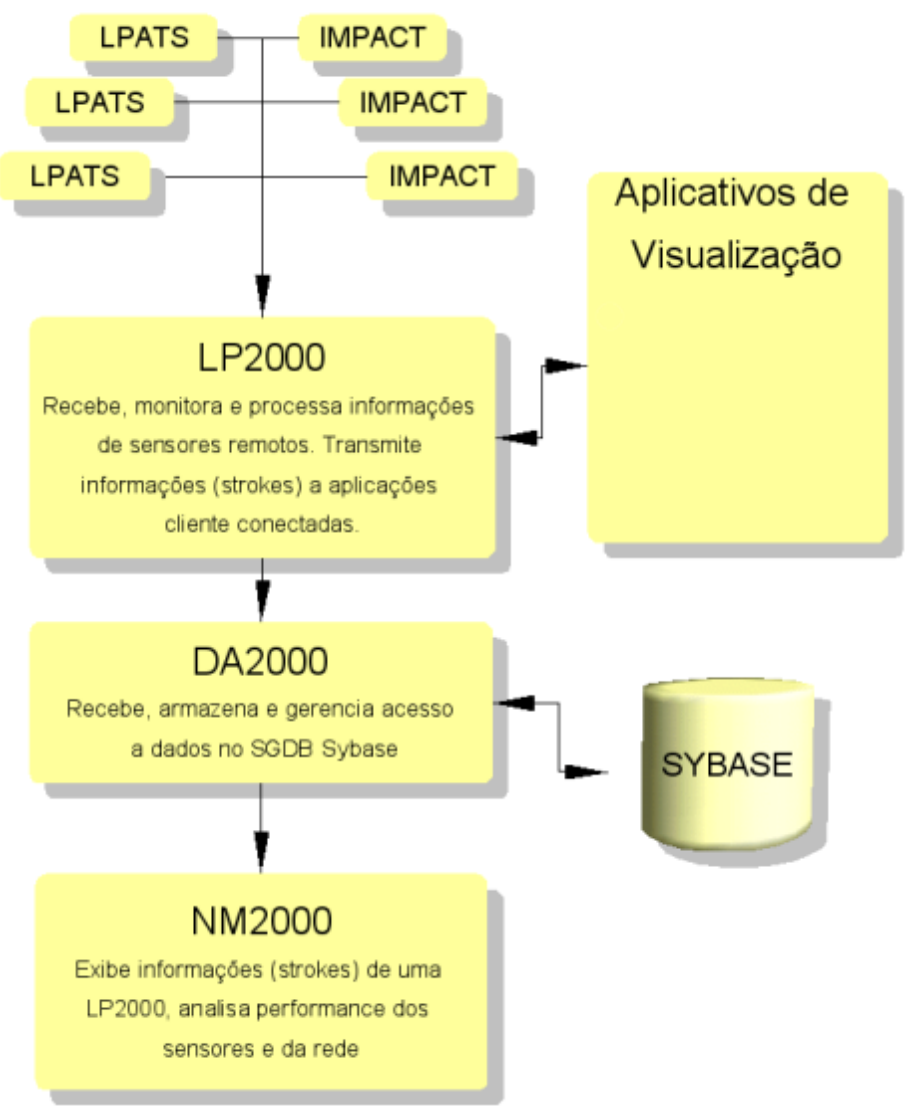

Figura 12 - Diagrama da central de processamento.

Fonte: (RINDAT, 2006). 
O LP2000 é um ambiente computacional que configura, monitora, coleta, armazena e processa as informações detectadas pelos sensores remotos. As posições dos raios e os parâmetros relacionados (intensidade, polaridade) são obtidos usando uma combinação de informações de ângulo, tempo e intensidade do sinal. Ele pode armazenar os dados brutos dos sensores ou ainda transmitir para outro sistema de armazenamento (DA2000) que permite acesso gerenciado utilizando ferramentas do tipo SYBASE, por exemplo, para armazenamento e acesso dos dados em tempo real, e acesso aos históricos com informações de descargas.

A visualização das informações de descargas atmosféricas pode ser feita através de computadores conectados diretamente à central LP2000, ao sistema de banco de dados DA2000, ou ainda transferidas em tempo real para um sistema de armazenamento de dados hidro-meteorológicos, o que permite a utilização em aplicativos de visualização. De posse das informações de descargas atmosféricas, é possível gerar produtos destinados a aplicações na previsão de tempo, análise e manutenção de sistemas elétricos, projetos de proteção de redes de transmissão e distribuição de energia e de telecomunicações, emissão de laudos de análise de eventos severos para seguradoras e empresas de engenharia em geral, entre outros produtos.

Para que haja uma boa qualidade dos resultados obtidos em termos de eficiência e precisão na detecção e localização das descargas atmosféricas, é preciso um grande número de fatores, incluindo a eficiência individual de cada sensor, o número médio de sensores que contribuem para a localização das descargas e da localização e distância entre os sensores (BENETI et al., 2005).

Para um perfeito entendimento dos métodos de detecção empregados no sistema, cabe entender os princípios básicos do funcionamento dos dois sistemas empregados:

O primeiro deles, denominado Time of Arrival - TOA (tempo de chegada) consiste na medida da diferença dos tempos de chegada de campos elétricos de baixa freqüência irradiados pelas descargas atmosféricas nuvem-solo a partir de diferentes sensores de uma rede de detecção.

Os sensores desta rede são basicamente antenas que são capazes de captar e medir os impulsos eletromagnéticos criados pelas descargas atmosféricas. O sinal do campo elétrico emitido pela descarga atmosférica demora certo tempo para atingir uma determinada antena da rede; se considerarmos $\mathrm{R}$ a distância entre a antena e o ponto atingido pelo raio, e $\mathrm{T}$ o intervalo de tempo para que a informação percorra a distância $\mathrm{R}$, podemos afirmar que $\mathrm{R}=c_{o} . \mathrm{T}$, sendo $c_{o}$ a velocidade da luz. A análise do intervalo de tempo decorrido para a 
chegada do sinal do campo elétrico a partir de duas antenas diferentes do sistema nos permite determinar uma curva na forma de uma hipérbole, sobre a qual o ponto onde o raio foi detectado é situado. Utilizando-se a mesma análise descrita anteriormente, porém agora entre uma das duas estações e uma terceira diferente, é possível a determinação de uma segunda hipérbole de provável localização da mesma descarga atmosférica. A intersecção das hipérboles obtidas torna possível determinar o ponto provável de impacto da descarga atmosférica. A Figura 13 mostra um exemplo de detecção de uma descarga atmosférica utilizando-se três sensores de tecnologia LPATS. Este método de detecção não é eficiente quando são utilizados apenas três sensores de tecnologia LPATS de uma rede, pois pode ocorrer uma ambigüidade na localização deste evento, ou seja, dois pontos distintos podem satisfazer a solução deste evento, como pode ser visto na Figura 14. O problema pode ser resolvido com a utilização do algoritmo em quatro ou mais sensores que tenham detectado o evento. Esse fato leva à construção de mais hipérboles por par de sensores, eliminando, assim, o problema.

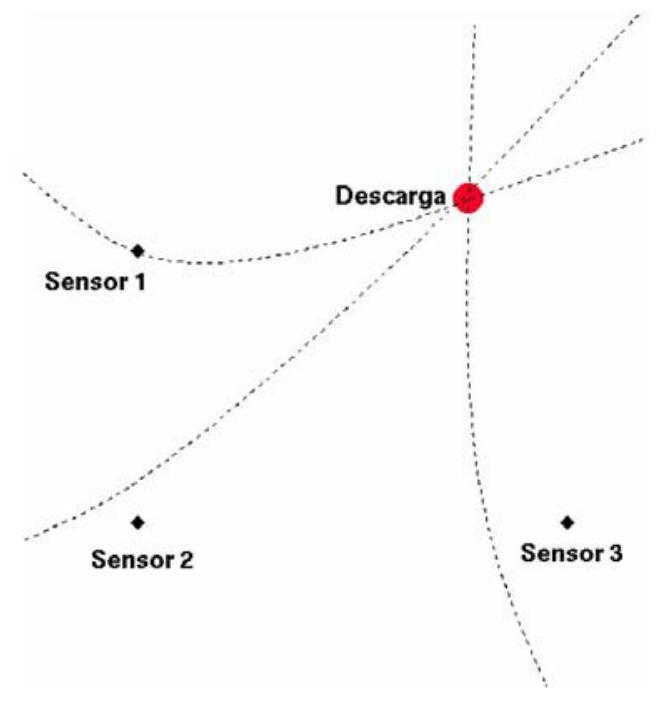

Figura 13 - Esquema ilustrativo do método Time of Arrival para a detecção de descargas atmosféricas por sensores do tipo LPATS.

Fonte: (BENETI, C.A.A. et al., 2005). 
Figura 14 - Esquema ilustrativo de uma ambigüidade no cálculo da posição de uma descarga atmosférica, quando utilizados apenas três sensores LPATS na detecção.

Fonte: (BENETI, C.A.A. et al., 2005).

Para o efetivo cálculo e precisão na localização da descarga atmosférica, neste tipo de tecnologia, a medida do tempo é extremamente importante. Desta forma, tanto a precisão desta medida, como o sincronismo dos diferentes sensores da rede de detecção são condições essenciais para uma detecção efetiva. No sistema LPATS, as estações são sincronizadas por um relógio de $10 \mathrm{MHz}$, regularmente sincronizado, assegurando estabilidade de detecção até 50 ns (BENETI et al., 2005).

O segundo método, denominado de Magnetic Direction Finding - MDF é usado para sensores capazes de detectar apenas a direção (azimute, em relação ao norte geográfico) de onde a perturbação gerada pela descarga atmosférica foi gerada. A Figura 15 ilustra esta situação. Para a determinação da posição onde a descarga ocorreu é necessária a participação de, no mínimo, três sensores de tecnologia MDF. Para cada descarga detectada, cada sensor MDF define uma direção (azimute) de onde essa descarga foi gerada. Com a informação de três sensores MDF é possível gerar três retas. Essas retas definem a área em que a descarga está inserida e através de uma estimativa otimizada é calculada a coordenada relativa ao evento detectado. 


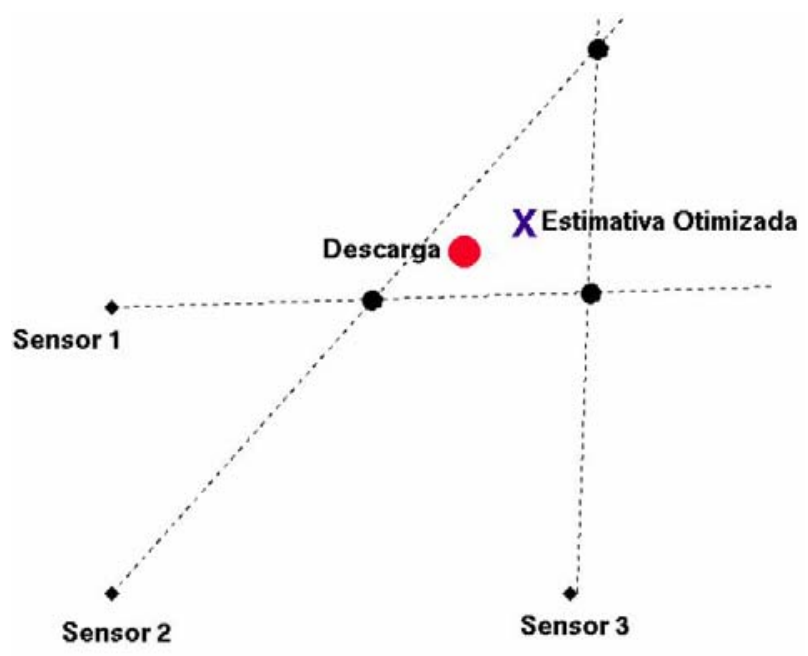

Figura 15 - Esquema ilustrativo do método MDF para a detecção de descargas atmosféricas. Fonte: (BENETI, C.A.A. et al., 2005).

Os sensores com a tecnologia IMPACT possuem a capacidade de detectar tanto o tempo de chegada da perturbação gerada pela descarga atmosférica, como a direção (azimute) deste evento. Assim, tendo-se as técnicas combinadas em apenas um sensor, é possível melhorar o desempenho da rede para a detecção de descargas atmosférica. As informações redundantes geradas por sensores do tipo IMPACT ajudam a melhorar a capacidade de detecção da rede. Essa redundância na informação faz com que apenas dois sensores do tipo IMPACT sejam necessários para a detecção da descarga, como mostra a Figura 16.

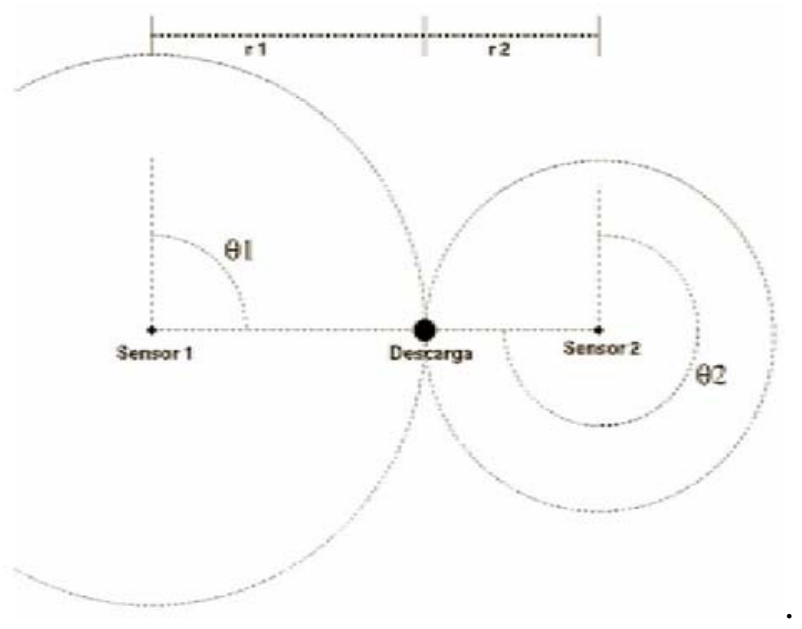

Figura 16 - Esquema ilustrativo de detecção de uma descarga atmosférica por meio de 2 sensores do tipo IMPACT.

Fonte: (BENETI, C.A.A. et al., 2005). 
Também é possível combinar os sensores do tipo LPATS (TOA) com os do tipo IMPACT (TOA e MDF) numa rede híbrida, como a existente na RINDAT.

A Figura 17 mostra uma solução ao se utilizar três sensores do tipo LPATS e dois do tipo IMPACT para a detecção de uma descarga atmosférica. Os sensores LPATS registram o tempo de chegada da perturbação gerada pela descarga (círculos pretos). Os sensores IMPACT percebem tanto o tempo de chegada da perturbação, como também a direção de onde veio a mesma (círculos e retas pontilhadas vermelhas). Assim, com o cruzamento das informações, é possível detectar a posição da ocorrência da descarga com grande precisão.

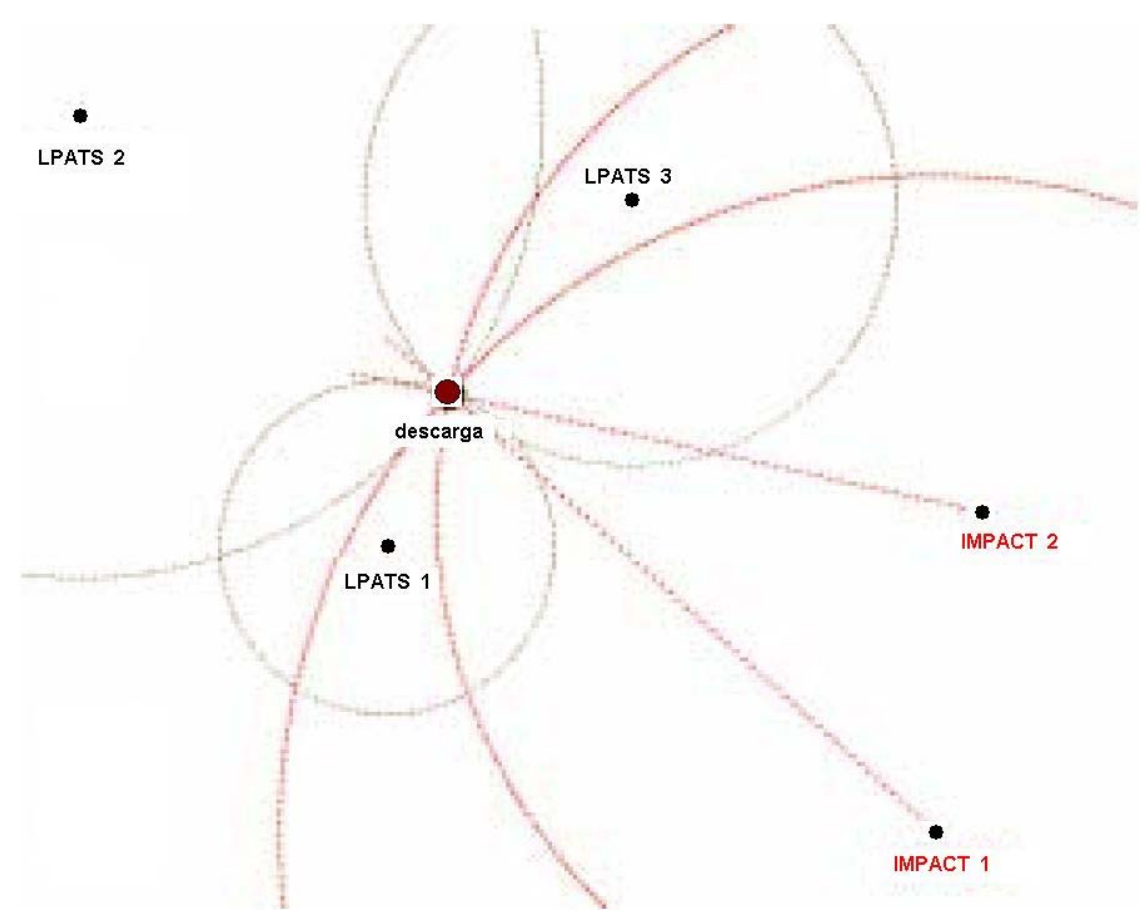

Figura 17 - Esquema ilustrativo da detecção de uma descarga atmosférica por sensores do tipo LPATS e do tipo IMPACT em uma rede híbrida.

Fonte: (BENETI, C.A.A. et al., 2005).

Assim, nota-se que com a combinação das duas tecnologias nos sensores e com a integração do sistema (RINDAT), a rede de detecção melhorou em muito sua eficiência.

A Figura 18 mostra os resultados de análise da eficiência de detecção de descargas na faixa de 5 kA a 10 kA durante o mês de maio de 2001. 


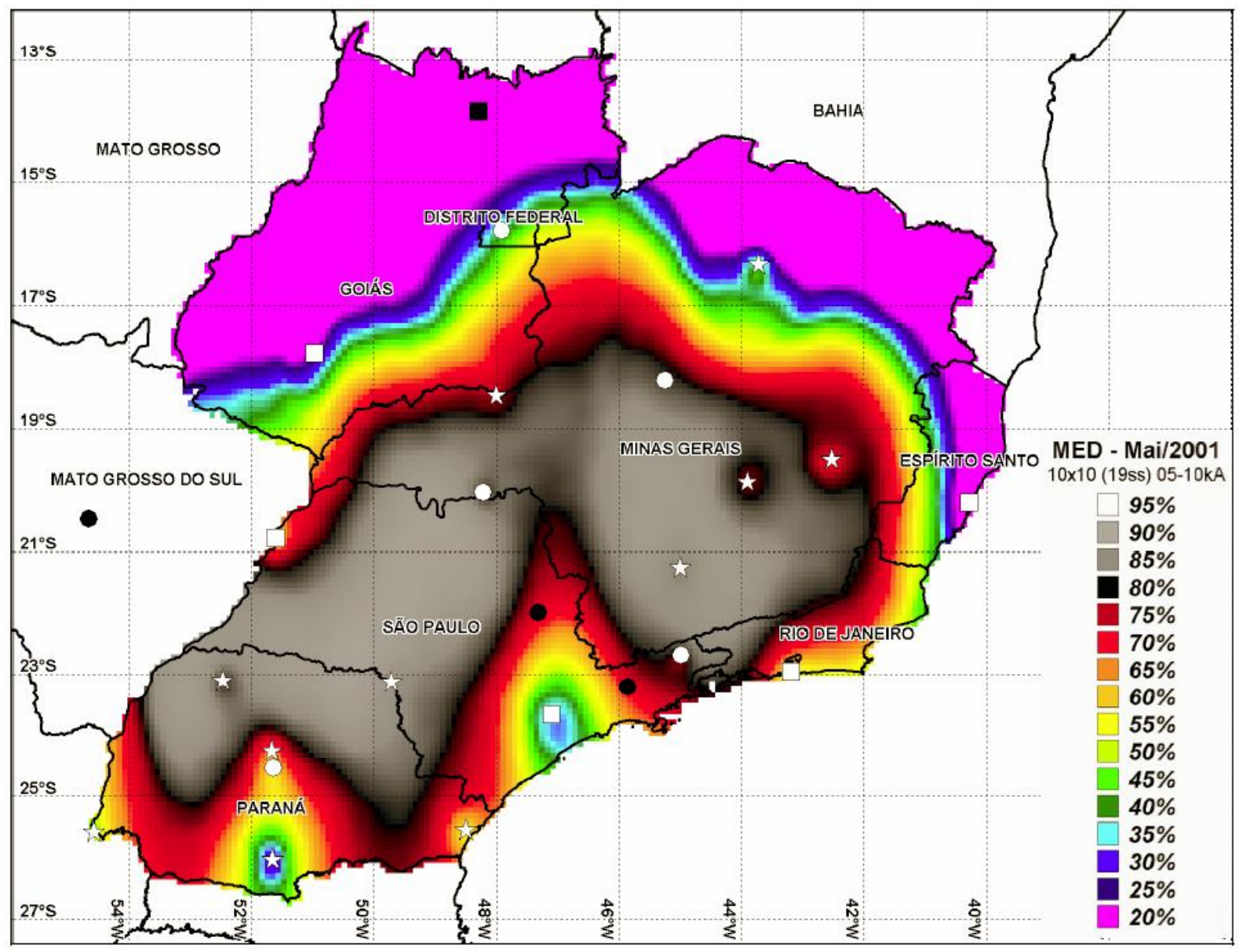

Figura 18 - Esquema ilustrativo da eficiência na detecção computacional para descargas atmosféricas na faixa de $5 \mathrm{kA}$ a $10 \mathrm{kA}$ (maio de 2001). Fonte: (NACCARATO, K.P. et al., 2006).

Com isso, o sistema RINDAT é uma ferramenta importante para a análise de uma série de questões envolvendo as descargas atmosféricas, como por exemplo a ocorrência de falhas em sistemas elétricos e de telecomunicações, incêndios, etc. 


\section{CUSTOS DA INTERRUPÇÃO DE ENERGIA ELÉTRICA}

\subsection{Considerações Gerais}

Atualmente a energia elétrica se tornou um bem quase que insubstituível, sem o qual o ser humano, principalmente nas grandes metrópoles, não consegue mais se adaptar. Basta analisar os diversos confortos que ela traz para os lares: iluminação, geladeira, freezer, microondas, televisão, máquina de lavar roupa, secadora, máquina de lavar prato, chuveiro, arcondicionado, aparelhos de DVD, equipamentos de som, rádio-relógio, telefone sem fio, microcomputador, carregadores de celular, dentre vários outros utensílios e eletrodomésticos. Sem mencionar a sua importância para os meios de transporte, como: trens, metrôs e até trólebus, que deixam de funcionar imediatamente devido a sua falta, podendo gerar, em alguns casos, um verdadeiro estado de caos e vandalismo.

Na indústria, ela é o insumo para produção, servindo de fonte de energia para as máquinas, motores e/ou controladores, hoje totalmente micro processados, necessitando então, de uma fonte de energia para o seu funcionamento.

Hospitais, clínicas, ambulatórios e demais áreas médicas também necessitam demais dessa energia, haja vista a grande dependência dos dispositivos e equipamentos de diagnósticos e tratamentos, assim como nas intervenções cirúrgicas, manutenção e / ou monitoramento do paciente.

Até a questão de segurança pública é afetada com o não funcionamento da iluminação das vias públicas, semáforos (sinaleiros) e postos policiais, colocando em risco a integridade física das pessoas e até mesmo de seus bens (veículos e residências).

O lazer, como os cinemas, parques de diversão, shopping centers, museus, teatros, casas de shows, restaurantes, dentre vários outros, também é afetado pela falta de energia elétrica, privando assim, o momento de recuperação do corpo e mente do ser humano.

Sob um ponto de vista subjetivo, pois contabilizar com precisão é uma tarefa árdua, pode-se citar os custos da perda de oportunidade de negócios, perda do lazer, perda de venda devido aos possíveis clientes que não adentraram no estabelecimento, perda dos negócios não efetuados em bolsa de valores durante a interrupção de energia elétrica, dentre vários outros. Assim, sua simples falta instantânea ou por um determinado tempo, causa uma série de transtornos a todos os sistemas elencados. Nos dias de hoje, em que expressões como "time is money”; "globalização”; “era da informação”; “era digital”, dentre outras são largamente utilizadas no mundo capitalista, os "minutos" que se perdem em uma seqüência de um 
processo são caracterizados como perdas financeiras, fazendo com que estas sejam contabilizadas. Assim, a falta de fornecimento de energia elétrica é caracterizada como um custo da interrupção.

\subsection{Custo pelo Lado da Oferta - Concessionária}

O lema "atender bem o consumidor dentro de padrões de continuidade adequada e com segurança a um custo global possível” (GOMES; SCHILLING, 1997) é o que a concessionária de energia elétrica almeja, porém, apesar de todos os esforços possíveis, um sistema elétrico está sujeito a vários problemas que podem levar à interrupção no fornecimento de energia aos consumidores (exemplo: descargas atmosféricas), sendo então de vital importância entender e minimizar os problemas oriundos destas interrupções bem como os custos a elas envolvidos.

Do ponto de vista da concessionária, podem ser citados como custos:

a energia não fornecida;

mão-de-obra para localizar o problema na rede de energia elétrica;

mão-de-obra para reparar o problema da rede de energia elétrica;

materiais e equipamentos substituídos decorrentes da anomalia;

armazenamento ou estocagem dos materiais e equipamentos;

provável depreciação da imagem da empresa devido ao problema;

pedidos de indenização:

o análise dos equipamentos danificados;

o equipe disponibilizada para a apuração de possível ocorrência;

o se procedente, valor a ser efetivamente pago ao consumidor.

É possível relacionar como custo, apesar de ser um custo indireto, os valores das equipes de apoio como “call center” , central de operação, almoxarifado, áreas de planejamento e setores administrativos e gerenciais. Ou seja, os vários setores da concessionária contribuem (através de rateio) para a formação dos custos da interrupção do fornecimento de energia elétrica. 


\subsection{Custo pelo Lado da Demanda - Consumidor}

Analisar os custos pelo lado da demanda não é uma tarefa fácil, pois, como a energia elétrica é um insumo para cada um dos consumidores, a sua falta pode provocar diversos transtornos, como por exemplo: perda de produção, perda de matéria-prima, ociosidade das instalações e de mão-de-obra, perda de lazer, etc. Portanto, é de suma importância que se saiba quanto custa a interrupção no fornecimento para cada tipo de consumidor, de modo que se possa dizer qual o real valor da energia elétrica para ele (GOMES; SCHILLING, 1997). Valores diferentes podem ocorrer entre consumidores, teoricamente similares, que tenham sofrido a mesma interrupção.

Isso faz com que a concessionária tenha dificuldades para determinar quais seriam os níveis aceitáveis ou satisfatórios para uma falta de energia elétrica (haja vista que acidentes e anomalias nem sempre são possíveis de se prever e evitar). Para atender os clientes da sua área de concessão, faz-se necessário definir os perfis de clientes. Magalhães et al. (2001) utilizou o conceito DPG (disposição a pagar: que é uma função "utilidade" da microeconomia, que nada mais é do que uma função do preço a ser pago para se auferir o benefício de uma alternativa em função da renda do indivíduo) quando efetuou a avaliação dos consumidores da classe residencial. Já na avaliação dos consumidores das classes comercial e industrial, utiliza-se apenas modelo de custos diretos associados à interrupção de energia elétrica: custo de reparo, produto estocado e deteriorado, venda não realizada, hora extra para compensar períodos interrompidos, entre outros.

Essa proposição não difere muito das propostas internacionais, tanto que o questionário apresentado no anexo A da norma IEEE Std. 1346-1998 contabiliza apenas os itens mensuráveis de uma produção (IEEE, 1998).

\subsection{Aspectos Jurídicos}

Na concepção jurídica, a energia elétrica é vista como um bem público e essencial, cuja exploração é privada e sujeita à comercialização, se tornando assim um "bem de consumo”. A seguir texto extraído do Código de Águas - Decreto 24.643 de 10 de julho de 1934: 
[...] Art. 6 - São Públicas dominicais todas as águas situadas em terrenos que também o sejam, [...]

[...] Art. 139 - O aproveitamento industrial das quedas de águas e outras fontes de energia hidráulica, quer do domínio público, quer do domínio particular, far-se-há pelo regime de autorizações e concessões instituídas [...]

[...] Art. 178 - No desempenho das atribuições [...] regulamentará e fiscalizará o serviço de produção, transmissão, transformação e distribuição da energia hidroelétrica, com o tríplice objetivo de:

a) assegurar serviço adequado;

b) fixar tarifas razoáveis;

c) garantir a estabilidade financeira das empresas.

[...] Art. 179 - Quanto ao serviço adequado a que se refere a alínea "a”do artigo precedente, resolverá a administração, sobre:

a) qualidade e quantidade do serviço;

b) extensões;

c) melhoramentos e renovação das instalações;

d) processos mais econômicos de operação.[...] (BRASIL, 1934).

Analisando-se agora a Lei 8.987, de 13 de fevereiro de 1995, que trata do regime de concessão e permissão da prestação de serviços públicos previsto no art. 175 da Constituição Federal (BRASIL, 1988), pode-se destacar:

[...] Art. $6^{0}$ - Toda concessão ou permissão pressupõe a prestação de serviço adequado ao pleno atendimento dos usuários, conforme estabelecido nesta lei, nas normas pertinentes e no respectivo contrato.

$\S 1^{\circ}$ Serviço adequado é o que satisfaz as condições de regularidade, continuidade, eficiência, segurança, atualidade, generalidade, cortesia na sua prestação e modicidade das tarifas.

$\S 2^{\circ} \mathrm{A}$ atualidade compreende a modernidade das técnicas, do equipamento e das instalações e a sua conservação, bem como a melhoria e expansão do serviço. 
$\S 3^{\circ}$ Não se caracteriza como descontinuidade do serviço a sua interrupção em situação de emergência ou após prévio aviso, quando:

I - motivada por razões de ordem técnica ou de segurança das instalações; e,

e) II - por inadimplemento do usuário, considerado o interesse da coletividade. (BRASIL, 1995).

Diante disso, uma interrupção no fornecimento de energia elétrica é tratada como supressão do "negócio venda de energia”, e como toda atividade de venda e compra de produto, ela é regida pela legislação vigente, no caso, o Código de Defesa do Consumidor.

\subsubsection{Constituição Brasileira}

Segundo a Constituição da República Federativa do Brasil de 1988, no seu Artigo 37, pelos danos é garantido o direito de regresso, cabendo salientar que nem sempre é possível a aplicação desse direito, a exemplo dos fenômenos de descargas atmosféricas:

[...] § $6^{\circ}$ - As pessoas jurídicas de direito público e as de direito privado prestadoras de serviços públicos, responderão pelos danos que seus agentes, nessa qualidade, causarem a terceiros, assegurado o direito de regresso contra o responsável nos casos de dolo ou culpa [...] (BRASIL, 1988).

\subsubsection{Código de Defesa do Consumidor}

A Lei 8.078/1990 (Código de Defesa do Consumidor) se coloca ao lado do consumidor, garantindo assim o direito de ressarcimento pela concessionária, que é o fornecedor da energia elétrica e, conseqüentemente, o responsável pela falta do produto para o consumidor.

[..] Art. 6 - São direitos básicos do consumidor:

[...] VI - a efetiva prevenção e reparação de danos patrimoniais e morais, individuais, coletivos e difusos;

X - a adequada e eficaz prestação dos serviços públicos em geral. [...]

[...] Art. 14 - O fornecedor de serviços responde independentemente da existência de culpa, pela reparação dos danos causados aos consumidores por defeitos relativos 
à prestação dos serviços, bem como por informações insuficientes ou inadequadas sobre sua fruição e riscos.

$\S 1^{\circ} \mathrm{O}$ serviço é defeituoso quando não fornece a segurança que o consumidor dele pode esperar, levando-se em consideração as circunstâncias relevantes, entre as quais:

I - o modo de seu fornecimento;

II - o resultado e os riscos que razoavelmente dele se esperam;

III - a época em que foi fornecido.

$\S 2^{\circ} \mathrm{O}$ serviço não é considerado defeituoso pela adoção de novas técnicas.

$\S 3^{\circ} \mathrm{O}$ fornecedor de serviços só não será responsabilizado quando provar:

I - que, tendo prestado o serviço, o defeito inexiste;

II - a culpa exclusiva do consumidor ou de terceiro.

$\S 4^{\circ}$ A responsabilidade pessoal dos profissionais liberais será apurada mediante a verificação de culpa [...] (BRASIL, 1990).

\subsubsection{ANEEL (Agência Nacional de Energia Elétrica) / CSPE (Comissão de Serviços Públicos de Energia)}

Dentre as várias legislações outorgadas pela ANEEL, quatro delas devem ser mencionadas:

a) Resolução $n^{0} 24$ de 27 de janeiro de 2000, que estabelece as disposições relativas à continuidade da distribuição de energia elétrica às unidades consumidoras (ANEEL, 2000a);

b) Resolução $n^{0} 456$ de 29 de novembro de 2000, que estabelece as condições gerais de fornecimento de energia elétrica (ANEEL, 2000b);

c) Resolução $\mathrm{n}^{0} 505$ de 26 de novembro de 2001, que estabelece as disposições relativas à conformidade dos níveis de tensão de energia elétrica em regime permanente (ANEEL, 2001);

d) Resolução Normativa $n^{\circ} 61$ de 29 de abril de 2004, que estabelece as disposições relativas ao ressarcimento de danos elétricos em equipamentos elétricos instalados em unidades consumidoras, causados por perturbação ocorrida no sistema elétrico (ANEEL, 2004). 
Em todas elas é clara a questão da qualidade e continuidade no fornecimento de energia aos consumidores, inclusive na especificação de índices de qualidade como:

DEC - Duração Equivalente de Interrupção por Unidade Consumidora

$$
D E C=\frac{\sum_{i=1}^{k} C a(i) \times t(i)}{C c}
$$

FEC - Freqüência Equivalente de Interrupção por Unidade Consumidora.

$$
F E C=\frac{\sum_{i=1}^{k} C a(i)}{C c}
$$

Onde:

DEC = Duração Equivalente de Interrupção por Unidade Consumidora, expressa em horas e centésimos de horas;

FEC = Freqüência Equivalente de Interrupção por Unidade Consumidora, expressa em número de interrupções e centésimos do número de interrupções;

Ca(i) = Número de unidades consumidoras interrompidas em um evento (i), no período de apuração;

t(i) = Duração de cada evento (i), no período de apuração;

$\mathrm{i} \quad$ = Índice de eventos ocorridos no sistema que provocam interrupções em uma ou mais unidades consumidoras;

$\mathrm{k}$ = = Número máximo de eventos no período considerado;

Cc = Número total de unidades consumidoras, do conjunto considerado, no final do período apuração.

Conjunto = Agrupamento de unidades consumidoras, dentro da área de concessão da empresa.

Cabe registrar que até o ano de 2000 os índices DEC e FEC eram os únicos que “mediam” a qualidade do fornecimento de energia elétrica para os consumidores de sua área de concessão. A seguir são apresentados dados evolutivos dos índices DEC e FEC do ano de 1996 até o ano de 2005, para o estado de São Paulo (Figura 19), região sudeste do Brasil (Figura 20) e do Brasil com todas as suas regiões (Figura 21). Ressalta-se que até o ano de 2000 os índices foram calculados com base nos procedimentos da então Portaria DNAEE $n^{0} 46$ de 17/04/1978, e que após isso, estão de acordo com as recomendações da Resolução ANEEL n ${ }^{0}$ 24 de 20/01/2000. Dentre essas mudanças, podem ser elencadas a melhoria na aquisição e 
registro de dados da interrupção, a mudança na composição das áreas geográficas para o cálculo dos índices (conjuntos) e sobretudo, o investimento na rede de energia elétrica pelas empresas controladoras dessas concessionárias após as privatizações.
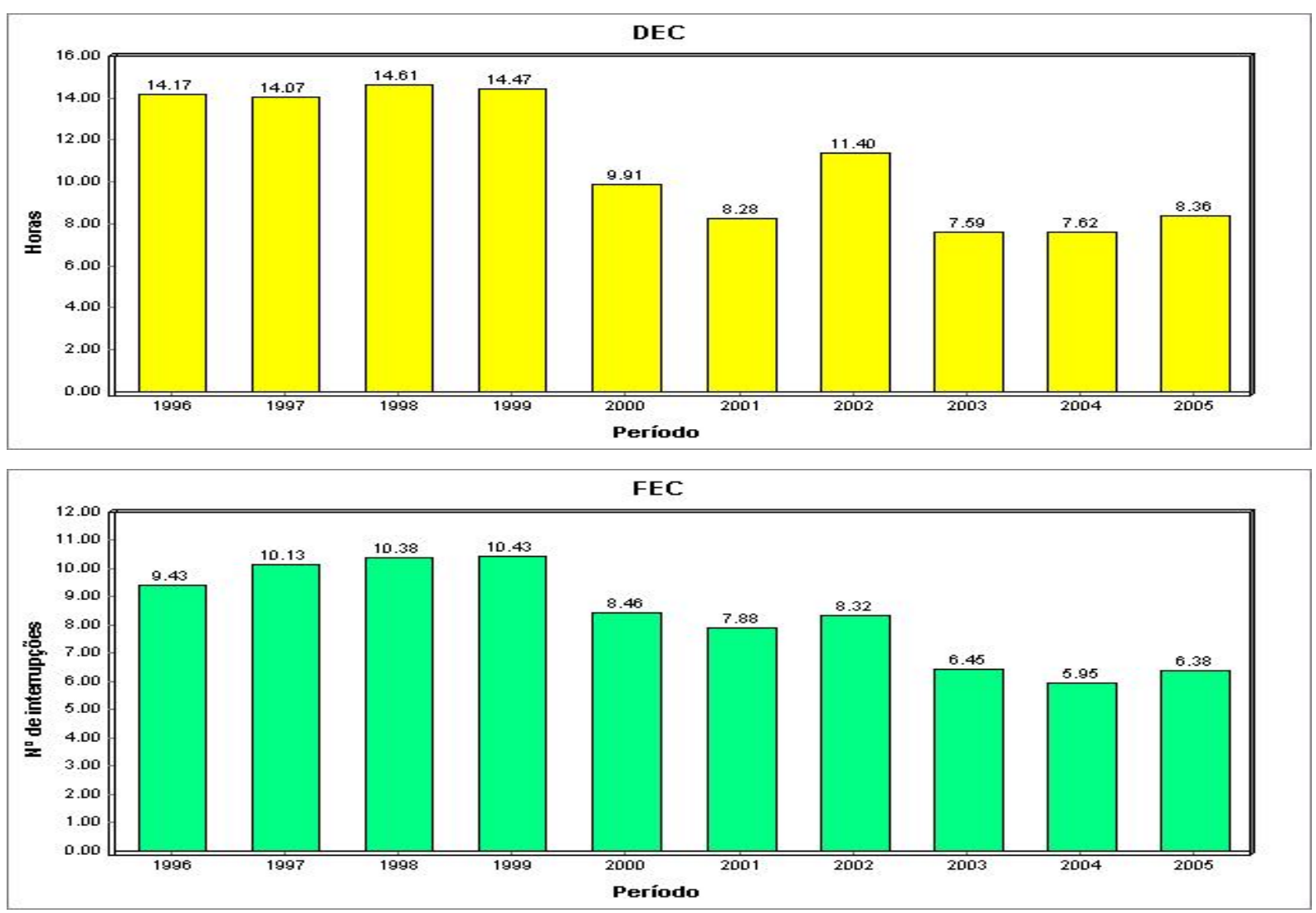

Figura 19 - Índices DEC e FEC do estado de São Paulo no período de 1996 a 2005.

Fonte: (ANEEL, 2007).

Na Figura 19, referente apenas ao estado de São Paulo, percebe-se nitidamente a variação dos índices até 1999 e após 2000, quando o DEC oscilava em torno de 14,33 horas anuais contra 10,09 horas dos últimos anos. Por outro lado o FEC vinha crescendo, tendo alcançado em 1999 o valor de 10,43 interrupções no ano, tendo caído bruscamente para 8,46 interrupções em 2000 e com valor de 6,38 interrupções em 2005, reflexo das mudanças elencadas acima.

Quanto à região sudeste, apresentada na Figura 20, nota-se uma situação diferente da análise relativa ao estado de São Paulo. Percebe-se que os índices estavam com tendência de redução, tendo os valores mínimos sido verificados no ano de 2001. 

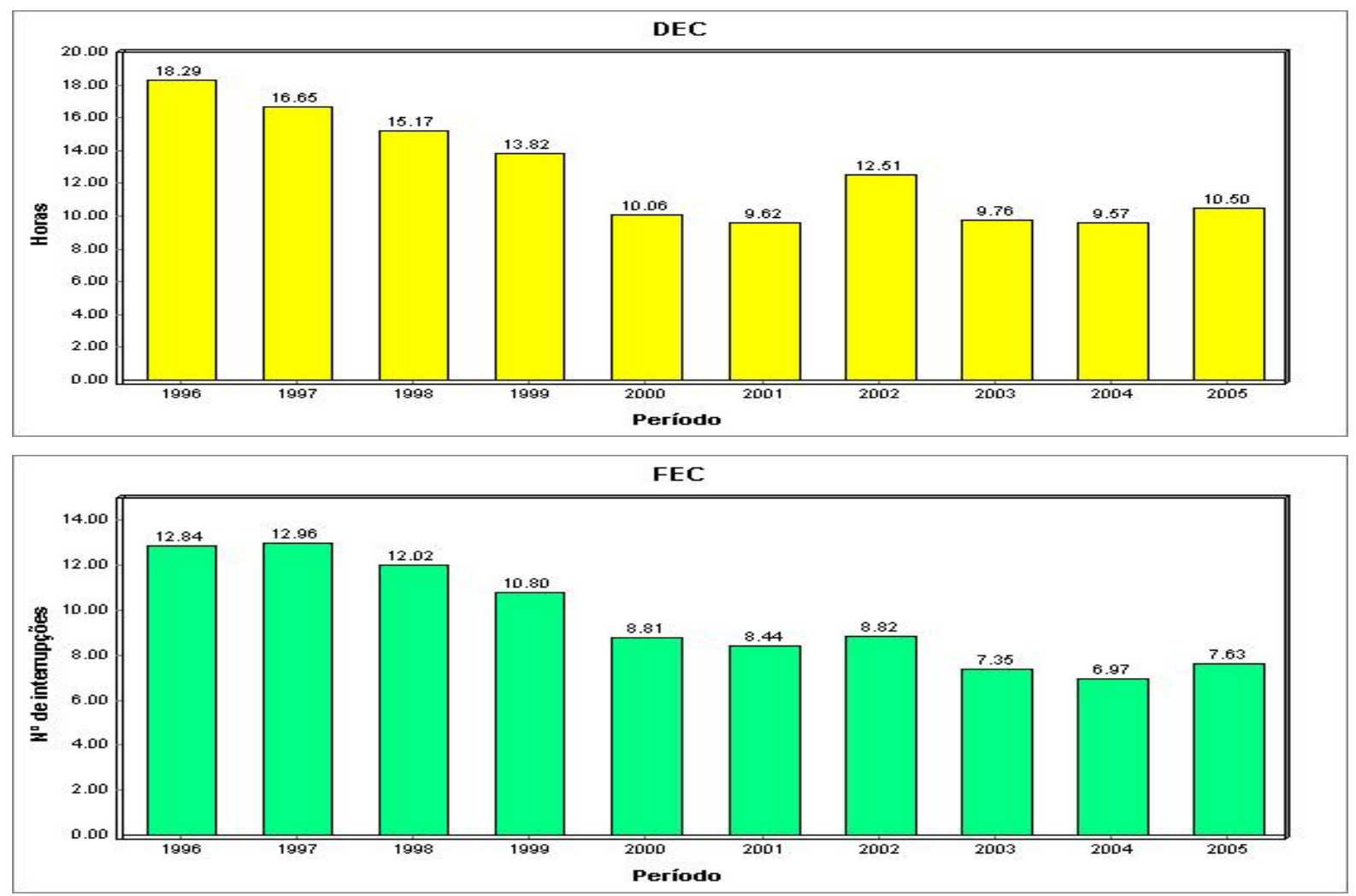

Figura 20 - Índices DEC e FEC da região sudeste do Brasil no período de 1996 a 2005.

Fonte: (ANEEL, 2007).
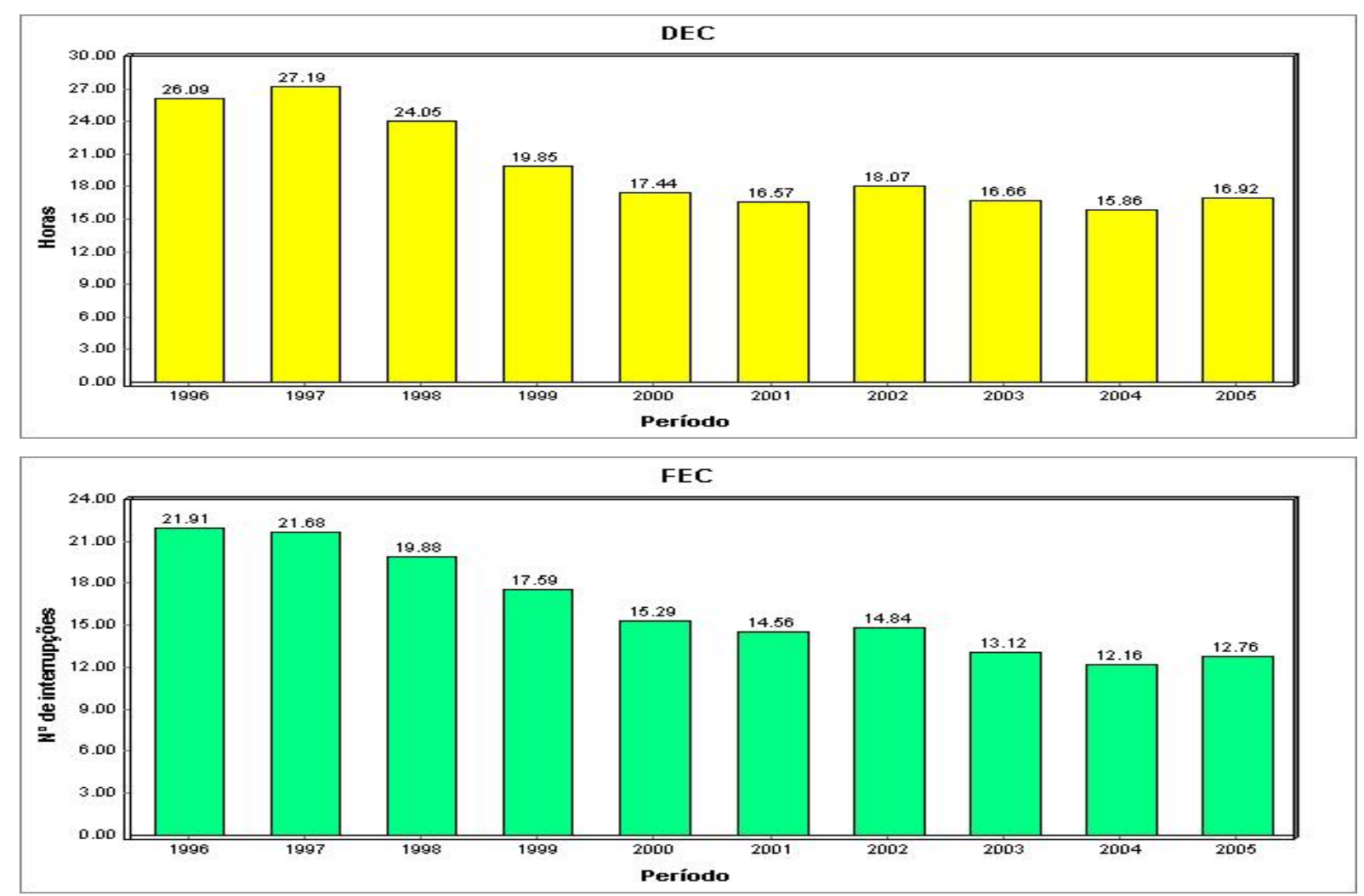

Figura 21 - Índices DEC e FEC do Brasil no período de 1996 a 2005.

Fonte: (ANNEL, 2007). 
Já na análise referente ao Brasil, como um todo, nota-se a redução dos valores no período 1996 a 2001. No ano de 2002 (época do “apagão”) os índices voltaram a subir, observando-se posteriormente uma nova redução.

Como já foi comentado, os índices DEC e FEC eram os únicos instrumentos de medição do desempenho de uma concessionária, servindo como indicadores técnicos para as tomadas de ações pelas empresas quanto à manutenção preventiva, tanto no que se refere ao alimentador (circuito), como na região, ou ainda para apurar as causas de ocorrências que mais contribuíram para penalizar os índices. As Figuras 22 e 23 apresentam, respectivamente, os índices DEC e FEC da Eletropaulo Metropolitana Eletricidade de São Paulo S.A. durante os anos de 2003 a 2005 de forma mensal, bem como a contribuição da causa descarga atmosférica frente às outras causas. É nítida a participação das descargas atmosféricas nos meses de chuva, que compreendem os meses de novembro a março do ano seguinte. Contudo, visualmente, tanto na duração quanto na freqüência não há uma contribuição relevante.

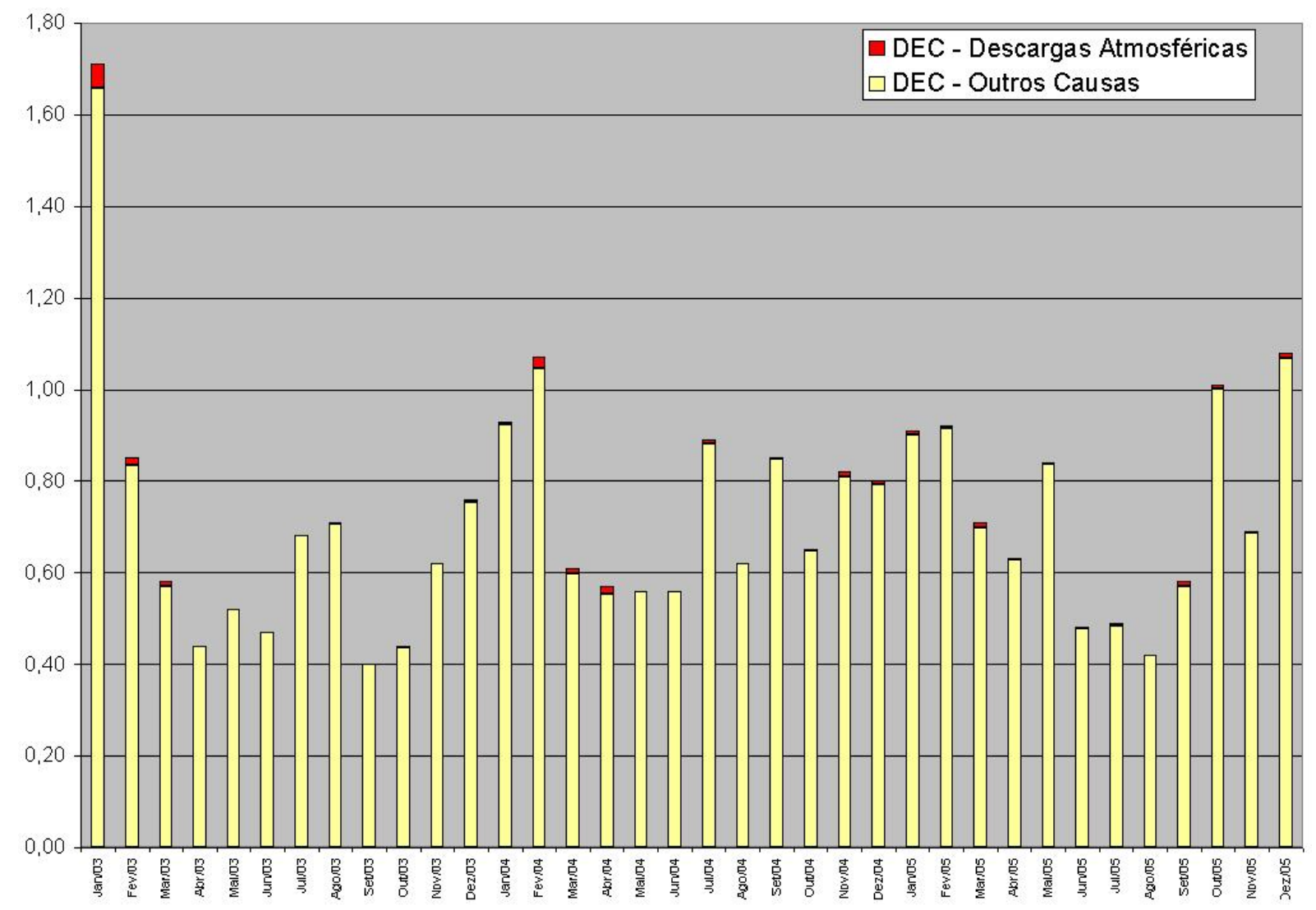

Figura 22 - Índice DEC de descargas atmosféricas Vs. outras causas, período mensal de 2003 a 2005. Fonte: (Eletropaulo Metropolitana Eletricidade de São Paulo S.A. - dados trabalhados pelo autor). 


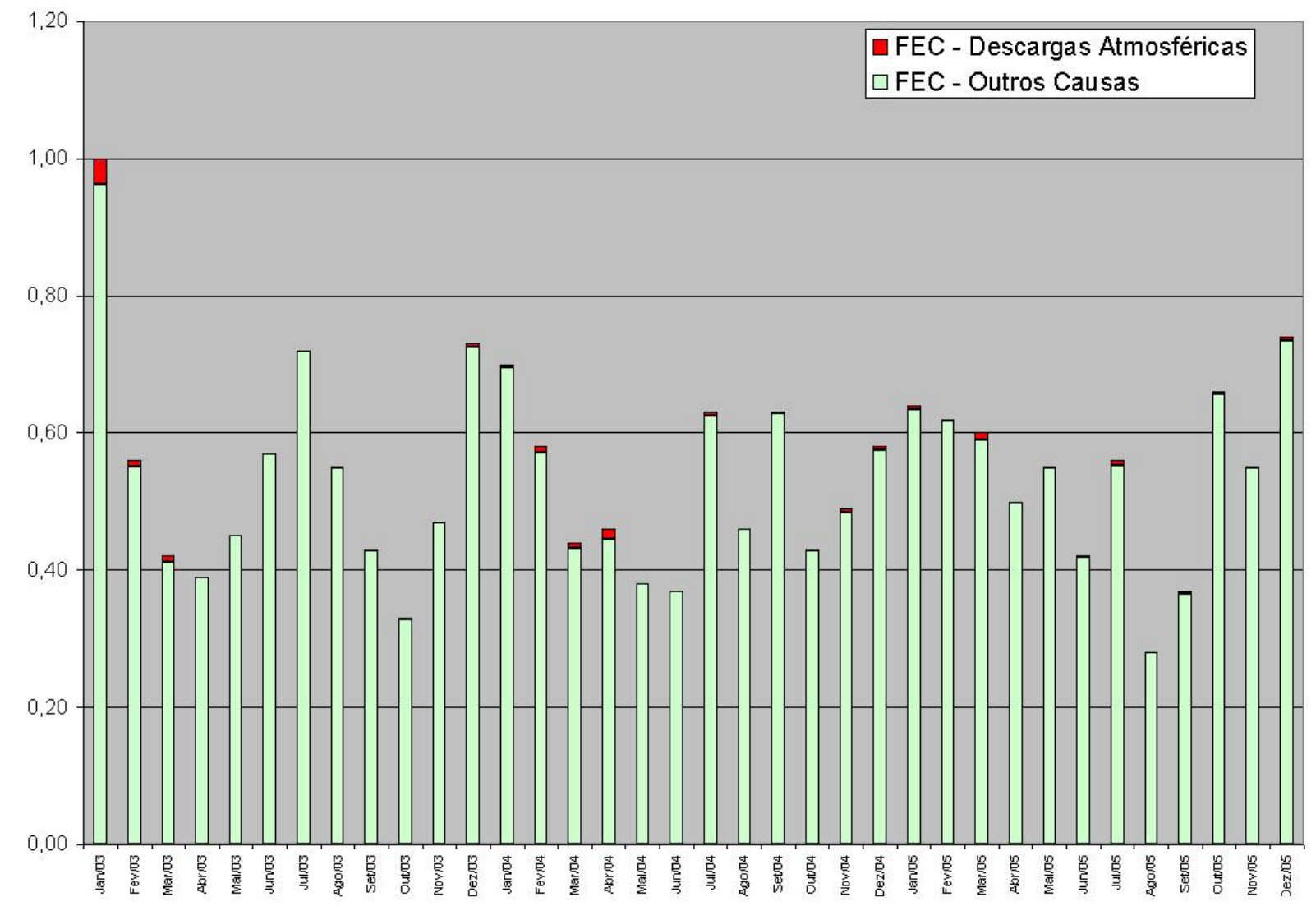

Figura 23 - Índice FEC de descargas atmosféricas Vs. outras causas, período mensal de 2003 a 2005. Fonte: (Eletropaulo Metropolitana Eletricidade de São Paulo S.A. - dados trabalhados pelo autor).

\subsection{O Pedido de Indenização - PID}

Os pedidos de indenização ou PIDs, como são conhecidos no meio das concessionárias de energia elétrica, têm como premissa analisar e apurar se o produto energia elétrica, durante o seu "fornecimento" ou "falta", pode ter causado algum dano pleiteado pelo consumidor (cliente).

Conforme apresentado no Capítulo 2, uma pesquisa feita na Bahia (NUNES FILHO, 2004), na concessionária COELBA e na Agência Reguladora local (AGERBA), mostra um índice bastante relevante quanto aos tipos de reclamações. Nessa pesquisa, nota-se uma participação muito elevada, $77,1 \%$, do item “danos elétricos e materiais”, valor este que reflete diretamente nos processos de PIDs. Apenas como dado comparativo, o item “interrupção de energia” representa apenas $2,6 \%$ das reclamações, o que mostra que para a região onde foi efetuada a 
pesquisa a falta de energia ainda tem uma repercussão menor quando comparada aos danos que o produto energia elétrica pode causar.

Analisando-se os dados dos PIDs das concessionárias de distribuição de energia elétrica do estado de São Paulo, sobretudo nas quantidades de pedidos recebidos, deferidos e valores de indenizações pagas, pode-se notar uma tendência crescente, conforme indicado na Figura 24.

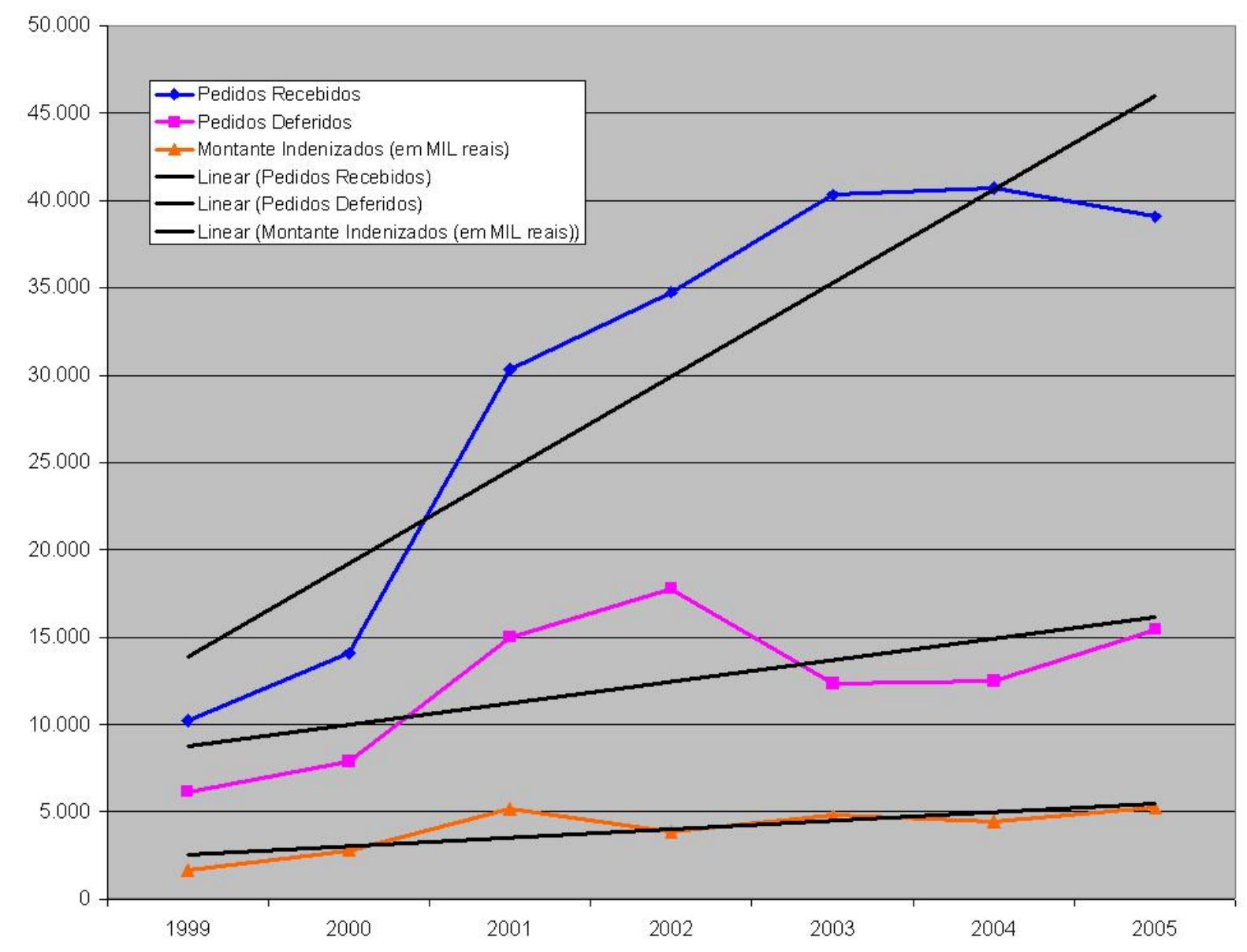

Figura 24 - Evolução do número de pedidos de indenização nas concessionárias paulistas no período de 1999 a 2005.

Fonte: (Comissão de Serviços Públicos de Energia - CSPE - dados trabalhados pelo autor).

Esse crescimento no índice preocupa em demasia as concessionárias, pois onera o “caixa” e conseqüentemente reduz a rentabilidade junto aos acionistas. Além disso contribui negativamente nas negociações quando da revisão tarifária, uma vez que os índices de satisfação do cliente se tornam ruins.

Existem vários projetos de P\&D (pesquisa e desenvolvimento) no âmbito da ANEEL focados na análise e/ou definições das causas e comprovação da real culpa da fornecedora de energia 
elétrica. A mesma preocupação fez com que a ANEEL editasse a resolução normativa $\mathrm{n}^{0} 61$, tentando padronizar e conseqüentemente uniformizar os procedimentos de análise dos PIDs. Essa mesma resolução define que as ocorrências devidas a descargas atmosféricas devem ser pagas, o que por si só já causou um aumento considerável na quantidade de solicitações procedentes, de 9,4 pontos percentuais em 2 anos, conforme descrito no Capítulo 2. Entretanto, o impacto das descargas atmosféricas é muito maior, haja vista que os danos possuem uma extensão maior e, conseqüentemente, um pleito maior de indenização.

A Figura 25 mostra o montante pago (percentualmente) no ano de 2005 e no primeiro trimestre de 2006 na concessionária Eletropaulo Metropolitana Eletricidade de São Paulo S.A.
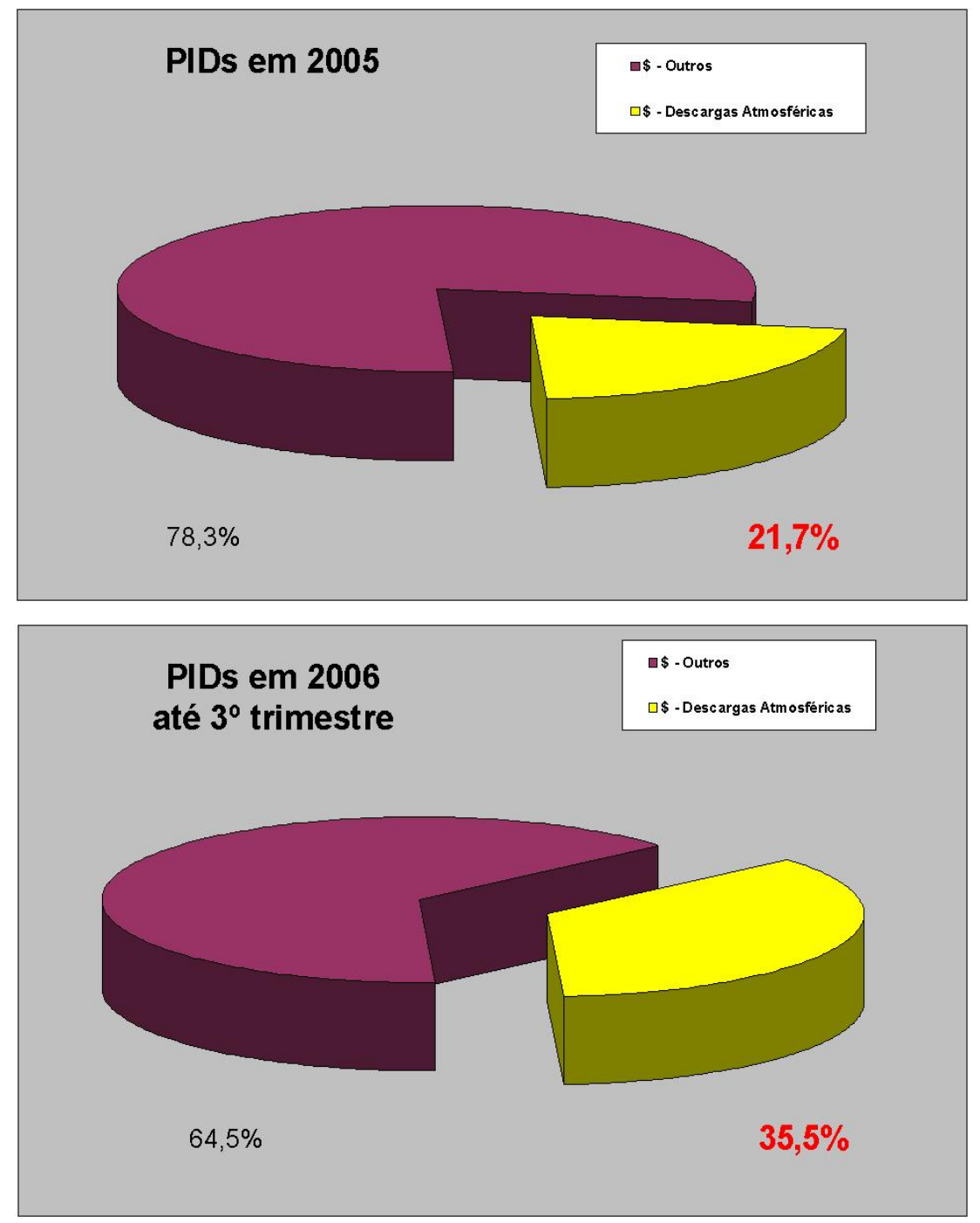

Figura 25 - Evolução do valor ressarcido por PIDs devido a descargas atmosféricas, no ano de 2005 e no primeiro trimestre de 2006.

Fonte: (Eletropaulo Metropolitana Eletricidade de São Paulo S.A. - dados trabalhados pelo autor). 
Nota-se claramente o volume na participação financeira da causa descarga atmosférica comparativamente aos demais casos.

\subsection{Tarifação}

O sistema de tarifação é regido pela Resolução ANEEL nº 456 de 29 de novembro de 2000 que define as condições gerais de fornecimento de energia elétrica.

[..]Art. $2^{\circ}$ Para os fins e efeitos desta Resolução são adotadas as seguintes definições...

$[\ldots]$

XV - Estrutura tarifária: conjunto de tarifas aplicáveis às componentes de consumo de energia elétrica e/ou demanda de potência ativas de acordo com a modalidade de fornecimento.

XVI - Estrutura tarifária convencional: estrutura caracterizada pela aplicação de tarifas de consumo de energia elétrica e/ou demanda de potência independentemente das horas de utilização do dia e dos períodos do ano.

XVII - Estrutura tarifária horo-sazonal: estrutura caracterizada pela aplicação de tarifas diferenciadas de consumo de energia elétrica e de demanda de potência de acordo com as horas de utilização do dia e dos períodos do ano, conforme especificação a seguir:

a) Tarifa Azul: modalidade estruturada para aplicação de tarifas diferenciadas de consumo de energia elétrica de acordo com as horas de utilização do dia e os períodos do ano, bem como de tarifas diferenciadas de demanda de potência de acordo com as horas de utilização do dia.

b) Tarifa Verde: modalidade estruturada para aplicação de tarifas diferenciadas de consumo de energia elétrica de acordo com as horas de utilização do dia e os períodos do ano, bem como de uma única tarifa de demanda de potência.

c) Horário de ponta (P): período definido pela concessionária e composto por 3 (três) horas diárias consecutivas, exceção feita aos sábados, domingos e feriados nacionais, considerando as características do seu sistema elétrico.

d) Horário fora de ponta (F): período composto pelo conjunto das horas diárias consecutivas e complementares àquelas definidas no horário de ponta.

e) Período úmido (U): período de 5 (cinco) meses consecutivos, compreendendo os fornecimentos abrangidos pelas leituras de dezembro de um ano a abril do ano seguinte.

f) Período seco (S): período de 7 (sete) meses consecutivos, compreendendo os fornecimentos abrangidos pelas leituras de maio a novembro. 
$[\ldots]$

XXII - Grupo "A": grupamento composto de unidades consumidoras com fornecimento em tensão igual ou superior a $2,3 \mathrm{kV}$, ou, ainda, atendidas em tensão inferior a 2,3 kV a partir de sistema subterrâneo de distribuição e faturadas neste Grupo nos termos definidos no art. 82, caracterizado pela estruturação tarifária binômia e subdividido nos seguintes subgrupos:

a) Subgrupo A1 - tensão de fornecimento igual ou superior a $230 \mathrm{kV}$;

b) Subgrupo A2 - tensão de fornecimento de $88 \mathrm{kV}$ a $138 \mathrm{kV}$;

c) Subgrupo A3 - tensão de fornecimento de $69 \mathrm{kV}$;

d) Subgrupo A3a - tensão de fornecimento de $30 \mathrm{kV}$ a $44 \mathrm{kV}$;

e) Subgrupo A4 - tensão de fornecimento de 2,3 kV a $25 \mathrm{kV}$;

f) Subgrupo AS - tensão de fornecimento inferior a $2,3 \mathrm{kV}$, atendidas a partir de sistema subterrâneo de distribuição e faturadas neste Grupo em caráter opcional.

XXIII - Grupo "B": grupamento composto de unidades consumidoras com fornecimento em tensão inferior a 2,3 kV, ou, ainda, atendidas em tensão superior a 2,3 kV e faturadas neste Grupo nos termos definidos nos arts. 79 a 81, caracterizado pela estruturação tarifária monômia e subdividido nos seguintes subgrupos:

a) Subgrupo B1 - residencial;

b) Subgrupo B1 - residencial baixa renda;

c) Subgrupo B2 - rural;

d) Subgrupo B2 - cooperativa de eletrificação rural;

e) Subgrupo B2 - serviço público de irrigação;

f) Subgrupo B3 - demais classes;

g) Subgrupo B4 - iluminação pública.

[...]

XXXV - Tarifa monômia: tarifa de fornecimento de energia elétrica constituída por preços aplicáveis unicamente ao consumo de energia elétrica ativa.

XXXVI - Tarifa binômia: conjunto de tarifas de fornecimento constituído por preços aplicáveis ao consumo de energia elétrica ativa e à demanda faturável.

XXXVII - Tarifa de ultrapassagem: tarifa aplicável sobre a diferença positiva entre a demanda medida e a contratada, quando exceder os limites estabelecidos.

XXXVIII - Tensão secundária de distribuição: tensão disponibilizada no sistema elétrico da concessionária com valores padronizados inferiores a 2,3 kV.

XIL - Tensão primária de distribuição: tensão disponibilizada no sistema elétrico da concessionária com valores padronizados iguais ou superiores a 2,3 kV.

XL - Unidade consumidora: conjunto de instalações e equipamentos elétricos caracterizado pelo recebimento de energia elétrica em um só ponto de entrega, com medição individualizada e correspondente a um único consumidor.

$[\ldots]$ 
Art. 47. O faturamento de unidade consumidora do Grupo "B” será realizado com base no consumo de energia elétrica ativa, e, quando aplicável, no consumo de energia elétrica reativa excedente, devendo, em ambos os casos, ser observada as disposições específicas estabelecidas nesta Resolução.

Art. 48. Os valores mínimos faturáveis, referentes ao custo de disponibilidade do sistema elétrico, aplicáveis ao faturamento mensal de unidades consumidoras do Grupo “B”, serão os seguintes:

I - monofásico e bifásico a 2 (dois) condutores: valor em moeda corrente equivalente a $30 \mathrm{kWh}$;

II - bifásico a 3 (três) condutores: valor em moeda corrente equivalente a 50 kWh;

III - trifásico: valor em moeda corrente equivalente a $100 \mathrm{kWh}$.

$\S 1^{\circ}$ Os valores mínimos serão aplicados sempre que o consumo medido ou estimado for inferior aos referidos neste artigo, bem como nos casos previstos nos arts. 32, 57, 70 e 71.

$\S 2^{\circ}$ Constatado, no ciclo de faturamento, consumo medido ou estimado inferior aos fixados neste artigo, a diferença resultante não será objeto de futura compensação.

Art. 49. O faturamento de unidade consumidora do Grupo "A”, observados, no fornecimento com tarifas horo-sazonais, os respectivos segmentos, será realizado com base nos valores identificados por meio dos critérios descritos a seguir:

I - demanda de potência ativa: um único valor, correspondente ao maior dentre os a seguir definidos:

a) a demanda contratada, exclusive no caso de unidade consumidora rural ou sazonal faturada na estrutura tarifária convencional;

b) a demanda medida; ou

c) $10 \%$ (dez por cento) da maior demanda medida, em qualquer dos 11 (onze) ciclos completos de faturamento anteriores, quando se tratar de unidade consumidora rural ou sazonal faturada na estrutura tarifária convencional.

II - consumo de energia elétrica ativa: um único valor, correspondente ao maior dentre os a seguir definidos:

a) energia elétrica ativa contratada, se houver; ou

b) energia elétrica ativa medida no período de faturamento.

III - consumo de energia elétrica e demanda de potência reativas excedentes: quando o fator de potência da unidade consumidora, indutivo ou capacitivo, for inferior a 0,92 (noventa e dois centésimos), nos termos dos arts. 64 a 69.

Parágrafo único. Para fins de faturamento, na impossibilidade de avaliação do consumo na ponta e fora de ponta, esta segmentação será efetuada proporcionalmente ao número de horas de cada segmento.

Art. 50. A Tarifa Azul será aplicada considerando a seguinte estrutura tarifária:

I - demanda de potência $(\mathrm{kW})$ :

a) um preço para horário de ponta (P); e 
b) um preço para horário fora de ponta (F).

II - consumo de energia (kWh):

a) um preço para horário de ponta em período úmido (PU);

b) um preço para horário fora de ponta em período úmido (FU);

c) um preço para horário de ponta em período seco (PS); e

d) um preço para horário fora de ponta em período seco (FS).

Art. 51. A Tarifa Verde será aplicada considerando a seguinte estrutura tarifária:

I - demanda de potência $(\mathrm{kW})$ : um preço único.

$\mathrm{II}$ - consumo de energia (kWh):

a) um preço para horário de ponta em período úmido (PU);

b) um preço para horário fora de ponta em período úmido (FU);

c) um preço para horário de ponta em período seco (PS); e

d) um preço para horário fora de ponta em período seco (FS)

[...]

Art. 53. Os critérios de inclusão na estrutura tarifária convencional ou horo-sazonal aplicam-se às unidades consumidoras do Grupo “A”, conforme as condições a seguir estabelecidas:

I - na estrutura tarifária convencional: para as unidades consumidoras atendidas em tensão de fornecimento inferior a $69 \mathrm{kV}$, sempre que for contratada demanda inferior a 300 kW e não tenha havido opção pela estrutura tarifária horo-sazonal nos termos do inciso IV;

II - compulsoriamente na estrutura tarifária horo-sazonal, com aplicação da Tarifa Azul: para as unidades consumidoras atendidas pelo sistema elétrico interligado e com tensão de fornecimento igual ou superior a $69 \mathrm{kV}$;

III - compulsoriamente na estrutura tarifária horo-sazonal, com aplicação da Tarifa Azul, ou Verde se houver opção do consumidor: para as unidades consumidoras atendidas pelo sistema elétrico interligado e com tensão de fornecimento inferior a $69 \mathrm{kV}$, quando:

a) a demanda contratada for igual ou superior a $300 \mathrm{~kW}$ em qualquer segmento horo-sazonal; ou,

b) a unidade consumidora faturada na estrutura tarifária convencional houver apresentado, nos últimos 11 (onze) ciclos de faturamento, 3 (três) registros consecutivos ou 6 (seis) alternados de demandas medidas iguais ou superiores a $300 \mathrm{~kW}$; e

IV - opcionalmente na estrutura tarifária horo-sazonal, com aplicação da Tarifa Azul ou Verde, conforme opção do consumidor: para as unidades consumidoras atendidas pelo sistema elétrico interligado e com tensão de fornecimento inferior a $69 \mathrm{kV}$, sempre que a demanda contratada for inferior a $300 \mathrm{~kW}$.

(ANEEL, 2000b) 
Todo consumidor, seja de baixa, média ou alta tensão, é tributado em um desses grupos e formas de tarifação.

O entendimento do tipo de tarifação se faz necessário para que se possa apurar o custo da energia não vendida, uma vez que pelo histórico do cliente é possível apurar qual o perfil de consumo ao longo do dia, semana, mês e ano. No caso dos consumidores do Grupo "B”, baixa tensão, essa análise deve ser feita pela média do consumo mensal, uma vez que a instalação de medidores com registrador ainda está em fase experimental, haja vista o custo de cada equipamento. Contudo, no Grupo “A”, o estudo é possível face à existência de massa de dados dos medidores de cada cliente, possibilitando, assim, determinar o custo ao longo do dia.

Cabe lembrar que este custo varia conforme o horário, mês e ano, seja devido à tarifação horo-sazonal, tanto no horário de ponta como fora de ponta, ou devido aos meses de tarifas úmida ou seca, ou ainda pelos ajustes tarifários que ocorrem todos os anos.

\subsection{Unidade Padrão de Serviço (UPS)}

São vários os motivos que levam as concessionárias a adotarem critérios para valorar os serviços executados:

a) determinação do tempo médio de execução de cada atividade;

b) forma clara de pagamento aos serviços executados por empresas terceiras nas redes de energia elétrica;

c) determinação da quantidade exata de material a ser empregado e retirado da obra / serviço;

d) estudo de tempos e métodos para reduzir o tempo de execução da atividade, seja por meio de ferramental, procedimento, ou mesmo emprego de equipamento com tecnologia moderna.

Esse valor, cuja unidade é tempo (horas), pode sofrer variações conforme região ou tipo de construção. Algumas tentativas de unificação foram feitas, por exemplo, envolvendo as 3 maiores distribuidoras de energia elétrica do estado de São Paulo antes da privatização. Como é um valor que necessita de constante manutenção face ao exposto anterior, ficou desatualizado com a privatização, obrigando as empresas a iniciarem um novo estudo. 
É uma informação útil para contabilizar os custos dos serviços realizados pelas equipes, sejam próprias da empresa ou de terceiros, uma vez que se trata de valor médio para um determinado serviço. Contudo, por se tratar de um valor médio, pode não retratar o custo diante das dificuldades encontradas no campo durante um atendimento de ocorrência. Para minimizar isso caberiam duas alternativas: a primeira seria determinar a UPS para cada serviço, porém, considerando situações adversas; a segunda seria contabilizar exatamente os custos em cada atendimento, o que nem sempre será exato, uma vez que a prioridade da equipe é restabelecer o fornecimento de energia o mais rápido possível e não apontar os tempos e etapas de execução de serviço.

\subsection{Custo da Imagem}

Quanto custa a marca de uma empresa? Quanto custa a imagem de uma empresa?

Com certeza são perguntas com as quais os executivos de uma concessionária de energia elétrica não se preocupariam antes das mudanças no modelo do setor elétrico, pois os consumidores eram cativos à empresa de energia elétrica da região. Para validar a importância deste custo, em 2002 a revista HSM Management, na edição de número 31 (março / abril), publicou na página 65 uma matéria de Slywotzky e Kania intitulada "Energia elétrica: de um mercado de massa aos relacionamentos”:

[...] As empresas de energia elétrica sempre representaram uma única coisa para a maioria dos consumidores: fornecimento confiável de eletricidade. Devido à desregulamentação do setor, essas empresas precisarão reinventar suas marcas para que passem a representar coisas diferentes para os diferentes segmentos de clientes.

Por exemplo, os planos de fornecimento de energia residencial evoluirão com base no ciclo de vida de cada consumidor. A oferta poderá ser modificada e usar como base um casal que tem filhos, os filhos crescem e vão cuidar de suas vidas, e o casal se aposenta.

Algumas famílias exigirão o fornecimento de energia "verde", produzida a partir de fontes renováveis; outras precisarão de planos de baixo custo. Portanto, as empresas terão de personalizar suas marcas para pequenos segmentos de clientes. Essa personalização em massa, e o potencial para relacionamento individualizado, já existe em setores como o de telefonia celular. [...] 
Por essa matéria nota-se uma mudança de paradigma para o negócio das empresas de energia elétrica. Assim, perguntas como "quanto é o custo do desgaste da imagem de uma empresa causada por uma interrupção de energia, seja ela programada ou acidental”, tornam-se latentes. O grande problema é que a marca de uma empresa é constituída por valores tangíveis e intangíveis (PINHO, 1996). Os intangíveis ${ }^{3}$ são os mais difíceis de serem avaliados ou mensurados. Assim, surgem conceitos como o Brand Equity, que segundo Aaker (1998) são conjuntos de ativos e passivos ligados a uma marca, seu nome e seu símbolo, que se somam ou se subtraem do valor proporcional por um produto ou serviço para uma empresa e / ou para os consumidores. Ainda segundo Aaker, tem como pilares 5 grandes categorias: lealdade à marca, conhecimento do nome, qualidade percebida, associação à marca em acréscimo à qualidade percebida e outros ativos do proprietário da marca (patentes, trademarks, etc).

A marca cria um valor econômico para a empresa, e esta por ser intangível, podem ter vida útil infinita e podendo criam barreiras emocionais e filosóficas contra a concorrência, bem como uma vantagem competitiva sustentável de longo prazo (NUNES, 2003).

O grande trabalho é efetuar a avaliação econômica da marca. Atualmente, grandes consultorias são contratadas para efetuarem estas avaliações para as grandes corporações. Em linhas básicas elas efetuam a avaliação com base nos custos, no mercado, nos lucros ou ainda no método do uso econômico (NUNES e HAIGH, 2003).

A título de exemplo, Souza cita (SOUZA, 1993) que a marca Coca-Cola pode valer US\$24,4 bilhões, enquanto a Pepsi-Cola vale US\$ 9,6 bilhões. Esses valores são destoantes se associados ao faturamento anual de cada empresa, US\$ 8,4 bilhões no caso da Coca-Cola, e US\$ 5,5 bilhões no caso da Pepsi-Cola.

Analisando agora as marcas de empresas brasileiras, têm-se os seguintes valores (http://www.brandfinance.com/Uploads/pdfs/BrazilMVBrands06.pdf):

Petrobrás - R\$ 9,24 bilhões;

Ambev - R\$ 6,68 bilhões;

Banco do Brasil - R \$ 4,51 bilhões;

Gerdau - R\$ 1,29 bilhões;

Submarino - R\$ 0,27 bilhões.

\footnotetext{
${ }^{3}$ Intangíveis: Economia: Diz-se de bens que não têm existência física, que não podem ser tocados.
} 
Diante destes números, com certeza é necessário que exista uma preocupação com a marca da empresa, que não é necessariamente apenas o logotipo, mas sim tudo o que ela representa, como credibilidade, sistema de operação e estabilidade financeira. 


\section{PROPOSTA DE METODOLOGIA DE APURAÇÃO DE CUSTOS E APLICAÇÃO EM CASOS REAIS}

\subsection{Proposta de Metodologia para Apuração de Custos}

Diante do problema exposto, fica a questão de quanto custam realmente os problemas causados pelas interrupções de energia elétrica, sobretudo quando analisados sob o enfoque dos custos decorrentes de descargas atmosféricas em sistemas de distribuição de energia.

A Figura 26 apresenta o fluxo da metodologia de análise de ocorrência proposto para determinação dos custos decorrentes de descargas atmosféricas em sistemas de distribuição de energia.

A primeira etapa consiste em correlacionar os desligamentos da rede de distribuição com a incidência de descargas atmosféricas, sejam essas descargas diretas ou indiretas (próximas à rede elétrica). Os dados da RINDAT são muito importantes para se efetuar a correlação entre o desligamento da rede e as descargas atmosféricas. A precisão das informações de tempo da RINDAT e do sistema de gerenciamento de ocorrências é de vital importância para o estudo da correlação da descarga atmosférica com as anomalias que esta venha a provocar na rede de distribuição.

A segunda etapa consiste em apurar os danos ou anomalias causados na rede de distribuição e contabilizá-los, sendo os mais habituais:

o em épocas de tempestade, é muito comum ocorrerem desligamentos dos alimentadores ou de trecho deles sem que haja uma causa visível, mesmo com uma vistoria das equipes de manutenção ao longo da rede de distribuição. Assim, estes desligamentos acabam geralmente sendo classificados como causados por descargas atmosféricas, ou como no jargão da concessionária, “percorrido e nada encontrado”. Para estes casos, faz-se necessário o rearme do disjuntor ou religador automático ou das seccionadoras dos alimentadores;

o danos em transformadores e conseqüente substituição;

o danos nos pára-raios e conseqüente substituição;

o rompimento de condutores e conseqüente substituição ou reparo;

o danos em isoladores e conseqüente substituição;

o danos em bancos de capacitores e conseqüente substituição. 
Após a determinação do(s) trecho(s) e período(s) interrompido(s), a terceira etapa consiste em se apurar o custo da energia não vendida. Para cada trecho(s), apurar os consumidores de baixa tensão e os de média tensão. Através do cadastro de faturamento da empresa, obter o consumo médio do horário em que cada cliente foi afetado pela interrupção. Pelo perfil do cliente e tipo de tarifação em que o mesmo está enquadrado (baixa tensão ou média tensão horo-sazonal), é possível determinar o valor monetário da energia que deixou de ser vendida.

A quarta etapa consiste na determinação dos custos de mão-de-obra envolvidos diretamente com o atendimento à ocorrência, como custo da equipe para localizar o defeito e o custo da equipe para efetuar os reparos de modo a restabelecer o fornecimento de energia elétrica.

A quinta etapa consiste em se determinar os custos dos equipamentos ou materiais substituídos para o reparo. Em algumas concessionárias, os custos da quarta e quinta etapas podem estar unificados através da UPS (unidade padrão de serviço), cabendo então verificar quais seriam, em cada caso, os valores que não estariam implícitos quando da utilização da UPS para então poder contabilizá-los.

A contabilização de toda a equipe envolvida de forma indireta no atendimento à ocorrência também é necessária para o estudo. Valores como o custo proporcional do “Call Center”, do centro de operações, custos com a equipe técnica, custo de estocagem dos equipamentos e materiais e outros custos administrativos têm características distintas em cada concessionária. O apontamento desses valores corresponde à sexta etapa.

Para a sétima etapa, a análise não será possível logo após a ocorrência, sendo necessárias algumas semanas, pois se trata dos PIDs correlacionados à ocorrência. Estes PIDs somente serão gerados quando houver o retorno da energia elétrica e se o consumidor se sentir lesado por algum dano que possa ter advindo da falta de energia elétrica, do qual a concessionária não consiga se isentar.

Custear a depreciação da imagem da empresa é a oitava etapa. A estimativa do custo correspondente deve ser feita após a definição de critérios de contabilização pela própria concessionária de energia elétrica. 


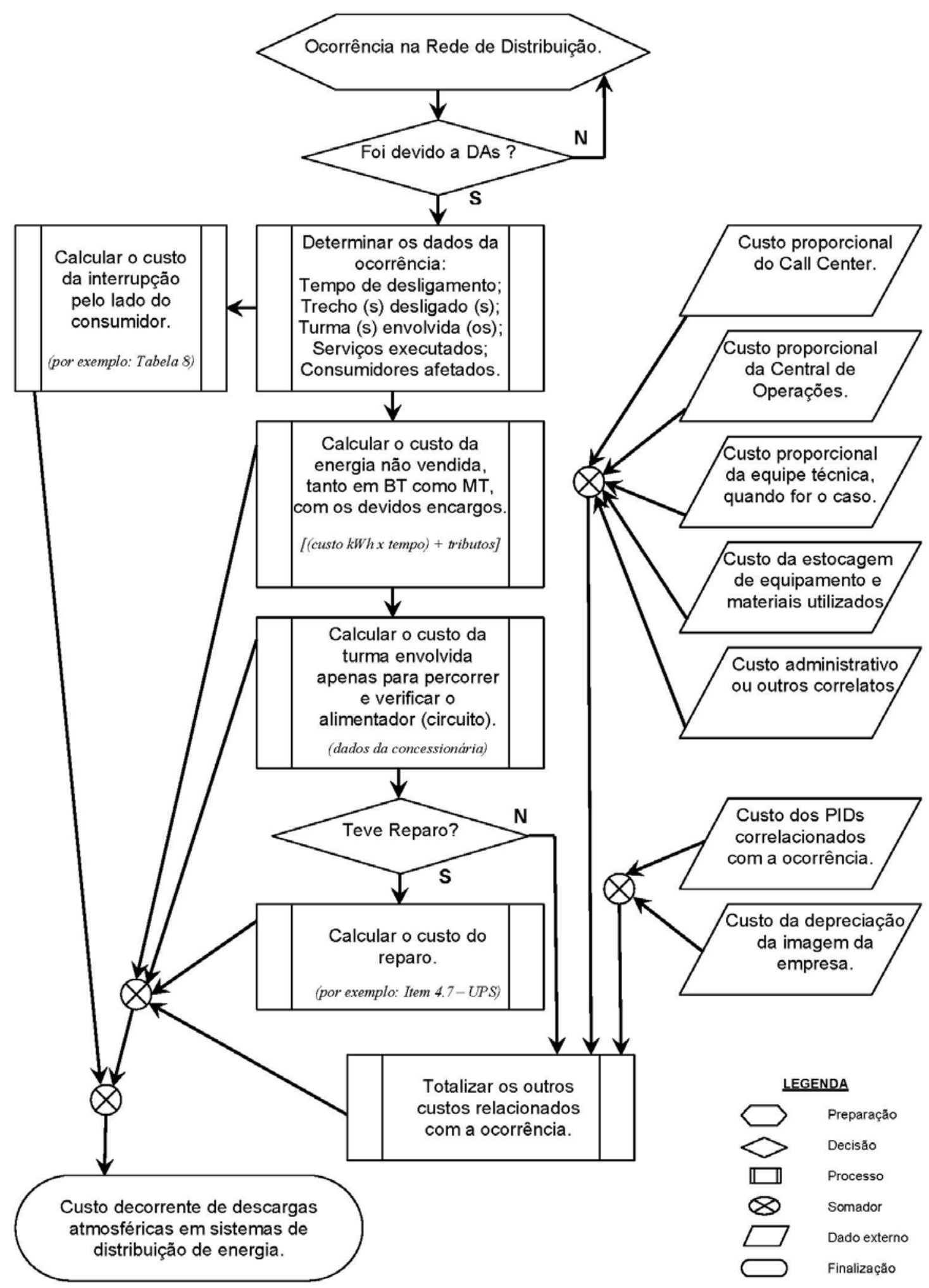

Figura 26 - Fluxograma correspondente à metodologia proposta para determinação dos custos decorrentes de descargas atmosféricas em sistemas de distribuição de energia. 
Determinar o custo pelo lado do consumidor é de extrema importância para se avaliar e, eventualmente, comparar com os custos do lado da concessionária de energia elétrica. Para se contabilizar este custo é necessário determinar os custos de produção parada, venda não ocorrida, perda de lazer e produtos deteriorados, dentre outros já relacionados no Capítulo 2. Contudo, a determinação desses valores encontra dificuldades, como a necessidade de preenchimento de questionário pelo cliente, que normalmente não tem como associar que a parada na empresa foi decorrente de uma descarga atmosférica, ou avaliar o custo de forma precisa, especialmente os itens subjetivos ou indiretos como o valor do lazer. A melhor forma de se determinar o custo pelo lado do consumidor, apesar de ser um valor médio do estado de São Paulo, é através da utilização da Tabela 8 apresentada no Capítulo 2, ponderando-se pelo tipo de consumidor do alimentador.

Analisando-se as etapas, nota-se a necessidade de informações de vários setores dentro da concessionária e que eventualmente podem não estar disponibilizados em uma área comum. Assim, para a aplicação da metodologia, é necessário envolver os setores, para que os mesmos se sensibilizem quanto à importância, veracidade e precisão dos dados. Desta forma, quanto maior for a quantidade e qualidade das informações, mais realista será o valor do custo obtido. Com esta proposta de metodologia para o levantamento do custo é possível avaliar o ônus causado pelas descargas atmosféricas em sistemas de distribuição e assim estudar e propor tecnologias para minimizar os danos causados por este fenômeno, bem como confrontar os custos de implementação dessas tecnologias com aqueles decorrentes de descargas atmosféricas.

\subsection{Considerações Gerais Aplicadas aos Casos Reais}

Para a aplicação da metodologia proposta, foram utilizadas ocorrências reais da Eletropaulo Metropolitana Eletricidade de São Paulo S/A (AES ELETROPAULO), maior distribuidora de energia elétrica do estado de São Paulo.

Para o estudo foram selecionadas três ocorrências na rede de distribuição do dia 30/01/2006, data em que se registrou o maior número de ocorrências na rede de distribuição de energia elétrica da concessionária em questão, e que apresentou o maior número de descargas atmosféricas. No dia da ocorrência, das 16 h00min até as $22 \mathrm{~h} 00 \mathrm{~min}$ foram registradas pelo SIMEPAR aproximadamente 800 descargas atmosféricas, com magnitudes na faixa de $6 \mathrm{kA} \mathrm{a}$ $80 \mathrm{kA}$. 
Objetivando ilustrar os pontos de queda das descargas atmosféricas, os mesmos foram plotados utilizando-se o padrão Grid UTM (Universal Transverse Mercator - Projeção Universal Transversal de Mercator), ou projeção de Mercator ou ainda projeção UTM como é conhecido. Este sistema foi apresentado em 1569 pelo geógrafo e cartógrafo flamengo Gerhard Kremer (de sobrenome latino Gerardus Mercator). O sistema de referencial de localização terrestre é baseado em coordenadas métricas definidas para cada uma das 60 zonas UTM, múltiplas de 6 graus de longitude. Em latitude este sistema de localização é limitado pelos paralelos $84^{\circ} \mathrm{N}$ e $80^{\circ} \mathrm{S}$, devido à quase inexistência de deformação. Por este sistema o estado de São Paulo está totalmente coberto pelas zonas $22 \mathrm{~K}$ e $23 \mathrm{~K}$, como se observa pela Figura 27.

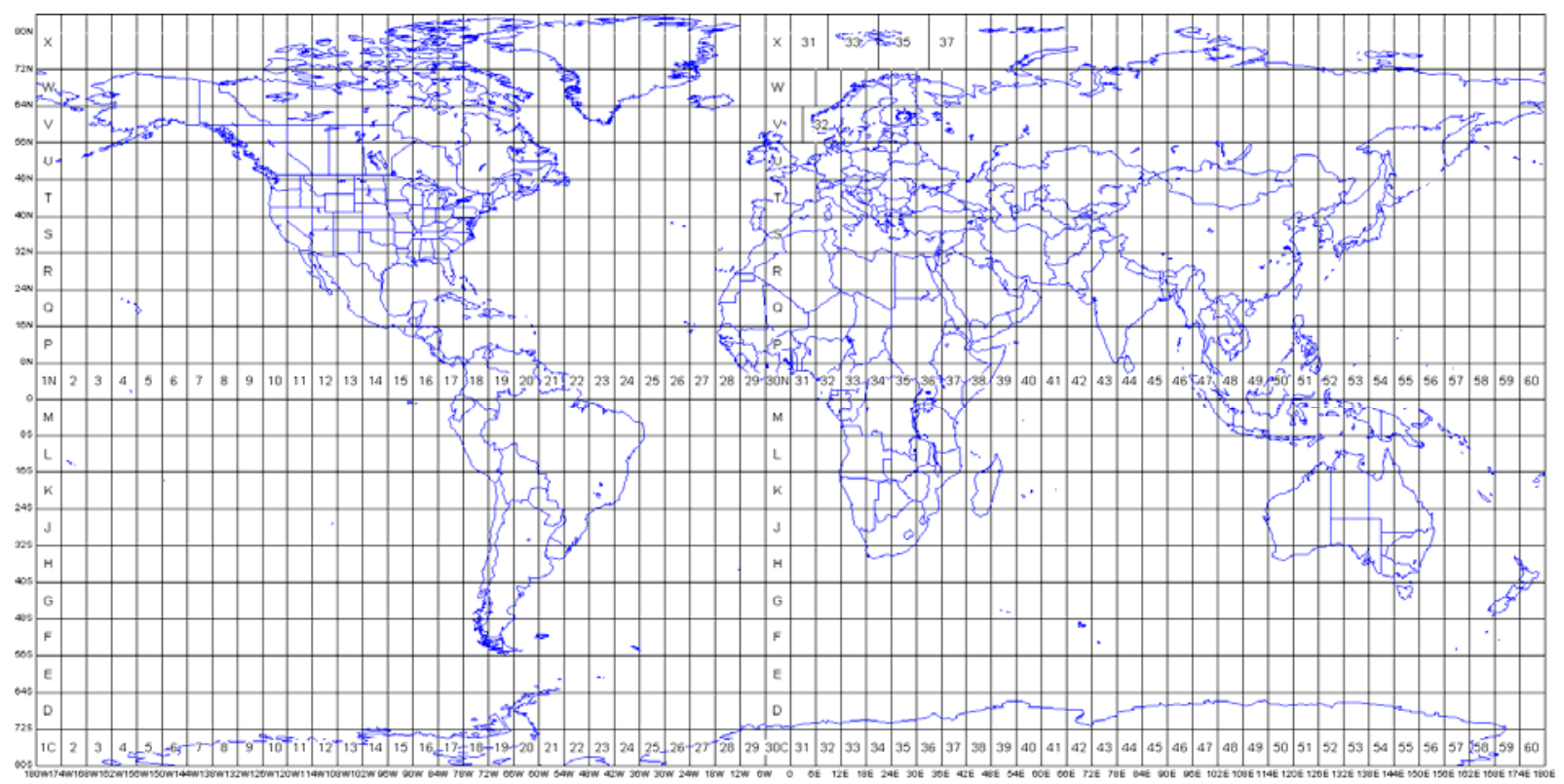

Figura 27 - Mapa ilustrativo com as projeções UTM no mundo.

Fonte: (MORTON, A., 2007). 
As considerações a seguir discriminadas foram utilizadas para os estudos em questão:

a) custo de deslocamento médio de uma equipe com 2 homens em um veículo dotado de sistema de comunicação, cesta aérea para serviços em redes energizadas, equipamentos e materiais para atendimento de ocorrências na rede de distribuição, estimado em R\$ 40,00 por hora (informação verbal) ${ }^{4}$;

b) valores de UPS - Unidade Padrão de Serviço (informação verbal) ${ }^{5}$ :

valor médio em reais de $01 \mathrm{UPS}=\mathrm{R} \$ 26,00$;

substituição de transformador: 10 UPS ou R\$ 260,00;

substituição de pára-raios: 03 UPS ou R\$ 78,00;

substituição / emenda em cabos: 01 UPS por metro ou R\$26,00 por metro;

substituição de cruzetas com isoladores: 4,5 UPS ou R\$ 117,00;

c) custo médio de aquisição de um transformador de 150 kVA (informação pessoal) ${ }^{6}$;

$\mathrm{R} \$ 9.500,00$ :

d) custo médio de reforma (reparo) de transformador de $150 \mathrm{kVA}$ (informação verbal) ${ }^{7}$;

substituição de enrolamento;

$\mathrm{R} \$ 4.800,00$;

e) custo da energia elétrica em baixa tensão:

consumo: $\mathrm{R} \$ 0,29906$ / kWh;

\footnotetext{
${ }^{4}$ Fornecida em reunião na Eletropaulo Metropolitana Eletricidade de São Paulo S/A em novembro de 2006.

${ }^{5}$ Obtida junto à Start Engenharia e Eletricidade Ltda em novembro de 2006.

${ }^{6}$ Fornecida pela A.Cabine Materiais Elétricos Ltda. Mensagem recebida por e-mail em novembro de 2006.

${ }^{7}$ Obtida junto à Trafo Equipamento Elétricos S/A em novembro de 2006.
} 
f) custo da energia elétrica em média tensão:

tarifa azul;

período úmido;

$>$ demanda na ponta: $\quad \mathrm{R} \$ 32,24 / \mathrm{kW}$;

$>$ demanda fora da ponta: $\mathrm{R} \$ 9,16 / \mathrm{kW}$;

> consumo na ponta: $\quad \mathrm{R} \$ 0,21737$ / kWh;

$>$ consumo fora da ponta: $\quad \mathrm{R} \$ 0,11782$ / kWh;

g) valor dos tributos federal PIS (Programa de Integração Social) e COFINS (Contribuição para o Financiamento da Seguridade Social) aplicados sobre a conta de energia elétrica, conjuntamente:

(fonte:http://www.eletropaulo.com.br/portal/page.cfm?Conteudo_ID=668\&desc=Impostos\%20e\%20outros\%20encargos )

em janeiro de 2006, PIS/COFINS = 5,5892\%;

h) valor do ICMS (Imposto sobre Circulação de Mercadorias e Prestação de Serviços), aplicado na conta de energia elétrica, no estado de São Paulo:

25\% para os consumidores de baixa tensão residencial;

$18 \%$ para os demais casos;

i) tarifas ajustadas conforme alíquotas de ICMS e PIS/COFINS:

$$
\text { Tarifa com tributos }=\frac{\text { Tarifa publicada }}{[1-(\text { ICMS }+ \text { PIS / COFINS })]}
$$


Baixa Tensão: ICMS = 25\% e PIS/COFINS = 5,5892\%

o consumo: $\quad \mathrm{R} \$ 0,43086$ / $\mathrm{kWh}$;

Baixa Tensão: ICMS = 18\% e PIS/COFINS = 5,5892\%

o consumo: $\quad \mathrm{R} \$ 0,39138 / \mathrm{kWh}$;

Média Tensão: ICMS = 18\% e PIS/COFINS = 5,5892\%

o demanda na ponta: $\quad \mathrm{R} \$ 42,19$ / $\mathrm{kW}$;

o demanda fora da ponta: $\mathrm{R} \$ 11,99 / \mathrm{kW}$;

o consumo na ponta: $\quad \mathrm{R} \$ 0,28448 / \mathrm{kWh}$;

o consumo fora da ponta: $\quad \mathrm{R} \$ 0,15419 / \mathrm{kWh}$;

j) os consumidores foram divididos nas seguintes categorias:

j1) residencial:

Baixa Tensão com ICMS de 25\%;

j2) comercial:

Baixa Tensão com ICMS de 18\%;

Média Tensão com ICMS de 18\%;

j3) industrial;

Baixa Tensão com ICMS de 18\%

Média Tensão com ICMS de 18\%;

j4) outros (exemplo: prédios do governo, etc.);

Baixa Tensão com ICMS de 18\%.

k) os valores do consumo médio informados correspondem ao valor médio mensal do alimentador de cada estudo. Assim, para se analisar o consumo horário, dividir-se-á o valor por 30 dias, e este por 24 horas, obtendo-se conseqüentemente, o "custo médio" horário; 
l) para a obtenção de uma ordem de grandeza para efeitos comparativos dos custos, os valores foram convertidos para dólar americano com a cotação comercial de venda do dia 30/01/2006 de US\$ $1.00=\mathrm{R} \$ 2,216$;

m) haja vista a inexistência de valor conhecido do custo da imagem, ou de informações que pudessem levar aos valores que poderiam ser estudados, este item foi desconsiderado nestas simulações;

n) os valores de custo correlatos como Call Center, Central de Operações, custo de estocagem, entre outros, mencionados no Capítulo 4, também não foram considerados devido à inexistência de dados;

o) os dados referentes ao PID foram contabilizados em novembro de 2006, garantindo-se assim a inexistência de pendência referente à data em estudo. 


\subsection{Aplicação da metodologia ao Caso A}

O primeiro caso a ser analisado (Caso A) se refere à Figura 28, que apresenta a região do alimentador afetado e o ponto correspondente ao disjuntor que atuou, bem como os pontos de incidência de descargas atmosféricas em um intervalo de tempo de 20 minutos (10 minutos antes e 10 depois) do instante de atuação do equipamento de proteção, neste caso o disjuntor.

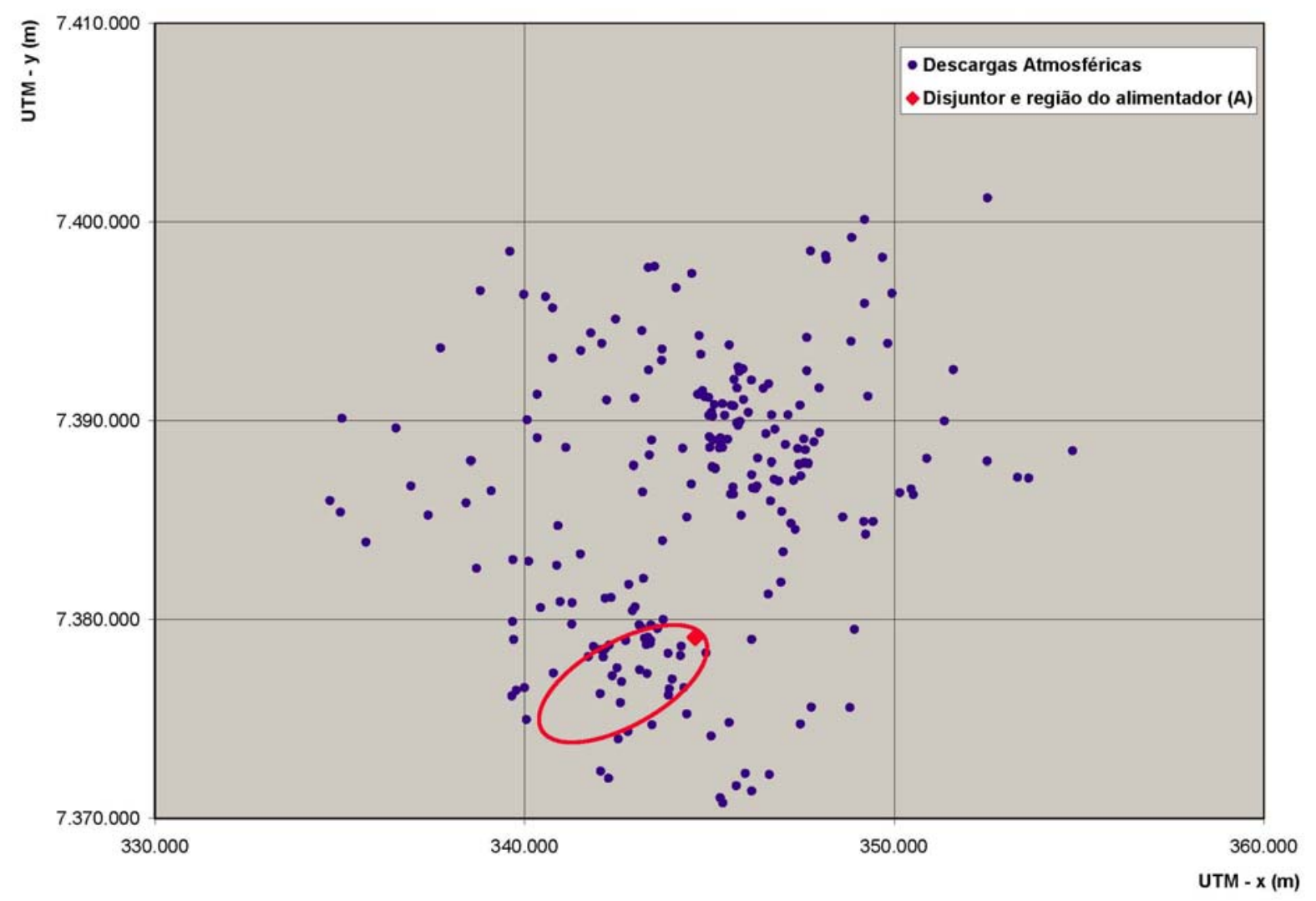

Figura 28 - Distribuição das descargas atmosféricas na região do alimentador analisado no Caso A. Fonte: (Eletropaulo Metropolitana Eletricidade de São Paulo S.A. - dados trabalhados pelo autor). 


\section{Os dados relativos ao Caso A são os seguintes:}

horário de início da ocorrência: 17h28min;

horário de término da ocorrência: 23h32min;

$>$ duração total da ocorrência: 6,07 horas;

$>$ consumidores residenciais:

o consumo médio mensal: 1.640.702 kWh;

o quantidade de consumidores:

baixa tensão: 9.712 (100\%);

consumidores comerciais:

o consumo médio mensal: $125.781 \mathrm{kWh}$;

o quantidade de consumidores:

> baixa tensão: 312 (85\%);

média tensão: 55 (15\%);

consumidores industriais:

o consumo médio mensal: 165.378 kWh;

o quantidade de consumidores:

> baixa tensão: 2 (5\%);

média tensão: 30 (95\%);

consumidores outros (exemplo: prédio do governo, etc.):

o consumo médio mensal: 201.370 kWh;

o quantidade de consumidores:

baixa tensão: 28 (100\%).

quantidade de PIDs relacionados a esta ocorrência: 04;

valor ressarcido pelos PIDs: R\$ 824,00;

quantidade de turmas utilizadas para o atendimento desta ocorrência:

o 01 turma para primeiro atendimento e para percorrer o alimentador;

o 02 turmas para executar os serviços;

Serviços executados:

o substituição de 01 transformador (com possibilidade de reparo);

o substituição de 02 pára-raios;

o reparo em 300 m de cabo rompido;

o substituição de 02 cruzetas com isoladores danificados. 
Cálculo da energia não vendida:

consumo médio residencial:

$$
\frac{1.640 .702 \mathrm{kWh}}{1 \times 24 \times 30 \text { horas }}=2.278,75 \frac{\mathrm{kWh}}{\mathrm{h}}
$$

o $100 \%$ está em baixa tensão $=2.278,75 \frac{k W h}{h}$

consumo médio comercial:

$$
\frac{125.781 \mathrm{kWh}}{1 \times 24 \times 30 \text { horas }}=174,69 \frac{\mathrm{kWh}}{\mathrm{h}}
$$

o $\quad 85 \%$ está em baixa tensão $=148,49 \frac{k W h}{h}$

o $15 \%$ está em média tensão $=26,20 \frac{k W h}{h}$

consumo médio industrial:

$$
\frac{165.378 k W h}{1 \times 24 \times 30 \text { horas }}=229,69 \frac{k W h}{h}
$$

o $\quad 05 \%$ está em baixa tensão $=11,48 \frac{k W h}{h}$

o $95 \%$ está em média tensão $=218,21 \frac{k W h}{h}$

consumo médio outros:

$$
\frac{201.370 \mathrm{kWh}}{1 \times 24 \times 30 \text { horas }}=279,68 \frac{\mathrm{kWh}}{\mathrm{h}}
$$

o $100 \%$ está em baixa tensão $=279,68 \frac{k W h}{h}$ 
Energia não vendida em baixa tensão:

Energia não vendida $=($ tarifa com ICMS + PIS $/$ COFINS $) \times$ tempo $\times$ consumo por hora

o Residencial com ICMS 25\%:

$\frac{R \$ 0,43086}{k W h} \times 6,07$ horas $\times \frac{2.278,75 k W h}{h}=R \$ 5.959,60$

o Comercial (ICMS 18\%):

$\frac{R \$ 0,39138}{k W h} \times 6,07$ horas $\times \frac{148,49 k W h}{h}=R \$ 352,77$

o Industrial (ICMS 18\%):

$\frac{R \$ 0,39138}{k W h} \times 6,07$ horas $\times \frac{11,48 k W h}{h}=R \$ 27,27$

o Outros (ICMS 18\%):

$\frac{R \$ 0,39138}{k W h} \times 6,07$ horas $\times \frac{279,68 k W h}{h}=R \$ 664,43$

Energia não vendida em média tensão:

o a ocorrência teve:

> 3,00 horas de duração no horário de ponta;

3,07 horas fora do horário de ponta;

o considerado valor de demanda igual ao consumo instantâneo;

o todas as tarifas com encargos de ICMS e PIS/COFINS;

$(R \$$ demanda na ponta $\times$ demanda na ponta $)+$

$+(R \$$ demanda fora da ponta $\times$ demanda fora da ponta $)+$

$+(R \$$ consumo na ponta $\times$ tempo na ponta $\times$ consumo na ponta $)+$

$+(R \$$ consumo fora da ponta $\times$ tempo fora da ponta $\times$ consumo fora da ponta $)=$

$=$ Custo $(R \$)$ da energia não vendida 
o Comercial (ICMS 18\%):

$$
\begin{aligned}
& \left(\frac{R \$ 42,19}{k W} \times 26,20 k W\right)+ \\
& +\left(\frac{R \$ 11,99}{k W} \times 26,20 k W\right)+ \\
& +\left(\frac{R \$ 0,28448}{k W h} \times 3,00 \text { horas } \times \frac{26,20 k W h}{h}\right)+ \\
& +\left(\frac{R \$ 0,15419}{k W h} \times 3,07 \text { horas } \times \frac{26,20 k W h}{h}\right)= \\
& =R \$ 1.454,54
\end{aligned}
$$

o Industrial (ICMS 18\%):

$$
\begin{aligned}
& \left(\frac{R \$ 42,19}{k W} \times 218,21 k W\right)+ \\
& +\left(\frac{R \$ 11,99}{k W} \times 218,21 k W\right)+ \\
& +\left(\frac{R \$ 0,28448}{k W h} \times 3,00 \text { horas } \times \frac{218,21 k W h}{h}\right)+ \\
& +\left(\frac{R \$ 0,15419}{k W h} \times 3,07 \text { horas } \times \frac{218,21 k W h}{h}\right)= \\
& =R \$ 12.112,16
\end{aligned}
$$

Total de energia não vendida:

o $\quad$ Residencial $=\mathrm{A} 01$

$$
\mathrm{R} \$ 5.959,60 \text {; }
$$

o Comercial $=\mathrm{A} 02+\mathrm{A} 05$

$$
\mathrm{R} \$ 352,77+\mathrm{R} \$ 1.454,54=\mathrm{R} \$ 1.807,31
$$

o $\quad$ Industrial $=\mathrm{A} 03+\mathrm{A} 06$

$$
\mathrm{R} \$ 27,27+\mathrm{R} \$ 12.112,16=\mathrm{R} \$ 12.139,44
$$

o $\quad$ Outros $=\mathrm{A} 04$

$$
\mathrm{R} \$ 664,43
$$

Custo Total da energia não vendida: A07 + A08 + A09 + A10

$$
\text { o } \quad \mathrm{R} \$ 20.570,79
$$


Cálculo da mão-de-obra e dos serviços executados:

Custo de deslocamento da equipe para localizar defeito e acompanhar serviço:

o Tempo x custo por hora

o $6,07 \times \mathrm{R} \$ 40,00=\mathrm{R} \$ 242,80$

Custo de substituição do transformador:

o UPS do serviço $x$ quantidade

o $\mathrm{R} \$ 260,00 \times 01=\mathrm{R} \$ 260,00$

Custo de substituição do pára-raio:

o UPS do serviço $x$ quantidade

o $\mathrm{R} \$ 78,00 \times 02=\mathrm{R} \$ 156,00$

Custo de reparo em cabo rompido:

o UPS do serviço $x$ metragem

o $\mathrm{R} \$ 26,00 \times 300 \mathrm{~m}=\mathrm{R} \$ 7.800,00$

Custo de substituição de cruzetas e isoladores danificados:

o UPS do serviço x quantidade

o $\mathrm{R} \$ 117,00 \times 02=\mathrm{R} \$ 234,00$

Custo Total da mão-de-obra e dos serviços executados:

$\mathrm{o} \quad \mathrm{A} 12+\mathrm{A} 13+\mathrm{A} 14+\mathrm{A} 15+\mathrm{A} 16$

o $\mathrm{R} \$ 8.692,80$.

Custo dos PIDs relacionados: R\$ 824,00

Custo de reparo do transformador: $\mathrm{R} \$ 4.800,00$ 
Total da interrupção devido à descarga atmosférica pelo lado da oferta ou concessionária:

$\mathrm{A} 11+\mathrm{A} 17+\mathrm{A} 18+\mathrm{A} 19$

$\mathrm{R} \$ 20.570,79+\mathrm{R} \$ 8.692,80+\mathrm{R} \$ 824,00+\mathrm{R} \$ 4.800,00$

$\mathrm{R} \$ 34.887,59$ (US\$ 15,743.49)

Cálculo do custo pelo lado da demanda ou do consumidor:

Utilizando-se a metodologia apresentada por Magalhães et al. (2001) no Capítulo 2, Tabela 8, obtêm-se o valor de:

6,07 horas $\times\left[\left(\frac{2.278775 W}{h} \times 0,90 \frac{U S \$}{k W}\right)+\left(\times\left[\frac{(174,70+279,68) k W}{h}\right] \times 1,70 \frac{U S \$}{k W}\right)+\left(\frac{229,69 k W}{h} \times 5,30 \frac{U S \$}{k W}\right)\right] \times 2,216 \frac{R \$}{U S \$}$

$R \$ 54.351,71(U S \$ 24,526.95)$

(A21)

Custo total da interrupção: “custo oferta” + “custo demanda” = A20 + A21

$R \$ 34.887,59+R \$ 54.351,71=R \$ 89.239,30$ (US\$ 40,270.44) 


\subsection{Aplicação da metodologia ao Caso B}

O segundo caso a ser analisado (Caso B) se refere à Figura 29, que apresenta a região do alimentador afetado e o ponto correspondente ao disjuntor que atuou, bem como os pontos de incidência de descargas atmosféricas em um intervalo de tempo de 20 minutos (10 minutos antes e 10 depois) do instante de atuação do equipamento de proteção, neste caso o disjuntor.

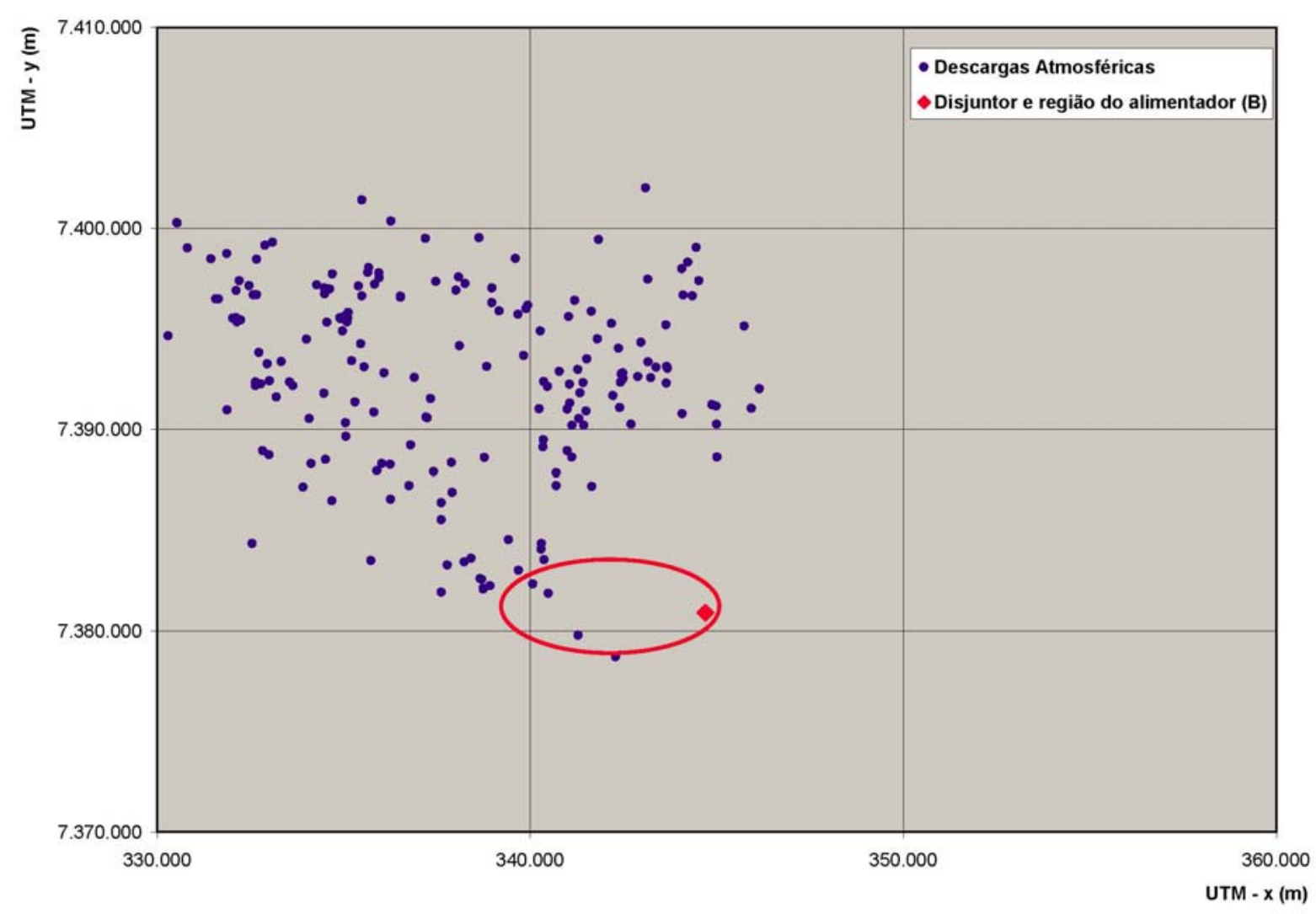

Figura 29 - Distribuição das descargas atmosféricas na região do alimentador analisado no Caso B. Fonte: (Eletropaulo Metropolitana Eletricidade de São Paulo S.A. - dados trabalhados pelo autor). 


\section{Os dados relativos ao Caso B são os seguintes:}

> horário de início da ocorrência: 17h10min;

> horário de término da ocorrência: 20h49min;

> duração total da ocorrência: 3,65 horas;

$>$ consumidores residenciais:

o consumo médio mensal: 590.380 kWh;

o quantidade de consumidores:

baixa tensão: 2.824 (100\%);

consumidores comerciais:

o consumo médio mensal: $525.121 \mathrm{kWh}$;

o quantidade de consumidores:

> baixa tensão: 294 (90\%);

> média tensão: 33 (10\%);

consumidores industriais:

o consumo médio mensal: 110.392 kWh;

o quantidade de consumidores:

$>$ baixa tensão: 2 (10\%);

$>$ média tensão: 20 (90\%);

consumidores outros (exemplo: prédio do governo, etc.):

o consumo médio mensal: 7.655 kWh;

o quantidade de consumidores:

baixa tensão: 12 (100\%).

quantidade de PIDs relacionados a esta ocorrência: 01;

valor ressarcido pelos PIDs: R\$ 422,00;

quantidade de turmas utilizadas para o atendimento desta ocorrência:

o 01 turma para primeiro atendimento e para percorrer o alimentador;

o 01 turma para executar os serviços;

Serviços executados:

o substituição de 01 transformador (perda total);

o substituição de 01 cruzeta com isoladores danificados. 
Cálculo da energia não vendida:

consumo médio residencial:

$$
\frac{590.380 \mathrm{kWh}}{1 \times 24 \times 30 \text { horas }}=819,97 \frac{\mathrm{kWh}}{\mathrm{h}}
$$

o $\quad 100 \%$ está em baixa tensão $=819,97 \frac{k W h}{h}$

consumo médio comercial:

$$
\frac{525.121 \mathrm{kWh}}{1 \times 24 \times 30 \text { horas }}=729,33 \frac{\mathrm{kWh}}{\mathrm{h}}
$$

o $90 \%$ está em baixa tensão $=656,40 \frac{k W h}{h}$

o $\quad 10 \%$ está em média tensão $=72,93 \frac{k W h}{h}$

consumo médio industrial:

$$
\frac{110.392 \mathrm{kWh}}{1 \times 24 \times 30 \text { horas }}=153,32 \frac{\mathrm{kWh}}{\mathrm{h}}
$$

o $10 \%$ está em baixa tensão $=15,33 \frac{k W h}{h}$
o $90 \%$ está em média tensão $=137,99 \frac{k W h}{h}$

consumo médio outros:

$$
\frac{7.655 k W h}{1 \times 24 \times 30 \text { horas }}=10,63 \frac{k W h}{h}
$$

o $\quad 100 \%$ está em baixa tensão $=10,63 \frac{k W h}{h}$ 
Energia não vendida em baixa tensão:

Energia não vendida $=($ tarifa com ICMS + PIS $/$ COFINS $) \times$ tempo $\times$ consumo por hora

o Residencial com ICMS 25\%:

$\frac{R \$ 0,43086}{k W h} \times 3,65$ horas $\times \frac{819,97 k W h}{h}=R \$ 1.289,51$

o Comercial (ICMS 18\%):

$\frac{R \$ 0,39138}{k W h} \times 3,65$ horas $\times \frac{656,40 k W h}{h}=R \$ 937,70$

o Industrial (ICMS 18\%):

$\frac{R \$ 0,39138}{k W h} \times 3,65$ horas $\times \frac{15,33 k W h}{h}=R \$ 21,90$

o Outros (ICMS 18\%):

$\frac{R \$ 0,39138}{k W h} \times 3,65$ horas $\times \frac{10,63 k W h}{h}=R \$ 15,19$

Energia não vendida em média tensão:

o a ocorrência teve:

> 3,00 horas de duração no horário de ponta;

0,65 horas fora do horário de ponta;

o considerado valor de demanda igual ao consumo instantâneo;

o todas as tarifas com encargos de ICMS e PIS/COFINS;

$(R \$$ demanda na ponta $\times$ demanda na ponta $)+$

$+(R \$$ demanda fora da ponta $\times$ demanda fora da ponta $)+$

$+(R \$$ consumo na ponta $\times$ tempo na ponta $\times$ consumo na ponta $)+$

$+(R \$$ consumo fora da ponta $\times$ tempo fora da ponta $\times$ consumo fora da ponta $)=$

$=$ Custo $(R \$)$ da energia não vendida 
o Comercial (ICMS 18\%):

$$
\begin{aligned}
& \left(\frac{R \$ 42,19}{k W} \times 72,93 k W\right)+ \\
& +\left(\frac{R \$ 11,99}{k W} \times 72,93 k W\right)+ \\
& +\left(\frac{R \$ 0,28448}{k W h} \times 3,00 \text { horas } \times \frac{72,93 k W h}{h}\right)+ \\
& +\left(\frac{R \$ 0,15419}{k W h} \times 0,65 \text { horas } \times \frac{72,93 k W h}{h}\right)= \\
& =R \$ 4.021,15
\end{aligned}
$$

o Industrial (ICMS 18\%):

$$
\begin{aligned}
& \left(\frac{R \$ 42,19}{k W} \times 137,99 k W\right)+ \\
& +\left(\frac{R \$ 11,99}{k W} \times 137,99 k W\right)+ \\
& +\left(\frac{R \$ 0,28448}{k W h} \times 3,00 \text { horas } \times \frac{137,99 k W h}{h}\right)+ \\
& +\left(\frac{R \$ 0,15419}{k W h} \times 0,65 \text { horas } \times \frac{137,99 k W h}{h}\right)= \\
& =R \$ 7.608,01
\end{aligned}
$$

Total de energia não vendida:

o $\quad$ Residencial $=$ B01

$$
\mathrm{R} \$ 1.289,51 ;
$$

o Comercial $=$ B02 + B05

$$
\mathrm{R} \$ 937,70+\mathrm{R} \$ 4.021,15=\mathrm{R} \$ 4.958,85
$$

o $\quad$ Industrial $=$ B03 + B06

$\mathrm{R} \$ 21,90+\mathrm{R} \$ 7.608,01=\mathrm{R} \$ 7.629,91 ;$

o $\quad$ Outros $=$ B04

$$
\mathrm{R} \$ 15,19
$$

Custo Total da energia não vendida: B07 + B08 + B09 + B10

o $\mathrm{R} \$ 13.893,46$ 
Cálculo da mão-de-obra e dos serviços executados:

Custo de deslocamento da equipe para localizar defeito e acompanhar serviço:

o Tempo x custo por hora

o $3,65 \times \mathrm{R} \$ 40,00=\mathrm{R} \$ 146,00$

Custo de substituição do transformador:

o UPS do serviço $x$ quantidade

o $\mathrm{R} \$ 260,00 \times 01=\mathrm{R} \$ 260,00$

Custo de substituição de cruzetas e isoladores danificados:

o UPS do serviço $x$ quantidade

o $\mathrm{R} \$ 117,00 \times 01=\mathrm{R} \$ 117,00$

Custo Total da mão-de-obra e dos serviços executados:

o $\mathrm{B} 12+\mathrm{B} 13+\mathrm{B} 14$

o R $\$ 523,00$.

Custo dos PIDs relacionados: $\mathrm{R} \$ 422,00$

Custo de aquisição do transformador: R \$ 9.500,00 
Total da interrupção devido à descarga atmosférica pelo lado da oferta ou concessionária:

$\mathrm{B} 11+\mathrm{B} 15+\mathrm{B} 16+\mathrm{B} 17$

$R \$ 13.893,46+R \$ 523,00+R \$ 422,00+R \$ 9.500,00$

$\mathrm{R} \$ 24.338,46$ (US\$ 10,983.06)

Cálculo do custo pelo lado da demanda ou do consumidor:

Utilizando-se a metodologia apresentada por Magalhães et al. (2001) no Capítulo 2, Tabela 8, obtêm-se o valor de:

3,65 horas $\times\left[\left(\frac{819,97 k W}{h} \times 0,90 \frac{U S \$}{k W}\right)+\left(\times\left[\frac{(729,33+10,63) k W}{h}\right] \times 1,70 \frac{U S \$}{k W}\right)+\left(\frac{153,32 k W}{h} \times 5,30 \frac{U S \$}{k W}\right)\right] \times 2,216 \frac{R \$}{U S \$}$

$R \$ 22.716,48$ (US\$ 10,251.12)

Custo total da interrupção: “custo oferta” + “custo demanda” = B18 + B19

$\mathrm{R} \$ \mathbf{2 4 . 3 3 8 , 4 6}+\mathrm{R} \$ 22.716,48=\mathrm{R} \$ \mathbf{4 7 . 0 5 4 , 9 4}(\mathrm{US} \$ 21,234.18)$ 


\subsection{Aplicação da metodologia ao Caso C}

O terceiro caso a ser analisado (Caso C) se refere à Figura 30, que apresenta a região do alimentador afetado e o ponto correspondente ao disjuntor que atuou, bem como os pontos de incidência de descargas atmosféricas em um intervalo de tempo de 20 minutos (10 minutos antes e 10 depois) do instante de atuação do equipamento de proteção, neste caso o disjuntor.

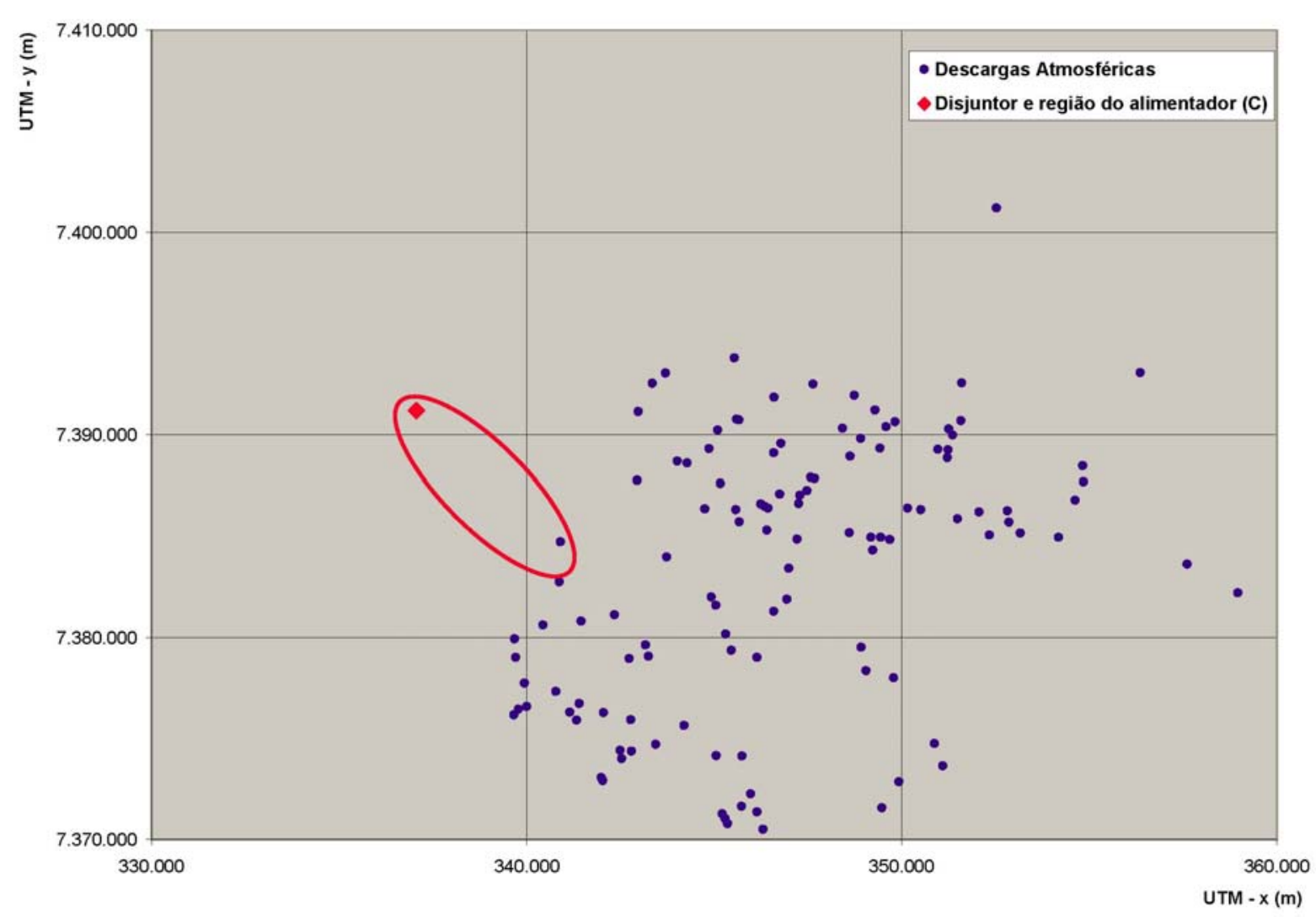

Figura 30 - Distribuição das descargas atmosféricas na região do alimentador analisado no Caso C. Fonte: (Eletropaulo Metropolitana Eletricidade de São Paulo S.A. - dados trabalhados pelo autor). 


\section{Os dados relativos ao Caso C são os seguintes:}

> horário de início da ocorrência: 17h41min;

> horário de término da ocorrência: 19h02min;

$>$ duração total da ocorrência: 1,35 horas;

$>$ consumidores residenciais:

o consumo médio mensal: 1.463.489 kWh;

o quantidade de consumidores:

baixa tensão: 5.780 (100\%);

consumidores comerciais:

o consumo médio mensal: 835.059 kWh;

o quantidade de consumidores:

> baixa tensão: 483 (95\%);

média tensão: 25 (05\%);

consumidores industriais:

o consumo médio mensal: 42.208 kWh;

o quantidade de consumidores:

$>$ baixa tensão: 3 (10\%);

$>$ média tensão: 26 (90\%);

consumidores outros (exemplo: prédio do governo, etc.):

o consumo médio mensal: 4.920 kWh;

o quantidade de consumidores:

baixa tensão: 6 (100\%).

quantidade de PIDs relacionados a esta ocorrência: 01;

valor ressarcido pelos PIDs: R\$ 158,00;

quantidade de turmas utilizadas para o atendimento desta ocorrência:

o 01 turma para primeiro atendimento e para percorrer o alimentador;

Serviços executados:

o Não foi executado nenhum serviço. 
Cálculo da energia não vendida:

consumo médio residencial:

$$
\frac{1.463 .489 \mathrm{kWh}}{1 \times 24 \times 30 \text { horas }}=2.032,62 \frac{\mathrm{kWh}}{\mathrm{h}}
$$

o $100 \%$ está em baixa tensão $=2.032,62 \frac{k W h}{h}$

consumo médio comercial:

$$
\frac{835.059 \mathrm{kWh}}{1 \times 24 \times 30 \text { horas }}=1.159,80 \frac{\mathrm{kWh}}{\mathrm{h}}
$$

o $95 \%$ está em baixa tensão $=1.101,81 \frac{k W h}{h}$

o 05\% está em média tensão = 57,99 $\frac{k W h}{h}$

consumo médio industrial:

$$
\frac{42.208 k W h}{1 \times 24 \times 30 \text { horas }}=58,62 \frac{k W h}{h}
$$

o $10 \%$ está em baixa tensão $=5,86 \frac{k W h}{h}$
o $90 \%$ está em média tensão $=52,76 \frac{k W h}{h}$

consumo médio outros:

$$
\frac{4.920 \mathrm{kWh}}{1 \times 24 \times 30 \text { horas }}=6,83 \frac{\mathrm{kWh}}{\mathrm{h}}
$$

o $100 \%$ está em baixa tensão $=6,83 \frac{k W h}{h}$ 
Energia não vendida em baixa tensão:

Energia não vendida $=($ tarifa com ICMS + PIS $/$ COFINS $) \times$ tempo $\times$ consumo por hora

o Residencial com ICMS 25\%:

$\frac{R \$ 0,43086}{k W h} \times 0,35$ horas $\times \frac{2.032,62 k W h}{h}=R \$ 1.182,28$

o Comercial (ICMS 18\%):

$\frac{R \$ 0,39138}{k W h} \times 0,35$ horas $\times \frac{1.101,81 k W h}{h}=R \$ 582,16$

o Industrial (ICMS 18\%):

$\frac{R \$ 0,39138}{k W h} \times 0,35$ horas $\times \frac{5,86 k W h}{h}=R \$ 3,10$

o Outros (ICMS 18\%):

$\frac{R \$ 0,39138}{k W h} \times 0,35$ horas $\times \frac{6,83 k W h}{h}=R \$ 3,61$

Energia não vendida em média tensão:

o a ocorrência teve:

> 1,00 horas de duração no horário de ponta;

0,35 horas fora do horário de ponta;

o considerado valor de demanda igual ao consumo instantâneo;

o todas as tarifas com encargos de ICMS e PIS/COFINS;

$(R \$$ demanda na ponta $\times$ demanda na ponta $)+$

$+(R \$$ demanda fora da ponta $\times$ demanda fora da ponta $)+$

$+(R \$$ consumo na ponta $\times$ tempo na ponta $\times$ consumo na ponta $)+$

$+(R \$$ consumo fora da ponta $\times$ tempo fora da ponta $\times$ consumo fora da ponta $)=$

$=$ Custo $(R \$)$ da energia não vendida 
o Comercial (ICMS 18\%):

$$
\begin{aligned}
& \left(\frac{R \$ 42,19}{k W} \times 57,99 k W\right)+ \\
& +\left(\frac{R \$ 11,99}{k W} \times 57,99 k W\right)+ \\
& +\left(\frac{R \$ 0,28448}{k W h} \times 1,00 \text { horas } \times \frac{57,99 k W h}{h}\right)+ \\
& +\left(\frac{R \$ 0,15419}{k W h} \times 0,35 \text { horas } \times \frac{57,99 k W h}{h}\right)= \\
& =R \$ 3.161,58
\end{aligned}
$$

o Industrial (ICMS 18\%):

$$
\begin{aligned}
& \left(\frac{R \$ 42,19}{k W} \times 52,76 k W\right)+ \\
& +\left(\frac{R \$ 11,99}{k W} \times 52,76 k W\right)+ \\
& +\left(\frac{R \$ 0,28448}{k W h} \times 1,00 \text { horas } \times \frac{52,76 k W h}{h}\right)+ \\
& +\left(\frac{R \$ 0,15419}{k W h} \times 0,35 \text { horas } \times \frac{52,76 k W h}{h}\right)= \\
& =R \$ 2.876,44
\end{aligned}
$$

Total de energia não vendida:

o $\quad$ Residencial $=\mathrm{C} 01$

$$
\mathrm{R} \$ 1.182,28 ;
$$

o Comercial $=\mathrm{C} 02+\mathrm{C} 05$

$$
\mathrm{R} \$ 582,16+\mathrm{R} \$ 3.161,58=\mathrm{R} \$ 3.743,75
$$

o $\quad$ Industrial $=\mathrm{C} 03+\mathrm{C} 06$

$\mathrm{R} \$ 3,10+\mathrm{R} \$ 2.876,44=\mathrm{R} \$ 2.879,53$

o Outros $=\mathrm{CO} 4$

$$
\mathrm{R} \$ 3,61
$$

Custo Total da energia não vendida: C07 + C08 + C09 + C10

o $\mathrm{R} \$ 7.809,18$ 
Cálculo da mão-de-obra e dos serviços executados:

Custo de deslocamento da equipe para localizar defeito e acompanhar serviço:

o Tempo x custo por hora

o $1,35 \times \mathrm{R} \$ 40,00=\mathrm{R} \$ 54,00$

Custo dos PIDs relacionados: R\$ 158,00

Total da interrupção devido à descarga atmosférica pelo lado da oferta ou concessionária:

$\mathrm{C} 11+\mathrm{C} 12+\mathrm{C} 13$

$\mathrm{R} \$ 7.809,18+\mathrm{R} \$ 54,00+\mathrm{R} \$ 158,00$

R\$ 8.021,18 (US\$ 3,619.67)

Cálculo do custo pelo lado da demanda ou do consumidor:

Utilizando-se a metodologia apresentada por Magalhães et al. (2001) no Capítulo 2, Tabela 8, obtêm-se o valor de:

1,35 horas $\times\left[\left(\frac{2.032,62 k W}{h} \times 0,90 \frac{U S \$}{k W}\right)+\left(\times\left[\frac{(1.159,80+6,83) k W}{h}\right] \times 1,70 \frac{U S \$}{k W}\right)+\left(\frac{58,62 k W}{h} \times 5,30 \frac{U S \$}{k W}\right)\right] \times 2,216 \frac{R \$}{U S \$}$

R\$ 12.335,39 (US\$ 5,566.51)

Custo total da interrupção: “custo oferta” + “custo demanda” = C14 + C15

$\mathrm{R} \$ \mathbf{8 . 0 2 1 , 1 8}+\mathrm{R} \$ 12.335,39=\mathrm{R} \$ 20.356,57$ (US\$ 9,186.18) 


\subsection{Análise}

Neste item são analisados os resultados referentes aos três casos considerados anteriormente.

\subsubsection{Custo lado concessionária Vs. Custo lado consumidor}

Comparando-se os custos vistos pelos lados da concessionária e do consumidor, obtêm-se as relações apresentadas na Tabela 14.

Tabela 14 - Relação entre custo lado da concessionária e custo lado do consumidor.

\begin{tabular}{ccccc}
\hline Caso & $\begin{array}{c}\text { Duração da } \\
\text { ocorrência (h) }\end{array}$ & Concessionária (R\$) & Consumidor (R\$) & Relação \\
\hline A & 6,07 & $34.887,59$ & $54.351,71$ & 0,64 \\
B & 3,65 & $24.338,46$ & $22.716,48$ & 1,07 \\
C & 1,35 & $8.021,18$ & $12.335,39$ & 0,65 \\
\hline
\end{tabular}

Nota-se que a quantidade e o tipo de consumidores interferem substancialmente na relação. Assim, circuitos que estejam em áreas densamente povoadas ou centros urbanos, naturalmente terão os custos mais altos quando comparados aos casos de alimentadores (circuitos) de áreas rurais. Contudo, circuitos com carga muito elevada, mesmo com poucos consumidores, também terão altos custos de interrupção. Assim, a análise não pode ser feita tomando-se como parâmetro apenas uma condição (quantidade de consumidores, tempo de interrupção ou carga instalada), devendo ser feita uma análise global do alimentador.

Já na análise pelo lado da concessionária, a condição de inexistência de defeito e rapidez em se religar o alimentador faz a diferença na redução do custo da interrupção. Essa condição é óbvia, mas nem sempre é possível executar rapidamente o serviço, seja pela ausência de equipe disponível, seja por dificuldades de locomoção devido ao trânsito ou ainda por eventual condição do local precária e insegura para a execução dos serviços.

Assim, como cada um dos custos leva em consideração parâmetros distintos, que não necessariamente interferem no outro, a relação entre os custos pode ser maior ou menor que a unidade, dependendo da situação considerada. 


\subsubsection{Comparação entre os casos A, B e C}

Analisando-se os custos tanto pelo lado da oferta (ou da concessionária) como pelo lado da demanda (ou do consumidor), nota-se que quanto mais rápido for o restabelecimento, menores serão os custos e que a existência de poucos consumidores (indicando baixo consumo) também é fator de redução desses custos. Nos estudos efetuados o Caso A teve um montante mais elevado, pois o tempo de interrupção foi de 6,07 horas contra 3,65 horas do Caso B e 1,35 horas do Caso C.

O tempo de reparo, que interfere diretamente no tempo total de interrupção, é outro fator preponderante para o aumento do custo.

O tempo de localização do defeito contribui também para o aumento dos custos de interrupção. O Caso C ilustra bem essa situação, pois não houve serviço executado, contudo teve-se um custo de $\mathrm{R} \$ \mathbf{7 . 8 0 9 , 1 8}$ apenas com a energia não vendida e deslocamento de equipe. Salientando-se que a duração foi de apenas 1,35 horas.

Para os casos analisados, os valores de PID pouco interferiram nos custos do lado da concessionária, representando apenas 2,36\% para o Caso A, 1,73 \% para o Cabo B e 1,97\% para o Caso C. Com certeza essa interferência é bastante móvel, pois depende, sobretudo, das proteções existentes na rede de distribuição, ou mesmo na entrada das residências (como é recomendado pelo NBR 5410:2004), que podem minimizar os efeitos decorrentes de uma descarga atmosférica. A existência de clientes “informados” ao longo de um alimentador também é fator de aumento dos PIDs, uma vez que estes irão recorrer dos seus direitos, amparados pela legislação em vigor.

\subsubsection{Custo da energia não vendida Vs. Custo de mão-de-obra e serviços}

No caso dos custos pelo lado da concessionária, aquele que mais contribui, normalmente, se refere à energia não vendida, que no Caso A representou 58,96\% do total. No Caso C a contribuição foi de $97,36 \%$ do total.

O custo de mão-de-obra teve uma representatividade menor no Caso A, com um valor de 24,92\% enquanto que no Caso C apenas 0,67\%. Esses valores são influenciados tanto pelo emprego de tecnologia na execução dos serviços como por eventual falta de atualização dos valores de custo do serviço. 
A energia não vendida representou $57,08 \%$ do custo total no Caso $\mathrm{B}$, estando no mesmo patamar do Caso A. Contudo, o fator que contribuiu para o aumento dos custos da concessionária foi a necessidade de reposição do transformador, equipamento caro, que neste caso teve de ser sucateado ou considerado como "perda total”.

Destaca-se que os valores apresentados estão aquém da realidade, pois alguns fatores propostos na metodologia não foram contabilizados nos três casos apresentados devido a falta de informação. No momento em que elas forem disponibilizadas, estes valores tenderão a subir, podendo então chegar a índices muito superiores aos do custo pelo lado do consumidor.

\subsection{Estimativa anual para toda a área de concessão}

A partir dos estudos de caso pode-se então estimar, a título de ilustração, qual o montante mínimo de custos decorrentes de descargas atmosféricas na rede de distribuição da concessionária em análise.

A Figura 22 (Capítulo 4) indica os valores de DEC mensais ao longo de 3 anos, podendo-se extrapolar o DEC anual na ordem de 0,30 horas / ano (observação: o DEC anual não é a soma dos DECs mensais, uma vez que a quantidade de consumidores pode variar ao longo do ano). No relatório 48500.002120/2006-23 (referente ao processo de homologação das tarifas de fornecimento de energia elétrica referentes à AES ELETROPAULO), disponível no site da ANEEL, tem-se o valor de faturamento anual de R \$ 7,2 bilhões para o consumo anual de 31 milhões de MWh.

Com estas informações é possível estimar o quanto se deixou de faturar em um ano devido às descargas atmosféricas:

$$
\text { (energia não faturada } D A)=R \$ 7,2 \text { bilhões } \times \frac{0,30 \text { hora } \times \text { dia }}{365 \text { dia } \times 24 \text { hora }}=R \$ 246.575,34 \text {. }
$$

Como o transformador é o item mais caro, caberia uma projeção anual do mesmo para o cálculo de custo. Assim, extrapolando o trabalho de Gouvêa et al. (1992) para uma taxa de falha de $1,5 \%$ para os transformadores, sendo que desse total $28 \%$ são devido a descargas atmosféricas (ou seja uma taxa de falha de 0,42\% devido a descargas atmosféricas), em um parque instalado da ordem de 150.000 unidades, haverá 630 transformadores queimados. Utilizando-se a taxa de reparo de $2,76 \%$ do total citada no trabalho, haverá 
17 transformadores em reparo e 613 transformadores com "perda total” (que precisarão ser substituídos). Utilizando-se os mesmos valores dos estudos de caso, obtêm-se os seguintes valores:

Custo médio de substituição do transformador:

o UPS do serviço $\mathrm{x}$ quantidade

o $\mathrm{R} \$ 260,00 \times 630=\mathrm{R} \$ 163.800,00$

Custo médio de reparo do transformador

o Valor médio de reparo $\mathrm{x}$ quantidade

o $\quad \mathrm{R} \$ 4.800,00 \times 17=\mathrm{R} \$ 81.600,00$

Custo médio de compra de transformador de média tensão

o Valor médio de compra x quantidade

o $\mathrm{R} \$ 9.500,00 \times 613=\mathrm{R} \$ 5.823 .500,00$

Custo total (estimado) com transformadores: R\$ 6.068.900,00 por ano.

Estimando-se que a quantidade anual de ocorrências devido a descargas atmosféricas seja de 896 casos (média anual de 2003 a 2005), com tempo médio da ocorrência de 1,50 horas (informação verbal) ${ }^{8}$, e utilizando-se o custo da turma dos estudos de caso obtém-se:

Custo de deslocamento da equipe para localizar defeito:

o quantidade $\mathrm{x}$ tempo $\mathrm{x}$ custo por hora

o $896 \times 1,50 \times \mathrm{R} \$ 40,00=\mathrm{R} \$ 53.760,00$

Assim, obtém-se como estimativa o custo anual de $\mathbf{R} \mathbf{\$} \mathbf{6 . 3 6 9 . 2 3 5 , 3 4}$ decorrente de descargas atmosféricas no sistema de distribuição em análise, o que representa, neste caso, $\mathbf{0 , 0 9 \%}$ do faturamento anual da empresa considerada.

\footnotetext{
${ }^{8}$ Fornecida em reunião na Eletropaulo Metropolitana Eletricidade de São Paulo S/A em janeiro de 2007.
} 
Cabe ressaltar, novamente, que os valores apresentados estão aquém da realidade, pois alguns fatores propostos na metodologia (como o custo da imagem, serviços executados, custos das áreas de apoio como o Call Center, dentre outros) não foram contabilizados devido a falta de informação. No momento em que elas forem disponibilizadas, estes valores tenderão a subir.

É importante salientar que a empresa em questão possui quase que a totalidade dos seus alimentadores (circuitos) em regiões urbanas, cuja característica é muito diferente de uma região rural, o qual é muito mais susceptível às descargas atmosféricas.

Diante dos resultados obtidos, tanto nas simulações de casos reais como na estimativa anual, ambos se mostraram bastante realistas, o que permite utilizar a metodologia como uma ferramenta para estimativa dos custos decorrentes de descargas atmosféricas em sistemas de distribuição de energia. 


\section{CONCLUSÕES E PROPOSTAS DE TRABALHOS FUTUROS}

As descargas atmosféricas são responsáveis por danos em equipamentos, faltas e desligamentos em sistemas de transmissão e distribuição de energia, ocasionando, portanto, perdas financeiras que até recentemente eram consideradas simplesmente prejuízos. Essa situação tem mudado significativamente após a publicação da Resolução Normativa ANEEL $n^{\circ}$ 61, de 29 de abril de 2004, que estabelece as disposições relativas ao ressarcimento de danos em equipamentos elétricos instalados em unidades consumidoras, causadas por perturbações no sistema elétrico. Durante a fase de levantamento dos dados notou-se um aumento significativo nos casos procedentes de PIDs (pedido de indenização de danos) devido às descargas atmosféricas, principalmente após a publicação da resolução acima mencionada. Esses valores variam muito de acordo com as características da região (urbanas ou rurais, residenciais, industriais ou comerciais) e do perfil sócio-econômico dos consumidores.

Em função da dificuldade de mensuração e da falta de um procedimento para análise dos custos decorrentes de descargas atmosféricas, sobretudo em sistemas de distribuição, verificou-se que a realização de um estudo voltado a essa questão representaria uma contribuição à área. Assim, este trabalho teve como principal objetivo desenvolver uma metodologia para determinação dos custos decorrentes de descargas atmosféricas em sistemas de distribuição de energia e verificar a sua aplicabilidade em casos reais, com comparação e análise dos resultados obtidos em diferentes situações.

A partir da análise dos casos considerados no estudo, nota-se que o valor totalizado do custo depende significativamente de fatores como:

número de consumidores - quanto maior a quantidade de consumidores afetados pela interrupção, maior se torna o custo decorrente;

tipos de consumidores existentes no alimentador - em função do maior consumo, a existência de consumidores do tipo industrial torna os custos muito mais elevados que no caso de existência de consumidores apenas do tipo residencial;

consumo médio de cada tipo de consumidor - o aumento do valor de consumo está diretamente ligado ao custo, haja vista o item energia não vendida; 
horário da ocorrência - com a tarifação horo-sazonal o custo no horário dito de ponta (que compreende um período contínuo de 3 horas) é mais elevado;

duração da interrupção / ocorrência - quanto mais tempo perdurar a interrupção, maior se torna o custo da interrupção, seja pela energia não vendida ou pelo custo das equipes envolvidas no atendimento;

tipo de danos causados na rede de distribuição - alguns equipamentos, como o transformador, elevam em muito o custo, principalmente se não puderem ser reparados. No caso de rompimento de condutores, danos a pára-raios, ou ainda necessidade de substituição de cruzetas ou isoladores, o custo também pode ter aumento significativo em função das despesas com a substituição dos equipamentos e, sobretudo, com a mão-de-obra.

A metodologia apresentada representa uma ferramenta útil para avaliação da viabilidade técnico-econômica de novas técnicas ou configurações de proteção que podem ser implantadas com o objetivo de melhorar a confiabilidade e os índices de qualidade de redes de distribuição de energia através da minimização dos efeitos das descargas atmosféricas.

Destaca-se que nem sempre as informações necessárias para a aplicação do procedimento estão disponíveis de forma clara e objetiva dentro das concessionárias, de modo que não foi possível utilizar, nas simulações, todos os parâmetros propostos na metodologia. O custo da imagem da empresa é um exemplo, pois a maioria das concessionárias de energia não dispõe de informações sobre o mesmo ou os estudos para a sua fixação ainda se encontram em fase embrionária. Essa situação remete um estudo mais detalhado sobre a avaliação do custo da imagem da empresa para uma proposta de trabalho futuro.

Deve-se realçar também a importância de se buscar uma melhor correlação entre os dados de descargas atmosféricas e de interrupções de fornecimento de energia, através da sincronização entre os instantes de ocorrência desses eventos, e de se reavaliar os dados referentes às UPS (unidade padrão de serviço) levando-se em conta o atual estado tecnológico. Tais medidas certamente acarretariam maior confiabilidade e precisão aos resultados. 


\section{REFERÊNCIAS BIBLIOGRÁFICAS}

AAKER D. A. Marcas: Brand Equity Gerenciando o Valor da Marca. Negócio Editora. São Paulo, 1998.

AGÊNCIA NACIONAL DE ENERGIA ELÉTRICA (ANEEL). Resolução no 24 de 27 de janeiro de 2000 - Estabelece as disposições relativas à continuidade da distribuição de energia elétrica às unidades consumidoras. Brasília, DF. Janeiro, 2000a. Disponível em: <http://www.aneel.gov.br/legislacao $>$. Acesso em: 09 Nov 2004.

AGÊNCIA NACIONAL DE ENERGIA ELÉTRICA (ANEEL). Resolução Normativa $\mathbf{n}^{\mathbf{0}} \mathbf{6 1}$, de 29 de abril de 2004 - Estabelece as disposições relativas ao ressarcimento de danos elétricos em equipamentos elétricos instalados em unidades consumidoras, causados por perturbações ocorrida no sistema elétrico. Brasília, DF. Abril, 2004. Disponível em: <http://www.aneel.gov.br/legislacao >. Acesso em: 10 Ago 2004.

AGÊNCIA NACIONAL DE ENERGIA ELÉTRICA (ANEEL). Resolução n $\mathbf{n}^{\mathbf{0}} \mathbf{5 0 5}$, de 26 de novembro de 2001 - Estabelece as disposições relativas à conformidade dos níveis de tensão de energia elétrica em regime permamente. Brasília, DF. Novembro, 2001.

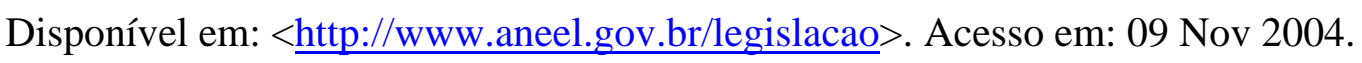

AGÊNCIA NACIONAL DE ENERGIA ELÉTRICA (ANEEL). Resolução no 456, de 29 de novembro de 2000 - Condições Gerais de Fornecimento de Energia Elétrica. Brasília, DF. Novembro, 2000b. Disponível em: <http://www.aneel.gov.br/legislacao $>$. Acesso em: 09 Nov 2004.

AGÊNCIA NACIONAL DE ENERGIA ELÉTRICA (ANEEL). Evolução do Desempenho dos Indicadores de Qualidade. Disponível em:

<http://www.aneel.gov.br/area.cfm?idArea=80>. Acesso em: 10 Jan 2007.

ANDERSON, R.B.; ERIKSSON, A. J. A Summary of lightning parameters for engeneering application. In: CIGRE, International Conference on Large High Voltage Electric Systems, CIGRÈ 1980 Session, Paris, August 27 - September 4, 1980. 
ANDRADE, M. T.; LANDINI, L. A. R.; PRADO Jr, F. A. A. Ressarcimento de Consumidores Relativos a Danos Decorrentes da Prestação dos Serviços Concedidos Uniformização de Procedimentos. XVI SNPTEE - Seminário Nacional de Produção e Transmissão de Energia Elétrica. Campinas, São Paulo, 2001.

ASSOCIAÇÃO BRASILEIRA DE DISTRIBUIDORES (ABRADEE). CODI-2.2.12.03.0 Análise das Conseqüências das Interrupções do Fornecimento de Energia Elétrica. Comitê de Distribuição. Rio de Janeiro, 1996.

ASSOCIAÇÃO BRASILEIRA DE NORMAS TÉCNICAS. ABNT NBR 5410:2004 Instalações Elétricas de Baixa Tensão. Associação Brasileira de Normas Técnicas. Rio de Janeiro. ABNT, 2004.

ASSOCIAÇÃO BRASILEIRA DE NORMAS TÉCNICAS. NBR 5419:2001 - Proteção de Estruturas Contra Descargas Atmosféricas. Associação Brasileira de Normas Técnicas. Rio de Janeiro. ABNT, 2001.

BENETI, C. A. A.; JUSEVICIUS, M. A. R.; GIN, R. B. B.; PATSKO, C. H. Identificação de áreas críticas de ocorrência de descargas atmosféricas na área de concessão da Eletropaulo. Instituto Tecnológico SIMEPAR, Curitiba, Paraná. 2005.

BERGER, K.; ANDERSON, R.B.; KRÖNINGER, H.; PALVA, V. Parameters of lightning flashes. Electra, no 41, p.23-37, July, 1975.

BOCCUZZI, C. V. Análise e Estabelecimento de Índices de Continuidade de Fornecimento para as Regiões da Área de Concessão da Eletropaulo. II Seminário Interno de Distribuição de Energia Elétrica. Eletropaulo. São Paulo, 1986.

BRASIL. Constituição da República Federativa do Brasil, de 5 de outubro de 1988.

BRASIL. DECRETO n 24.643, de 10 de julho de 1934. Código de Águas.

BRASIL. LEI no 8.078, de 11 de setembro de 1990. Código de Proteção e Defesa do Consumidor. 
BRASIL. LEI n ${ }^{0}$ 8.987, de 13 de fevereiro de 1995. Regime de Concessão e Permissão da Prestação de Serviços Públicos.

BRASIL. LEI n ${ }^{\mathbf{0}}$ 10.406, de 10 de janeiro de 2002. Novo Código Civil Brasileiro.

Brazil’s Most Valuable Brands 2006. Disponível em:

< http://www.brandfinance.com/Uploads/pdfs/BrazilMVBrands06.pdf>.

Acesso em: 10 Jan 2007.

CAMARGO, P. T. Custo Social da Energia Elétrica. 1989, 203p. Tese (Mestrado) Fundação Getúlio Vargas. Rio de Janeiro, 1989.

DI PIETRO, M. S. Z. Direito Administrativo. São Paulo, 2004. $17^{a}$ edição, p. 554-555 / 402408 / 86-90. Atlas.

ELETROBRÁS. Relatório da Pesquisa Sobre Custo de Interrupção no Fornecimento de Energia Elétrica. Março, 1991.

Faturamento Anual da Eletropaulo. Disponível em:

< $\underline{\text { http://www.aneel.gov.br/aplicacoes/noticias_area/arquivos/48500002120200623_1.pdf> }}$.

Acesso em: 15 jan 2007.

FOLHA DE SÃO PAULO. Aneel define regras para ressarcir danos a aparelhos. Caderno Dinheiro, Seção Energia, p.B3, 01 de maio de 2004. São Paulo.

FÜHRER, M. C. A. Resumo de Direito Civil. São Paulo, 2002. 26a edição, Malheiros Editores Ltda.

GOMES, P.; ZANI, C. R.; SCHILLING M. Th.; CALDAS, G. P.; CAFÉ, F. F. Determinação dos custos de interrupção do Fornecimento de Energia Elétrica. Eletricidade Moderna, nº 268, p. 146-152, Julho, 1996. São Paulo. 
GOMES. P.; SCHILling M. Th. Custo de Interrupção: Conceituação, Metodologia de Avaliação, Valores Existentes e Aplicações. In: XIV SNPTEE - Seminário Nacional de Produção e Transmissão de Energia Elétrica. Belém. Pará, 1997.

GOUVÊA. M. R.; RIBEIRO. J. A.; PACHECO NETO. S.; MARTINS. M. J.; DOMANESCHI. M. Análise de Taxas de Falha em Transformadores de Distribuição. Relatório CED - 052 / EQPT 001 / RL 001 / OR. Centro de Excelência em Distribuição de Energia Elétrica. IEE/USP - ELETROPAULO - CESP - CPFL. São Paulo, 1992.

GUIMARÃES, L. C. S. O Custo da Qualidade do Fornecimento de Energia Elétrica. Informativo CODI - Comitê de Distribuição de Energia Elétrica. Rio de Janeiro. Janeiro, 1986.

Happy 300th Birthday, Benjamin Franklin! Disponível em:

< http://www.carnetdevol.org/actualite/franklin/benjamin.htm>. Acesso em: 09 nov 2006.

IBÁNEZ, H. F.; AVENDAÑO, C. A.; ORTIZ, H. E. Correlation Between Keraunic Level and Losses of Electricaland Electronic Equipment for the City of Bogotá (Colômbia). In: VIII SIPDA - International Symposium on Lightning Protection. São Paulo, 2005.

IBÁNEZ, H. F.; AVENDAÑO, C. A.; ORTIZ, H. E. Correlação entre nível ceráunico e danos em aparelhos eletroeletrônicos. Eletricidade Moderna, $\mathrm{n}^{\circ}$ 390, p. 72-79, Setembro, 2006. São Paulo.

IEEE Std 1346-1998 - IEEE Recommended Practice for Evaluating Electric Power System Compatibility With Electronic Process Equipment. New York. USA. 1998.

Impostos e Outros Encargos. Disponível em:

$<$ http://www.eletropaulo.com.br/portal/page.cfm?Conteudo_ID=668\&desc=Impostos\%20e\% 20outros\%20encargos >. Acesso em: 27 jan 2007.

JUCÁ, A. S. Avaliação do Relacionamento Entre Consumidores e Concessionárias na Solução de Conflitos por Danos Elétricos: Proposta de Adequação. 2003. 178p. Tese (Doutorado) - Escola Politécnica da Universidade de São Paulo. São Paulo, 2003. 
KAGAN, N. Sistema Computacional para Suporte à Decisão no PID. In: Congresso ENERSHOW, 2003. São Paulo. Anais, 2003.

KANASHIRO, A.G.; PIANTINI, A. The effect of the secondary loads on the voltage surges transferred through distribution transformers. In: XIII ISH - International Symposium on High Voltage Engineering, Delft, the Netherlands, August 2003.

KINDERMANN, G. Descargas Atmosféricas. Sagra-DC Luzzatto. Rio Grande do Sul, 1992.

MAGALHÃES, C. H. N.; GOUVÊA, M. R.; SILVA, F. A. T.; TAHAN, C. M. V.; ARAÚJO FILHO, L. G. C. Avaliação do Custo Social de Interrupção do Fornecimento de Energia Elétrica do Lado da Demanda no Estado de São Paulo. In: XVI SNPTEE - Seminário Nacional de Produção e Transmissão de Energia Elétrica. Campinas. São Paulo, 2001.

MASSAUD, A. G.; SCHILLING, M. Th.; HERNANDEZ, J. P. Electricity restriction costs. IEE Proc.-Gener. Transm. Distrib, vol. 141, nº 4, p. 299 - 304, Julho, 1994.

MORTON, A. UTM Grid Zones of the World. Disponível em:

<http://www.dmap.co.uk/utmworld.htm>. Acesso em: 10 jan 2007.

NACCARATO, K. P.; PINTO Jr, O; PINTO, I. R. C. A. A Detection Efficiency Model for the Brazilian Lightning Detection Network (RINDAT). In: $19^{\text {th }}$ International Lightning Detection Conference \& $1^{\text {st }}$ International Lightning Meteorology Conference. Tucson, Arizona, USA. Abril, 2006.

NOSAKI, S.; PINTO Jr, O.; PINTO, I.R.C.A.; FERRAZ, E. C. Estudo dos Efeitos das Descargas Atmosféricas no Sistema de Distribuição da Elektro. In: I CITENEL Congresso de Inovação Tecnológica em Energia Elétrica. Brasília. DF. 2001.

NUNES FILHO, F. B. De que Reclama o Consumidor de uma Concessionária de Energia Elétrica? In: X CBE - Congresso Brasileiro de Energia. Rio de Janeiro, 2004.

NUNES G. Gestão Estratégica da Marca. Revista FAE BUSINESS, nº 7, p. 36-39, novembro, 2003. 
NUNES G.; HAIGH D. Marca Valor do Intangível. Editora Atlas. São Paulo, 2003.

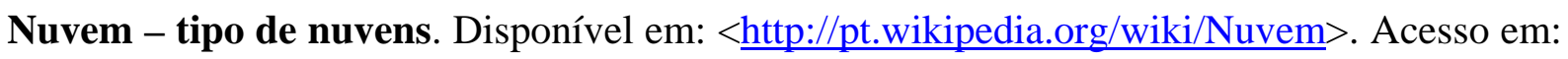
09 nov 2006.

OBASE, P. F.; PIANTINI, A. Surtos Atmosféricos Transferidos à Rede Secundária via Transformadores. 20p. Boletim Técnico da Escola Politécnica da USP, Departamento de Engenharia de Energia e Automação Elétricas; BT/PEA/0507 - EPUSP Escola Politécnica da Universidade de São Paulo. São Paulo, 2005.

OBASE, P. F.; PIANTINI, A. Over voltages on LV networks associated with direct strokes on the primary line. ICLP $2006-28^{\text {th }}$ International Conference on Lightning Protection, Kanazawa, Japan, 2006.

OBASE, P. F.; PIANTINI, A.; KANASHIRO, A. G. Sobretensões em Redes de Distribuição Causadas por Descargas Atmosféricas Diretas no Primário. In: GROUND'2004 and $1^{\text {st }}$ LPE - International Conference on Grounding and Earthing \& $1^{\text {st }}$ International Conference on Lightning Physics and Effects. Belo Horizonte, MG, Brasil, November, 2004.

PIANTINI, A. Contribuição ao estudo das tensões induzidas em linhas de distribuição por descargas atmosféricas indiretas. São Paulo, 1991. 205 p. Dissertação (Mestrado) Escola Politécnica, Departamento de Energia e Automação Elétrica da Escola Politécnica da Universidade de São Paulo, São Paulo, 1991.

PIANTINI, A.; JANISZEWSKI, J. M . Induced voltages on distribution lines due to lightning discharges on nearby metallic structures. IEEE Transactions on Magnetics, Estados Unidos, v. 34, p. 2799-2802, 1998.

PIANTINI, A.; JANISZEWSKI, J. M. Lightning induced voltages on distribution lines close to buildings. In: $25^{\text {th }}$ INTERNATIONAL CONFERENCE ON LIGHTNING PROTECTION (25th ICLP), 2000, Rhodes. ICLP 2000 - Conference Proceedings. Ryon : University of Patras, 2000. v. B. p. 558-563. 
PIANTINI, A.; JANISZEWSKI, J. M . Lightning induced voltages on distribution transformers: the effects of line laterals and nearby buildings. In: VI International Symposium on Lightning Protection, 2001, Santos. VI International Symposium on Lightning Protection - Proceedings. São Paulo : IEE/USP, 2001. p. 77-82.

PIANTINI, A.; JANISZEWSKI, J. M. Influência de Ramais e Edificações nas Tensões Induzidas em Linhas de Distribuição Urbanas devido a Descargas Atmosféricas. In: XV Seminário Nacional de Distribuição de Energia Elétrica - SENDI 2002, Salvador, BA, Brasil, 2002.

PIANTINI, A.; JANISZEWSKI, J. M. Avaliação do Número de Interrupções em Linhas de Média Tensão Devido a Descargas Atmosféricas Indiretas. In: XVIII SNPTEE Seminário Nacional de Produção e Transmissão de Energia Elétrica, Curitiba, PR, Brasil, Outubro, 2005.

PIANTINI, A. ; KANASHIRO, A. G . A distribution transformer model for calculating transferred voltages. In: 26th International Conference on Lightning Protection, 2002, Cracóvia. International Conference on Lightning Protection - Conference Proceedings. Cracóvia : Association of Polish Electrical Engineers, 2002. v. II. p. 429-434.

PIANTINI, A.; SILVA NETO, A. Tensões Induzidas em Linhas de Baixa Tensão por Descargas Atmosféricas. IEEE/PES T\&D 2004, São Paulo, Brazil, November, 2004).

PIANTINI, A.; SILVA NETO, A. Lightning Induced Voltages on LV Distribution Lines. ICLP $2006-28^{\text {th }}$ International Conference on Lightning Protection, Kanazawa, Japan, 2006.

PINHO J. B. O Poder das Marcas. Summus Editorial. São Paulo, 1996.

PINTO Jr., O. A Arte da Guerra Contra os Raios. Oficina de textos. São Paulo, 2005.

PINTO Jr., O; PINTO, I. R. C. A. Tempestade e Relâmpagos no Brasil. INPE , 2000. 
PINTO Jr., O; PINTO, I. R. C. A.; NACCARATO, K.P.; SABA, M. M. F. Brazilian Integrated Lightning Detection Network - RINDAT. Disponível em: <www.fmi.fi/kuvat/pinto.pdf>. Acesso em: 09 nov 2006.

RAKOV, V. A. Lightning Parameters Important for Lightning Protection. In: VI SIPDA - International Symposium on Lightning Protection. Santos, 2001.

RINDAT: Rede Integrada Nacional de Detecção de Descargas Atmosféricas. Disponível em: <http://www.rindat.com.br>. Acesso em: 09 nov 2006.

ROMERO, F. Avaliação do comportamento dos campos eletromagnéticos gerados por descargas atmosféricas nuvem-terra. São Paulo, 2007. 155 p. Dissertação (Mestrado em Energia) - Programa Interunidades de Pós-Graduação em Energia da Universidade de São Paulo, São Paulo, 2007.

SALATA, L. A. M; KIRCHNER, C. A. R; BRIZIDA, F. J. A; Martins, J. C; BARRETO, P. E. Q. M. Relatório da Comissão Especial do CREA Para Apuração das Causas do BLECAUTE ocorrido no dia 11/03/1999. CD-ROM CREA-SP. São Paulo, 2000.

SHIGA, A.A.; PIANTINI, A.; PEGOLLO, C. A. G. Custos Relativos a Descargas Atmosféricas em Sistemas de Distribuição de Energia. In: SBSE - Simpósio Brasileiro de Sistemas Elétricos 2006, Campina Grande, PB, Brasil, Julho 2006a.

SHIGA, A.A.; PIANTINI, A.; PEGOLLO, C.A.G. Considerações sobre os Custos Decorrentes de Descargas Atmosféricas em Sistemas de Distribuição de Energia. In: XVII SENDI - Seminário Nacional de Distribuição de Energia Elétrica, Belo Horizonte, MG, Brasil, Agosto 2006b.

SHIGIHARA, Miltom. Avaliação de correntes de descargas atmosféricas através de medições diretas em estruturas altas. São Paulo, 2005. 152 p. Dissertação (Mestrado em Energia) - Programa Interunidades de Pós-Graduação em Energia da Universidade de São Paulo, São Paulo, 2005. 
SILVA NETO, A.; PIANTINI, A. Sobretensões em redes de baixa tensão causadas por descargas atmosféricas indiretas. 15p. Boletim Técnico da Escola Politécnica da USP, Departamento de Engenharia de Energia e Automação Elétricas; BT/PEA/0422 - EPUSP Escola Politécnica da Universidade de São Paulo. São Paulo, 2004.

SILVA, S. P.; PIANTINI, A.; FRANCO, J. L.; GONÇALVES, J. Lightning performance studies for a $13.8 \mathrm{kV}$ distribution network. In: VII SIPDA - INTERNATIONAL SYMPOSIUM ON LIGHTNING PROTECTION. Curitiba, Paraná, 2003. p. 137-143.

SLYWOTZKY, A. J.; KANIA J. Os Padrões de Marca na Prática. HSM Management, $n^{\circ}$ 31, p.65, março-abril, 2002.

SMIDT, E. R. Lightning analysis in a hight-voltage transmission environment. Vaissala News, United States, 2003.

SOUZA, M. G.; NEMER A. Marca \& Distribuição. Makron Books. São Paulo, 1993.

UMAN, M. A. Lightning. In: DOVER PUBLICATION INC., p. 298. New York, 1984.

UMAN, M.A. Natural lightning. IEEE Transaction on Industry Applications, vol. 30, p.785-790, May-June, 1994. 